Portland State University

PDXScholar

$1-1-1980$

\title{
The effect of costs and constraints on the optimum employment combination of full-time and part-time faculty at urban community colleges
}

Zoe Annette Arrington

Portland State University

Follow this and additional works at: https://pdxscholar.library.pdx.edu/open_access_etds Let us know how access to this document benefits you.

\section{Recommended Citation}

Arrington, Zoe Annette, "The effect of costs and constraints on the optimum employment combination of full-time and part-time faculty at urban community colleges" (1980). Dissertations and Theses. Paper 569.

https://doi.org/10.15760/etd.569

This Dissertation is brought to you for free and open access. It has been accepted for inclusion in Dissertations and Theses by an authorized administrator of PDXScholar. Please contact us if we can make this document more accessible: pdxscholar@pdx.edu. 
THE EFFECT OF COSTS AND CONSTRAINTS ON THE OPTIMUM EMPLOYMENT

COMBINATION OF FULL-TIME AND PART-TIME FACULTY

AT URBAN COMMUNITY COLLEGES

by

Zoe Annette Arrington

A dissertation submitted in partial fulfillment of the requirements for the degree of

DOCTOR OF PHILOSOPHY

Portland State University

1980 
AN ABSTRACT OF THE DISSERTATION OF Zoe Annette Arrington for the Doctor of Philosophy presented July 17, 1980.

Title: The Effect of Costs and Constraints on the Optimum Employment Combination of Full-time and Part-time Faculty at Urban Community Colleges.

APPROVED BY MEMBERS OF THE DISSERTATION COMMITTEE:

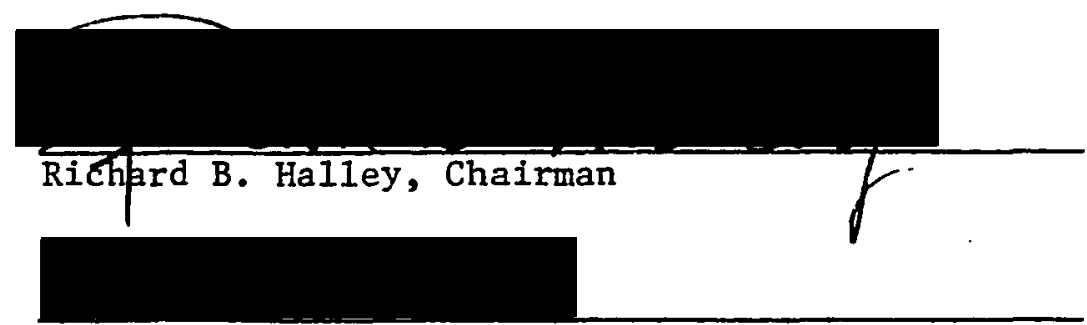

Leonard D Cain, Jr.

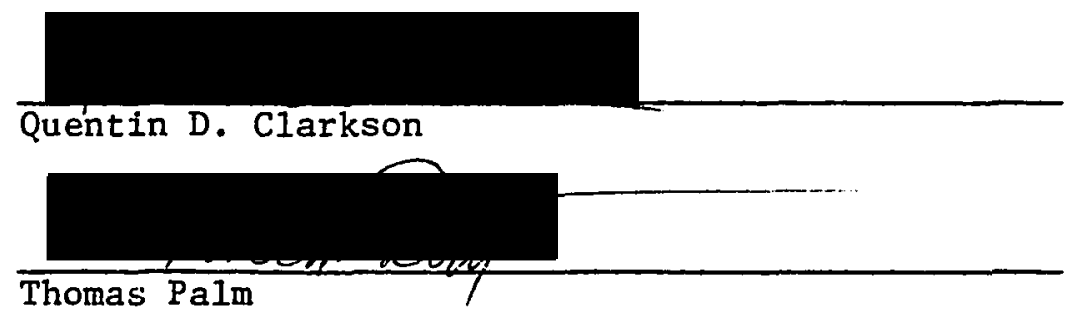

The labor market for part-time faculty at community colleges has changed such that in the past decade the number of instructors who teach part-time now outnumber those who teach full-time. This dissertation examines the full-time and part-time labor markets arguing that two separate labor markets exist. The supply in an urban area is nearly perfectly elastic for both full-time and part-time faculty; the demand side of the labor market is characterized by a number of costs. Data on costs were collected by two separate questionnaires, one to faculty and one to the personnel office of each college. The costs differ 
between full-time faculty and part-time faculty and include wages and fringe benefits, which are higher for the full-time than for the parttime faculty, and turnover costs which, on the basis of the total cost of the two groups, are higher for the part-time than for the full-time faculty.

Because a service is produced, the input side rather than the output side of the labor market is used to estimate the expected productivity of the two groups. Literature on human resource investment is used as a basis for examination of productivity difference of the two groups. The labor market for the two faculty groups is segmented; however, the faculty perform nearly identical services and thus are considered perfect substitutes although not on a one-to-one ratio. The productivity difference between the rull-time and part-time faculty is based on data collected by the faculty questionnaire.

Based on the theoretical predictions and using the above data, the dissertation examines the effect of costs and constraints on the optimum employment combination of full-time and part-time faculty at urban community colleges. The hypothesis examined is that colleges act in a rational way given costs, productivity, and other constraints. Linear programming was used to examine the problem, and results showed that community colleges do act in a rational way, and will minimize total cost or maximize output. Further examination simulated conditions that might affect the community college from internal or external sources. The purpose of the simulation analysis was to determine the optimum combination of full-time and part-time instructors and the effect 
on the output or costs to the college. Simulations included changes in constraints, total budget, and total output requirements, and adjustments of costs and productivity relationships between the two faculty groups. The results showed that the college would adjust its parttime faculty, which formed a relatively variable factor of production, rather than its full-time faculty. 
TO THE OFFICE OF GRADUATE STUDIES AND RESEARCH:

The members of the Committee approve the dissertation of Zoe Annette Arrington presented July 17, 1980.

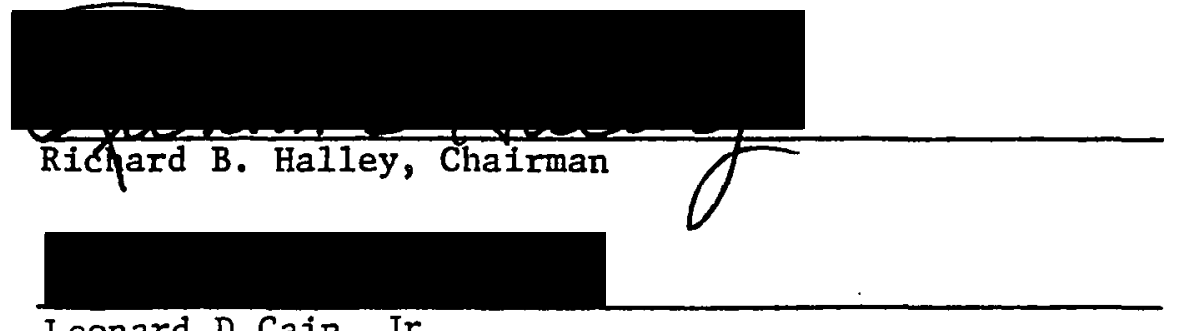
Leonard D Cain, Jr.

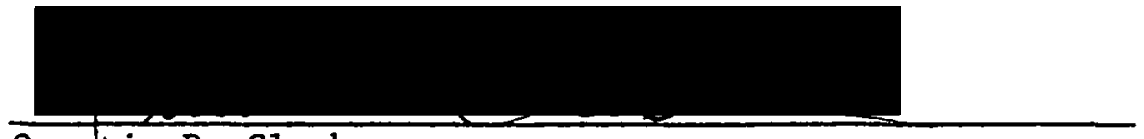
Quentin D. Clarkson

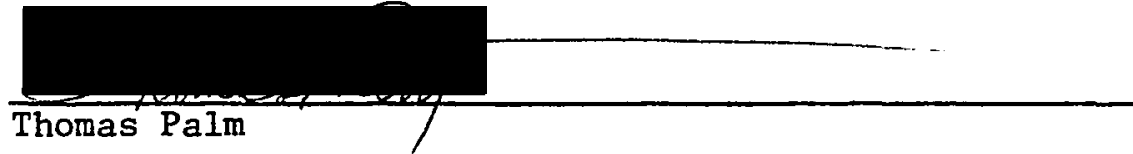

APPROVED:

Nohad A. Toulan, Dean, Skhool of Urban Affairs

Stanley E. Rauch, Dean, Graduate Studies and Research 


\section{ACKNOWLEDGMENTS}

A number of individuals made contributions at various phases of this dissertation. I am indebted to my comittee members for their generous contributions of time and patience. Dr. Richard Halley, my chairman, provided guidance and made numerous suggestions at various stages. Dr. Thomas Palm helped me produce a more logical, cohesive, and theoretically sound piece of work. Dr. Quentin Clarkson contributed his expertise on statistics, logic, and data gathering. Dr. Leonard Cain helped to remind me that there are ideas and theories besides those of economists. Additional contributions came from Don Fiser of Portland Community College who acted as my professional consultant.

I also wish to acknowledge the help of Don Uppendahl, Portland Community College, Pat McGaffigan, Mt. Hood Community College, and Jim Peinter, Clackamas Community College, and a number of other individuals at these colleges who contributed their time and the resources of their organizations.

Assistance also came from the following persons: Dawn O'Donnell for her considerable effort in the editing and proofreading of the final drafts, Darey Shell for her work on the computer programing segments, and Katie Liectke for her typing of most of the dissertation. And, for being so patient and understanding while I completed work on the dissertation, thank you to my family, especially Wes Oleson. 
TABLE OF CONTENTS

PAGE

ACKNOWLEDGMENTS $\quad$ • $\quad$ • $\quad$ •

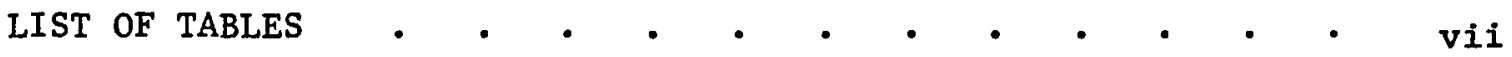

CHAPTER

I INTRODUCTION AND REVIEW OF LITERATURE $\quad$ • $\quad$ • $\quad$ • $\quad . \quad 1$

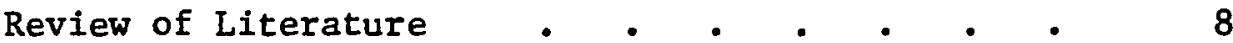

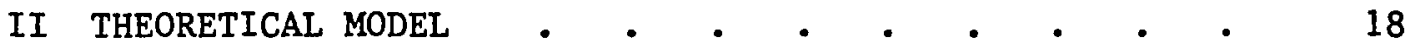

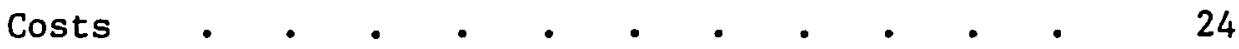

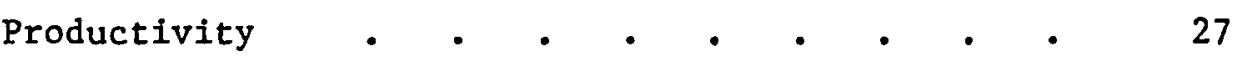

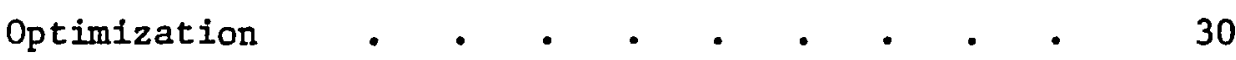

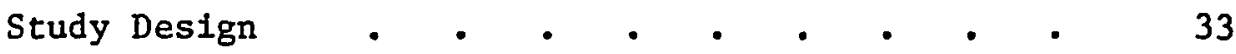

III Numbers, Hours Worked, and Costs of Labor Productivity

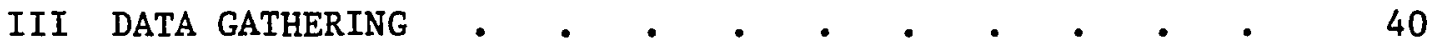

IV DEMOGRAPHIC CHARACTERISTICS • • • • • • • 52

Number and Time Allocation . . . . . . 53

Employment Stability and Instability . . . . 61

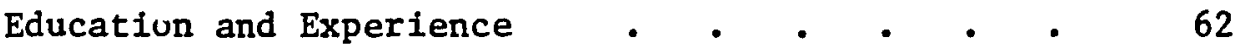

V COSTS AND PRODUCTIVITY • • • • • • • • 76

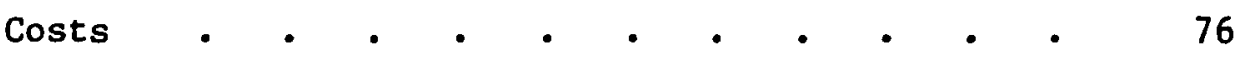

Wage Costs

Fringe Benefits and Total Compensation

Turnover Costs 
Productivity • • • • • • • • • • 93

Regression Analysis Approach

The Salary Schedule Approach

The Productivity Measurement . . . . .

VI THE LINEAR PROGRAMMING PROBLEM AND CONSTRAINT •

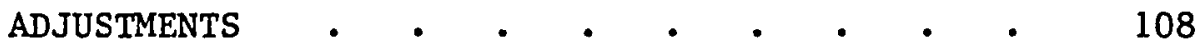

Optimization: The Current Status . . . . 115

Constraint Adjustment Between Faculty Groups . 121

Adjustment of Budget Constraints . • • . 125

Adjustment of Total Productive Hours . . . 128

VII RATIO ADJUSTMENTS WITH LINEAR PROGRAMMING • • 132

Cost Ratio Adjustments • • • • • • . 133

As an Output Maximization Problem

As a Cost Minimization Problem

Productive Hour Changes $\quad$. $\quad$.

As a Cost Minimization Problem

As an Output Maximization Problem

VIII CONCLUSIONS AND IMPLICATIONS • • • • • • • 152

BIBLIOGRAPHY . . . . . . . . . . . . 157

APPENDIX A : QUESTIONNAIRES . • • • • • . . . 171

APPENDIX B: MEAN AND MEDIAN HOURS PER WEEK AT EACH ACTIVITY

BY FTF AND PTF • • • • • • • • • • • 175

APPENDIX C: CLASSES TAUGHT BY FACULTY . . . . . . . 177

APPENDIX D: TURNOVER COSTS . . . . . . . . . . . . . 178

APPENDIX E: REGRESSION MODEL AND RESULTS • • • • • • 179

APPENDIX F: SALARY PLACEMENT AND LEVEL ADVANCEMENT $\quad$ • 181

APPENDIX G: HYPOTHETICAL SALARY DATA AND CALCULATIONS • • 193

APPENDIX H: CONSTRAINT ADJUSTMENT OF FACULTY GROUPS • • 199 
APPENDIX I: ADJUSTMENT OF BUDGET CONSTRAINTS . • • 205

APPENDIX J: ADJUSTMENT OF TOTAL PRODUCTIVE HOURS: COST

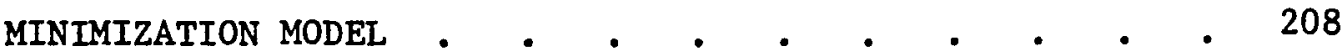

APPENDIX K: COST RATIO ADJUSTMENTS: PROBLEM VIEWED AS

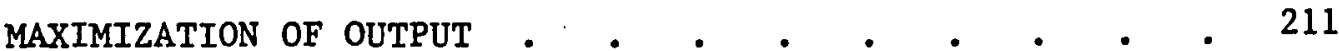

APPENDIX L: COST RATIO ADJUSTMENTS: PROBLEM VIEWED AS

MINIMIZATION OF TOTAL COST • • • • . . . . 217

APPENDIX M: PRODUCTIVITY RATIO ADJUSTMENTS: PROBLEM VIEWED

AS MINIMIZATION OF TOTAL COST . . . . . . . 223

APPENDIX N: PRODUCTIVITY RATIO ADJUSTMENTS: PROBLEM VIEWED

AS MAXIMIZATION OF OUTPUT • • • • • • • • 229 
I Total and Percent LDC and FTE Enrollment . . . • 43

II Population, Sample, and Response by College • • • 44

III State Investment Pool Interest Rates for Various

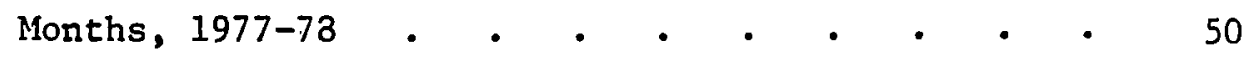

IV Total Faculty Employed by Colleges by Number and Percent, October 1979 • • • . . . • . 54

V Number and Percent of Faculty in Study Population . - 55

VI Weekly and Total Hours of Work per Term by FTF and PTF.$\quad \cdot \quad \cdot \quad \cdot \quad \cdot \quad \cdot \quad \cdot \quad \cdot \quad \cdot \quad \cdot 56$

VII Full-time Faculty Required to Replace Part-time

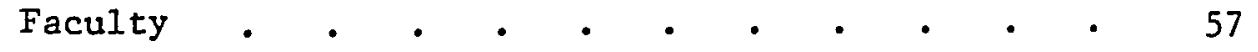

VIII Mean Time in Teaching and Non-teaching Related

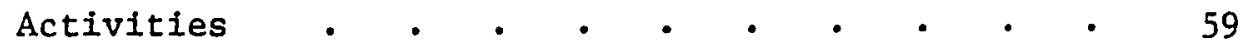

IX Average Length of Employment in Terms, Standard

Deviation, and Coefficient of Variation $\cdot \quad \cdot \quad \cdot 61$

$X$ Cumulative Percent Hired of Faculty Currently

Employed • • • •

XI Wage Per Hour •

XII Percent of Faculty Holding at Least a Master's

Degree $\quad \cdot \quad \cdot \quad \cdot \quad \cdot \quad \cdot \quad \cdot \quad \cdot \quad \cdot \quad \cdot \quad \cdot \quad \cdot 65$

XIII Full-time and Part-time Job Experience from all

Sources by FTF and PTF $\quad \cdot \quad \cdot \quad \cdot \quad \cdot \quad \cdot 67$ 
XIV Teaching Experience from all Sources by FTF and PTF $\quad . \quad . \quad . \quad . \quad . \quad . \quad . \quad . \quad . \quad .69$

$\mathrm{XV}$ Number and Percent of Moonlighters and Exclusive

Part-timers . . . . . . . . . . 70

XVI Mean Age of Faculty Groups . • • • • • • • 71

XVII Composition by Sex of Instructors at Various Levels

of Education, United States, 1970 . $\quad$ • . . 72

XVIII Percent Female of Faculty Groups • • • • • • • 73

XIX Wage Cost per Term of FTF and PTF Working Current

Hours and Hypothetical Wage Cost if FTF

Replaced PTF • • • . • . . . • . . 80

$\mathrm{XX}$ Fringe Benefits as Percent of Hourly Wage . . . . . 81

XXI Wages, Fringe Benefits and Total Compensation per

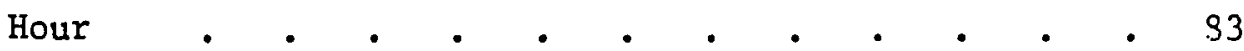

XXII Total Compensation Cost per Term of FTF and PTF

Working Current Hours and Hypothetical

Compensation Cost if FTF Replaced PTF . . . . $\$ 6$

XXIII Yearly Turnover of Faculty for 3-Year Period . • • $\quad 38$

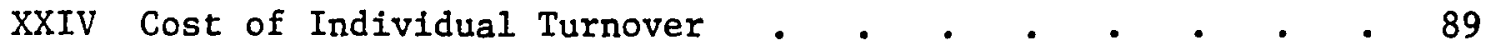

XXV Total Cost of Turnover per Term . . . . . . . . 91

XXVI Total Compensation and Turnover Costs per Term of

FTF and PTF Working Current Hours and Hypo-

thetical Cost if FTF Replaced PTF . • . • . 92

XXVII Productivity Measure Based on Salary Schedule . . . . 101

XXVIII Hours Actually Worked and Productive Hours of Output • 105 
XXIX Productivity per Term of FTF and PTF Working Current

Hours and Hypothetical Productivity if FTF

Replaced. PTF •. • . . . . . . . . . 106

XXX Compensation, Turnover, Interest, and Total Costs of

Faculty per Week • • • • • . • • • 111

XXXI Actual Hours and Productive Hours of Output Each Week $\quad 110$

XXXII Number of Faculty Employed and Tenured • . • • . 112

XXXIII Optimization: The Problem Viewed as Output Maximization . 117

XXXIV Optimization: The Problem Viewed as Cost Minimization • 118

XXXV Options to Increase Output: Problem Viewed as Output

Maximization $\quad \cdot \quad \cdot \quad \cdot \quad \cdot \quad \cdot \quad \cdot \quad \cdot \quad \cdot \quad \cdot 119$

XXXVI Options to Save Costs: Problem Viewed as Cost Mini-

mization $\quad . \quad \cdot \quad \cdot \quad \cdot \quad \cdot \quad \cdot \quad \cdot \quad \cdot 120$

XXXVII Cost for Each Productive Hour by Faculty . • • • $\quad 124$

XXXVIII Budget Decrease Limits • • • • • • • • • • 127

XXXIX Productive Hours Decrease Limits • • • • • • $\quad 131$

XL Breakpoints of Cost Ratio Adjustments: Problem

Viewed as Minimization of Total Cost . . . . 139

XLI Breakpoints of Cost Ratio Adjustments: Problem

Viewed as Maximization of Output . . . . . 143

XLII Breakpoints of Productivity Ratio Adjustments:

Problem Viewed as Minimization of Total Cost . . 148

XLIII Breakpoints of Productivity Ratio Adjustments:

Problem Viewed as Maximization of Output . . . 151 
XLIV Mean Hours per Week at Each Activity by FTF and PTF . . 175

XLV Median Hours per Week at Each Activity by FTF and PTF . 176

XLVI Number and Percent of Classes Taught by Faculty . • . 177

XLVII Cost of Individual Turnover for FTF, PTF, and PTF ${ }_{y}$. . 178

XLVIII Hypothetical Salary Data and Calculations . . . . 193

XLIX Constraint Adjustment of Faculty Groups: College A

Problem Viewed as Minimization of Total Cost . . 199

L Constraint Adjustment of Faculty Groups: College B

Problem Viewed as Minimization of Total Cost . . 200

LI Constraint Adjustment of Faculty Groups: College C

Problem Viewed as Minimization of Total Cost . . 201

LII Constraint Adjustment of Faculty Groups: College A

Problem Viewed as Maximization of Output • • . 202

LIII Constraint Adjustment of Faculty Groups: College B

Problem Viewed as Maximization of Output . . . 203

LIV Constraint Adjustment of Faculty Groups: College C

Problem Viewed as Maximization of Output . . . 204

LV Adjustment of Budget Constraints: College A

Problem Viewed as Maximization of Output . . . 205

LVI Adjustment of Budget Constraints: College B

Problem Viewed as Maximization of Output . • . 206

LVII Adjustment of Budget Constraints: College C

Problem Viewed as Maximization of Output . . . 207

LVIII Adjustment of Total Productive Hours: College A

Problem Viewed as Minimization of Total Cost • • 208 
LIX Adjustment of Total Productive Hours: College B

Problem Viewed as Minimization of Total Cost • •

LX Adjustment of Total Productive Hours: College C

Problem Viewed as Minimization of Total Cost • • 210

LXI Cost Ratio Adjustments: Problem Viewed as Maximization

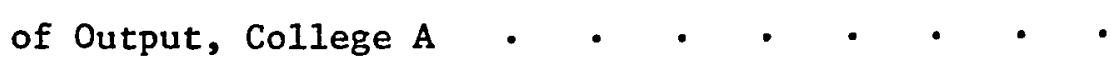

LXII Cost Ratio Adjustments: Problem Viewed as Maximization of Output, College B • • • • • • • • 212

LXIII Cost Ratio Adjustments: Problem Viewed as Maximization of Output, College C $\mathrm{C} \quad \cdot \quad \cdot \quad \cdot \quad \cdot \quad \cdot 213$

LXIV Options to Increase Output: Adjustments of Cost Ratios Problem Viewed as Maximization of Output, College A

LXV Options to Increase Output: Adjustments of Cost Ratios

Problem Viewed as Maximization of Output, College B

LXVI Options to Increase Output: Adjustments of Cost Ratios

Problem Viewed as Maximization of Output, College C

LXVII Cost Ratio Adjustments: Problem Viewed as Minimization of Total Cost, College A . . . . . . .

LXVIII Cost Ratio Adjustments: Problem Viewed as Minimization of Total Cost, College B . . . . . . . . 218

LXIX Cost Ratio Adjustments: Problem Viewed as Minimization of Total Cost, College C . . . . . .

LXX Options to Save Costs or Increase Output: Cost Ratio Adjustments, Problem Viewed as Minimization of Total Cost, College A 
LXXI Options to Save Costs or Increase Output: Cost Ratio Adjustments, Problem Viewed as Minimization of Total Cost, College B $\quad \cdot \quad \cdot \quad \cdot \quad \cdot \quad \cdot \quad \cdot \quad \cdot \quad$ - 221 LXXII Options to Save Costs or Increase Output: Cost Ratio Adjustments, Problem Viewed as Minimization of Total Cost, College C . . . . . . . . 222

LXXIII Productivity Ratio Adjustments: Problem Viewed as Minimization of Total Cost, College A • • • • 223

LXXIV Productivity Ratio Adjustments: Problem Viewed as Minimization of Total Cost, College B . • • $\quad 224$ IXXV Productivity Ratio Adjustments: Problem Viewed as Minimization of Total Cost, College C . . . . 225 LXXVI Options to Save Cost or Increase Output: Productivity Ratio Adjustments, Problem Viewed as Minimization

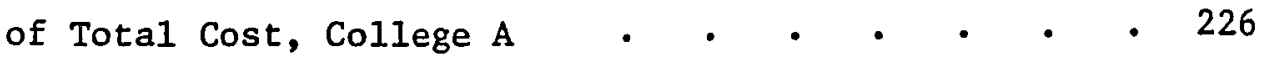
LXXVII Options to Save Cost or Increase Output: Productivity Ratio Adjustments, Problem Viewed as Minimization

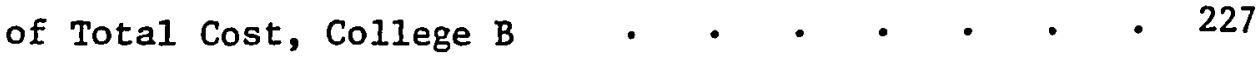

LXXVIII Options to Save Cost or Increase Output: Productivity Ratio Adjustments, Problem Viewed as Minimization

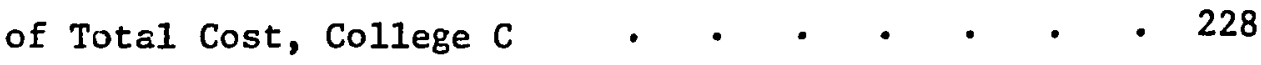

LXXIX Productivity Ratio Adjustments: Problem Viewed as Maximization of Output, College A . . • . . 229 LXXX Productivity Ratio Adjustments: Problem Viewed as Maximization of Output, College B . • • • . 230 
xiii

TABLE

LXXXI Productivity Ratio Adjustments: Problem Viewed as

Maximization of Output, College C . • • • • 231

LXXXII Options to Increase Output: Productivity Ratio

Adjustments, Problem Viewed as Maximization of

Output, College A • • . • • . • • • 232

LXXXIII Options to Increase Output: Productivity Ratio

Adjustments, Problem Viewed as Maximization of

Output, College B • • • • .

LXXXIV Options to Increase Output: Productivity Ratio

Adjustments, Problem Viewed as Maximization of

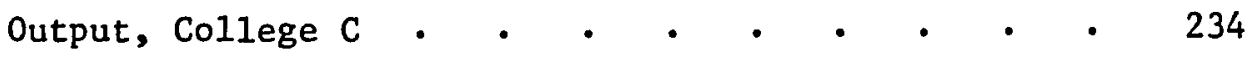




\section{CHAPTER I}

\section{INTRODUCTION AND REVIEW OF LITERATURE}

The purpose of this dissertation is to examine the effect of costs and constraints on the use of full-time and part-time instructors at community colleges. The hypothesis is that community colleges act in a manner predicted by economic assumptions of rationality. This fundamental assumption of microeconomic theory, i.e., that firms act in a rational way, is extended to community colleges in a specific Standard Metropolitan Statistical Area (SMSA). The questions considered are whether community colleges minimize cost or, alternatively maximize output with respect to their internal costs, the constraints imposed upon them by an urban labor supply, and their evaluation of faculty available to teach full-time and part-time. The dissertation examines the potential impact of various simulated conditions, such as budgetary decreases or wage increases, on costs, output, and employment of the two faculty groups.

There are a number of reasons why this topic merits extensive examination. First, the increase in the use of part-time faculty at all institutions, particularly at community colleges, has been dramatic. In the 1968-69 academic year at Oregon's publicly controlled community colleges, there was 1.0 part-time faculty for every 1.3 full-time faculty, but by the 1978-79 academic year part-time faculty outnumbered ful1-time faculty by a ratio of 2.1:1 (American Association of Junior Colleges 1969 and 1979). Second, the community colleges experienced dramatic growth during the 1960's and ear1y 1970's. In the state of 
Oregon, for example, the operating costs of community colleges grew from $\$ 10,000,000$ during the $1967-68$ academic year to nearly $\$ 90,000,000$ during 1977-78 (Oregon Department of Education 1979).

Third, the community college is an attractive alternative to the four-year college or university, as it provides not only an "open door" admissions policy but alternate educational opportunities, including vocational and technical areas of study. The community college also offers traditional lower division college classes at less cost to the student than does the university or college. Finally, the fact that tax dollars provide the major source of funds subjects community colleges to scrutiny. In Oregon, tax dollars from mostly state and local sources accounted for over 80 percent of the operating costs during the 1977-78 academic year.

The fast growth era of most institutions of higher education, including community colleges, appears to be over (Freeman 1976). The reasons for the decline in the rate of growth of community colleges are complex: demographic changes, governmental fund allocation decreases, other budgetary tightening, and inflationary pressures (Tuckman, Caldwe11, and Vogler 1978). Regardless of the reasons for the decline in growth, budgetary restrictions have caused colleges to become more sensitive to fluctuations and shifts in enrollments, demands for wage increases from faculty and other groups, and tax revenue changes.

Academic institutions have attempted a number of methods to reduce instructional costs and to cope in other ways with reduced budgets, including upward adjustment of student-faculty ratios, incorporation of new technology such as computer instruction and televised courses, and 
the use of part-time faculty rather than full-time faculty. Increasing the use of part-time faculty is one of the most frequently used methods of adjusting to declining or stabilized resources (McGuire 1978).

To date there has been little research relating to the economic impact on the colleges of part-time faculty. With the increasing use of these faculty, economic questions arise regarding the costs and productivity of the two faculty groups, the optimum use of each, and the options available to the college in response to budgetary and enrol1ment fluctuations and other cost and constraint adjustments at the college. This dissertation addresses these issues.

Part-time faculty form a supplementary, although important and often large, part of the total faculty. In general colleges do not encourage these instructors to become permanent faculty. There is no mechanism which allows part-time faculty to advance in rank or status.

Full-time faculty and part-time faculty have different supply and demand schedules but are treated by the college as relatively good substitutes for each other. Full-time faculty members form the nucleus of the teaching faculty and provide a number of other necessary services as well as continuity to the teaching staff. The college has developed pay levels and other incentives which encourage these faculty to remain as permanent members of the college.

The college employs faculty from both groups and appears to recognize the employment-related costs of each. Research has indicated that the wage component, full-time faculty cost more than part-time faculty as measured on a per hour of work basis (Tuckman and Vogler 1978). 
Employment decisions are made on more than just cost considerations; the employing organization examines the value of the product that the respective groups produce as well as other factors.

While the purpose of the research is to examine the behavior of community colleges in urban labor markets, the originality of inquiry comes from two sources: first, the model includes an examination of non-wage costs and how they influence the college's behavior. The development of the theory of non-wage costs did not take place smoothly or quickly; few studies include non-wage costs as variables. Although a major article by Walter $0 i$ was published as early as 1962 , only sporadic research on that topic has been published since.

The second distinctive aspect of this research is its inclusion of part-time workers. Research examining the full-time labor force is common; however, only a very small number of studies on the economics of part-time workers has been published, and studies that do exist have examined the supply side of the labor market.* This dissertation examines the demand side--more specifically, from the community college's standpoint-rather than from the supply side.

The community college is only one type of organization which uses part-time workers. Other industries which use large amounts of parttime help are services, agriculture, and retail trade. These three account for nearly 45 percent of all part-time work experience but only 25 percent of total employment (Morse 1969). Other industries, notably durable good manufacturing, certain non-durable goods-producing in-

*See for example: Gramm 1973, Morgenstern and Hamovitch 1976, and Owen 1977a. 
dustries, and transportation and public utilities, use almost no parttime workers. While part-time work experience varies greatly among industries and occupations, for the economy as a whole it has been increasing substantially. The proportion of part-time workers in the labor force has grown from 12.6 percent of all workers in 1948 to 22.9 percent in 1976 (Hedges and Gallogly 1977).

The distinction between full-time and part-time is usually made in terms of specific hours worked. Full-time is defined in the Current Population Survey (CPS) as 35 working hours or more per week, while part-time is less than 35 hours. This distinction ignores the other important differences between full and part-time workers; they differ in more ways than merely in hours worked. Differences exist on the basis of wage levels, fringe benefits and other economic costs (Daski 1974), and also in terms of social status and other less quantifiable aspects of work. This research examines such differences using a particular type of labor market.

Community colleges located in urban areas have available to them large numbers of educated persons who are available and willing to teach part-time. From the college's standpoint, there are three reasons for the use of part-time instructors: such instructors provide colleges with flexibility to adjust their course offerings, they allow colleges access to specialized talent and skills within the community, and their wages usually cost less than those of full-time faculty (Koltai 1977). The number of part-time faculty employed at the community college, as well as at other institutions of higher education, has increased substantially in the past decade (Cartter 1976, Abel 1977, and Tuckman 
1978). The decision to hire part-time faculty by these institutions is based on a number of changes which have taken place both within the college and externally. The environment in which colleges and universities, as well as all other levels of public and private educational institutions, exist has changed drastically during the last decade. The 1960's was a decade of fast growth in student enrollment leading to greater demand for all inputs of education, including instructors (Freeman 1971, 1976, 1977, 1980b).

The growth of student enrollment slowed and in some cases reversed itself in the 1970's, leading to an effect on the demand for inputs similar to the acceleration principle which is usually applied to the demand for capital goods (Freeman 1976). This shift in demographic factors led to a decline in the rate of increase in demand for instructors at all levels of education. The relative decline in enrollment was coupled with a recessionary economic environment which resulted in a general tightening of budgetary allocations at the local and state level. Both of these led to budget restrictions applied to all spending for education purposes (Radner 1975).

The cost squeeze was further emphasized when student enrollment shifted from one academic discipline to another. The college found it necessary to increase class offerings in some areas but decrease them in others. While the shift was difficult with full-time faculty who were specialists in one area and often tenured, the community college found it could accommodate the shift in offerings with part-time faculty members who were not tenured and whose positions were easy to create or to eliminate. Colleges subject to financial pressures apparently have 
found a relief valve in the increasing use of part-time instructors.

The above discussion centers on conditions of demand for college instructors; however, there are two sides to any market. Supply conditions also facilitated the use of part-time instructors in urban areas. The demographic factors which led to a decline in the rate of increase in demand for college instructors resulted in excess quantity supplied of faculty. Large numbers of persons were trained in the 1960 's for teaching jobs at all levels of education from grade school to high school and higher education. The excess quantity demanded in the 1960's dramatically shifted to conditions of excess quantity supplied in the $1970^{\prime} s$, resulting in a large influx of persons trained and available to teach at the community college but few new jobs (Freeman 1976).

Coupled with excess quantity supplied was the changing social environment of the 1970's. Many persons continue to prefer a full-time profession such as teaching, which has security, status, and a good income. However, increasingly within the urban scene there are those who prefer a looser connection with the labor force. The motivations of these individuals are diverse: many prefer a part-time job so they can engage in other activities and interests; some are secondary breadwinners within the family or share the workload with their partners. Some have income from other sources and prefer to supplement this income with a part-time job rather than a full-time profession (Hallaire 1968, Cartter 1976).

While many prefer part-time work, a large number of persons want ful1-time teaching positions but cannot find them (Freeman 1971, 1976 
1977. Tuckman and Tuckman 1980). Although the prospects of moving into these positions are slight, many of these individuals seem willing to teach part-time, accepting lower income and fewer fringe benefits, no prospects for promotion and tenure, and lower social status than a full-time teaching job would bring.

\section{REVIEW OF THE LITERATURE}

Traditional theory represents labor as a variable factor of production and capital as fixed in the short run. A factor of production is variable if its cost is totally associated with current production; that is, if the input quantity can be changed easily and quickly to needed changes in output. A fixed factor is one which cannot easily be changed in the short run. Traditional theory is accepted by most economists as a close representation of reality.

Traditional theory has been challenged by the development of a number of theories. The idea that labor is not a completely variable factor of production began with the early economists,* who briefly discussed the existence of non-competing groups in the labor market. The whole population does not compete indiscriminately for all jobs because of the existence of barriers such as social position and the formal education and training necessary to qualify for an occupation. John Clark (1923) discussed the impact of training and education but viewed them as costs either to the individual or the community, rather than to the firm. Clark suggested that entrepreneurs would not be willing to invest resources to train workers because tangible security to the firm

*See for example: Mill 1848 and Cairnes 1874. 
was lacking which resulted in the opportunity for trained workers to shift away from the particular job.

The recognition by economists that labor is a variable factor of production is compatible with the view by this same group that labor turnover should be encouraged in order to assure the most efficient allocation of scarce resources. In direct contrast, business people have always been interested in reducing labor turnover because of the costs associated with it. In 1917, a collection of articles, with primary contributions by businessmen, was published by the American Academy of Political and Social Science to explore the "problem" of labor turnover. An article by Fisher (1917) suggested a number of ways to reduce labor turnover, including discouragement of alcoholism, instruction in the proper use of income, continuous paychecks, pure drinking water, and mid-day meals on the job.

These early writings are of interest here because they recognized the importance of education and training in the differentiation of various types of labor. More recent writings have refined the theory that labor is not a completely variable factor of production. The development of this idea took two major steps: first, the idea that education and training by labor cause differences in the "return" to this factor of production led to the conclusion that investment in labor is conceptually similar to investment in physical capital. Second, the recognition of labor as a quasi-fixed factor led to theoretical predictions and empirical research on the impact of non-wage costs on the behavior of the firm and the worker. 
Literature in this area is quite well developed and generally accepted by economists; because of this, discussion here is Iimited. Becker (1962) and Mincer (1962) made major contributions in their articles dealing with training and education as investments in labor. Becker's article is a general overview of the theoretical and empirical implications of investment in human capital. His attempt was to broaden earlier work concerning investment in human capital and to redefine the current usage of the term to include activities in addition to formal education. Becker stated that diverse activities such as onthe-job training and other less formal education and training, information acquisition, and health improvement activities could all be included in investment in human capital.

Mincer's article, like Becker's, deals with education as a process of investment in human capital, although his specific interest is onthe-job training. This aspect of training has long been neglected but is an extremely important part of the whole training process. Mincer views formal education as an initial general stage serving as preparation for a more intensive and spectalized training period which occurs when the individual enters the labor force. Mincer's article included some aggregate estimates on the cost of education and on-the-job training.

The use of investment in human capital to estimate relative wage differences originally developed from literature concerning the economics of sex and race discrimination. It was expanded by Smith (1976a, 1976b, 1977a, 1977b) and used in a series of articles and books in which pay differentials between government and private sector workers were examined. 
The second step in the development of the Idea that labor is not a completely variable factor of production is the recognition that training, education, and other investments, if financed by the firm, influence the firm's behavior. Firms are willing to finance training in their labor forces under a number of conditions. If a firm does finance training, the result is labor costs which are in addition to the wage costs. Under these conditions, labor has non-wage costs and can no longer be defined as a completely variable factor of production. Holt, Modigliani, Muth, and Simon (1960) published a book designed to guide business people in making practical business decisions, including decisions on employment costs. The model developed recognized what these business people have known for years: that the work force is not a completely variable factor of production. The HMMS model includes non-wage costs such as hiring and termination, and attempts to make the non-wage costs explicit and measurable. The authors recognized that many of these costs are posted in accounting records while others are economic costs and thus are of ten hidden.

Walter Oi (1962) developed a short run theory of labor based on non-wage, employment-related costs he called "quasi-fixed," which include hiring, training, and termination costs. These costs influence the employer's decisions because labor is viewed by the firm no longer as completely variable but as having elements of both variable and fixed costs. Oi examined the cyclical behavior of employment, unemployment, and earnings with aggregate data using the wage as a measure of the degree of fixity. He concluded that higher degrees of fixity of an occupation result in smaller changes in employment and labor turnover, 
and lower unemployment.

While most research has made assumptions concerning the actual amount of these "fixed costs" of employment, the Conference Board Record (Myers 1967) presented the approximate cost of one component of fixed costs: hiring. Four different categories of workers were examined: professional, managerial, and technical; clerical; skilled; and semiskilled and unskilled workers. The research was part of a larger study on job vacancy conducted by the Office of Manpower, Evaluation, and Research of the United States Department of Labor. The data provided the first information on the actual cost of hiring and indicated that the cost of hiring is greater with high pay categories, a finding consistent with the assumptions concerning fixed costs and wage levels made by $0 i$, Rosen, and others.

Garbarino (1964) examined the impact of certain non-wage costs, or fringe benefits, on the decision-making process surrounding the use of overtime as a substitute for new employees. His results suggest that fringe benefits are not a barrier to expanding employment, although Garbarino (1964, 1966) and MacDonald (1966) stated that some other laborrelated costs which may be important were excluded from the model and may have influenced the results.

Ehrenburg (1971a) developed and empirically tested a model of influence of fringe benefits on overtime behavior. His results are in direct contradiction to Garbarino's; however, Ehrenburg's study was more complete in including as part of the model fixed employment costs in addition to fringe benefits (regardless of what his title suggests). The empirical test indicated that quasi-fixed costs of employment relative 
to the overtime wage rate caused employers to be less likely to add new employees and more likely to use their current work force more intensively, that is, to use overtime. The study examined a large number of individual establishments, using data from the Bureau of Labor Statistics. Ehrenburg's results are consistent with the theory of quasi-fixed costs as an investment in the current work force and a cost consideration in the production process.

Rosen (1968) also examined the impact of fixed costs on specific labor markets. In the labor market he studied, the labor hour variation is higher among those occupations which have higher fixed costs. Rosen concluded that high fixed costs influence employers to attempt to use the workers in these occupations more efficiently. In other words, occupations which have high fixed costs will tend to have smaller variations in employment and hours per worker and, in general, will also have smaller changes in the level and composition of the work force. In a subsequent article, Rosen (1969) developed a supply and demand model to examine differences within the interindustry wage and hours structure. The model uses the conventional supply specification of income-leisure and tastes, so the difference from other supply and demand models is the demand side in which Rosen includes non-wage costs of labor. Along with the wage, these investment costs influence the demand not only for employment but also for hours of work. Rosen concluded that an increase in the demand for hours would result either from a decrease in the wage rate or from an increase in the "user cost" of labor, the specific investment of the firm into employees. Nadiri and Rosen (1973) expanded on these ideas in a book dealing 
with conditions of production. The model is an extensive examination of both short run and long run conditions, including as part of the total model the influence of fixed costs of labor on employment, hours of work, and other inputs to the production process. However, the main interest of the study is on the conditions of disequilibrium on the demand side of the market.

The influence of non-wage costs as a factor in the behavior of the employer and employee was developed into a more complete theory of labor markets by Doeringer and Piore in their book Internal Labor Markets and Manpower Analysis (1971). The major theme of the book is that many labor markets are not competitive but have formed into non-competitive groups called internal labor markets. While this is similar to Kerr (1954), Doeringer and Piore extended the theory to suggest that a number of non-wage factors encourage the formation of internal labor markets into highly structured markets with rules and regulations surrounding entry, exit, training, wage and non-wage payment levels, and internal mobility.

The internal labor market is shielded from the competitive environment of the external labor market but is interconnected with the more competitive market at points of entry and exit. In contrast to the internal labor market which is largely shielded from external influences, the external market is more subject to the forces of supply and demand assumed by conventional economic theory.

Doeringer and Piore also suggested a classification scheme by which the types of internal labor markets could be distinguished: manorial markets, craft-type markets, and the external labor markets. Alexander (1974) suggested that the degree of mobility could be used to classify 
these labor markets and that greater amounts of firm-specific training takes place more of ten in manorial than in craft-type internal labor markets. Alexander excluded part-time and casual labor from his analysis.

In a separate article, Doeringer (1967) discussed the structure of manorial-type internal labor markets and the influence of technological changes in product demand, and the effect of various types and quality of labor on the static and dynamic adjustments of labor markets. He suggested that fluctuations in the demand for output of ten lead to the development of a dual internal labor force: one permanent, which provides the core, and the other temporary. The permanent internal labor force has more rights including internal mobility, training rights, and of ten higher pay levels. Doeringer did not discuss part-time labor. The influence of non-wage costs on workers other than full-time personnel has been examined only incidentally. In The Peripheral Workex, Morse (1969) provided an overview of two types of peripheral workers: the part-time worker and the intermittent worker. While he provided a thorough examination of the history of the peripheral worker from the supply side, Morse did not deal in great detail with the demand side of the labor market for peripheral workers. However, he did discuss general aspects of the demand for peripheral workers. Using the theory developed by Becker, Morse discussed the probable unwillingness of employers to finance firm-specific training of peripheral workers because the expected rate of return from such training is less for an intermittent employee than for a full-time employee.

In an extensive study of part-time workers, Owen (1977a) discussed 
a number of reasons why unit labor costs increase with shorter hours. Owen examined the impact of the shorter number of hours of work on willingness of employers to finance the training of part-time employees, concluding, as did Morse, that the amortization period is shorter for part-time than for full-time workers even if the turnover rates of the two groups are the same.

Owen pointed out that additional costs may increase with parttime workers: if part-time workers replace the full-time labor force, the amount of work may not increase but the number of persons will, with corresponding increase in the costs associated with information dissemination, supervision, and communication. Recruitment and screening costs also increase directly with the number of persons.

Owen (1977a, 1978) and Nollen, Eddy, Martin and Monroe (1976), predicted that the earnings of part-time workers are less than the earnings of full-time workers because employers are reluctant to invest in workers who are not committed to full-time jobs. Therefore part-time workers would be expected to have lower average earnings. The National Longitudinal Survey data were used to explore a similar topic (Jones and Long 1979). The authors found empirical evidence consistent with the hypothesis that workers and their employers have less incentive to invest in on-the-job training when the employee works only part-time. The specific research area of part-time instructors in community colleges has not been explored in detail. Prior to the mid-1950's, very few part-timers were employed by institutions of higher learning, hence the area was not seen as one of particular concern. The growth of parttime faculty at community colleges has been documented (see the American 
Association of Junior Colleges, various years), but exploration of the implications of such growth has been limited to a small number of recent articles. In an article by Price and Lane (1976), use of parttime instructors by community colleges was examined to determine what factors lead colleges to employ part-time faculty. The factors analyzed were control, scope, student-faculty ratios, size, and years of operation; none was found statistically significant in determining the relative size of the part-time faculty use at the college. The authors did suggest (although they had no data to back up their claim) that the community college was able to attain a greater flexibility in course offerings at a smaller total cost than the four-year institution due to its use of part-time faculty.

The characteristics of the part-time faculty in institutions of higher learning have been examined by Tuckman (1978) with data generated by an AAUP survey.* The author examined the personal, college, and other job-related characteristics, and the work histories of part-time faculty. In an article based on the same data source, Tuckman and Vogler (1978) examined wage levels of part-timers; their analysis seems to suggest that those who teach part-time are paid less than those who teach full-time although the differences diminished when adjusted for rank. The authors did not adjust for the personal characteristics of the two groups of faculty and admitted that rank differences may be a form of discrimination. The authors also examined the structural characteristics of the part-time faculty labor market, concluding that while the market for full-time faculty is national, that for part-time faculty is local.

*See appendix of Tuckman (1978) for description of the sample. 
CHAPTER II

THEORETICAL MODEL

The community college uses two distinct types of faculty: fulltime and part-time. The full-time instructors are employed with the expectation that they will perform two services: first, they are expected to teach a minimum number of classes, and second, they are expected to perform additional duties including developing coursework and attending meetings. There is no need to rehire full-time faculty (FTF) on a term-to-term basis unless special conditions present themselves since the job may be regarded as permanent. Although the college has increasingly hired FTF under special contracts and temporary conditions, most faculty hold permanent contracts.

Part-time faculty (PTF) are hired by the college to teach specific classes. Usually these faculty are hired to teach one specific class and if the college has additional classes for the PTF to teach, they must be rehired. This rehiring may take the form of a short telephone call or verbal statement by the administrator or department head to an individual who has taught for the college before.

Similarities do exist between the FTF and PTF. The general educational background of each type of faculty is comparable; most community colleges require a master's degree in the field as a minimum requirement although they will accept less in special circumstances (Lombardi 1975). Few differences exist between the kinds of classes which FTF teach and those allocated to part-time instructors; both are college-transfer lowerdivision classes in which the instructor is required to prepare lectures 
or class discussion material, instruct students in-class, fill out grade forms, and engage in other related activities.

While these are some of the similarities between the two types of faculty, there are differences in a number of important areas. They are separated by wage levels, fringe benefits and other non-wage payments, administrative procedures including hiring and termination practices, seniority rules, advancement and accompanying pay increases, social status within the college, and a number of other policies and practices. In addition to teaching which both types of faculty perform, the FTF also engage in other duties at the college. While the advising of students is part of the weekly work load of full-time faculty, they also develop curriculum, perform the role of decision-maker, attend meetings, and execute a number of other functions which are not done by either college administrators, support staff, or part-time instructors.*

PTF are paid to teach a specific class or classes and with few exceptions are not paid to perform other tasks. The college views parttime instructors as a flexible part of the total faculty. It makes no commitment to them even though many teach for years and become de facto an almost permanent part of the faculty. Nonetheless, if circumstances required it, the college could terminate all PTF with relative ease. The demand for college faculty is therefore a demand for two distinct types of faculty, with part-time instructors viewed much like a variable factor of production since the college is able to adjust the input levels of faculty. FTF can then be considered a fixed factor of

* See supporting data in subsequent chapters: 
production. The college cannot adjust the input of FTF without great difficulty.

On the supply side, there are differences in motivation between full-time and part-time faculty. Persons who wish to teach full-time generally intend to treat teaching as their lifetime profession. This is the career to which they devote all, or almost all, their working hours. Part-time instructors have more diverse motivations (Tuckman 1978). Many have full-time jobs in other fields and teach to keep up with current information or to meet and discuss issues in their fields with other people. High school teachers and local business people are of ten willing to teach for these reasons. Some probably teach for the additional money that part-time teaching brings; these may include graduate students from surrounding universities who are willing to teach classes in their area of knowledge.

Given these characteristics of PTF and FTF, the supply and demand for labor can be viewed as two separate schedules. In fact, it appears that there is very little movement between the two groups: the FTF member is unlikely to become a part-timer (at least at the part-time pay level), because all FTF hold full-time positions, and for most these are permanent jobs. FTF of ten moonlight at their respective colleges; however, the policy on pay and the willingness of the college to allow its instructors to moonlight vary widely. On the other hand, PTF often wish to become full-time. In the AAUP study, nearly 17 percent of the sample specified that they would like to become full-time (Tuckman and Vogler 1978). Another author found a majority of her sample would accept a full-time position if it were available (Abel 1977 ). However, evidence suggests 
that the part-timer has little chance of becoming a full-time instructor. The labor market at two-year institutions for full-timers appears to be contracting or at least not growing, while that for PTF is expanding. Thus there are few new full-time positions available (Tuckman, Caldwell, and Vogler 1978, and Abel 1977).

Furthermore, the labor market for FTF and PTF differs in structure. The labor market for FTF tends to be at least regional if not national in character (Brown 1967). The individual seeking a full-time instructional position competes with others in a relatively large geographic area. For example, a community college located in an Oregon SMSA would find applicants from the Pacific Northwest, California, and perhaps many other states, rather than merely the specific SMSA. No individual college or applicant has an impact on the market for FTF, hence at the entry level the market is competitive.

The market for PTF is in contrast to that for FTF. It can be considered local in character, perhaps as large as an entire SMSA, but often only a portion of the metropolitan area. The willingness of PTF to move or even travel great distances to teach is limited by the potential income. If PTF income is relatively small and cannot be considered a source of steady income, the individual probably would not be willing to change residences to acquire the part-time teaching position. Nor would an individual be willing to travel great distances to teach one or two classes if the direct cost of the travel and the indirect cost of the travel time involved were greater than the increase in income itself. Empirical evidence on the contribution of income from part-time teaching comes from two studies. Abel (1977) found that while 32 percent 
of her sample relied on part-time teaching to provide at least half of their personal income, at least 22 percent of the same sample held positions at more than one campus. Using the AAUP sample of part-time teachers at institutions of higher education, Tuckman and Vogler (1978) found that part-time teaching provided an average of 10 percent of an individual's income and 6 percent of the household income. In addition to the evidence of the contribution of part-time teaching to household income, the AAUP survey asked if the part-time instructor would be willing to move residences to accept an academic position elsewhere. (Ful1-time or part-time was not specified.) Nearly 67 percent stated that they would not or could not, or that it would be difficult to move. Many of the PTF in this dissertation sample hold a full-time job elsewhere and thus probably would be unwilling to move to accept a parttime position at a college outside the SMSA. Other PTF are not employed ful1-time, but hold other part-time positions or are attending a university themselves and therefore would probably be unwilling to move or even commute to a part-time position outside the imnediate metropolitan area. The willingness of PTF to move is restricted by their current activity, whether job, school, homemaking, or personal preference, and a move to a more attractive part-time job is restricted by the adverse effect on the current alternative activity.

The unwillingness of PTF to move residences or commute to a different geographic area results in a market structure in which the buyer has monopsony or oligopsony power in the factor market. In an urban area, only a few institutions exist which are buyers of labor while many individuals are willing to work for the institution; thus, no 
individual seller can influence the market wage; that is, the supply curve is perfectly elastic. Differences in wages offered to part-timers by institutions may exist in part because of the tendency of the prospective faculty member to make a decision based on the close proximity of the institution to the alternative activity. Tuckman and Caldwell (1979) found a coefficient of variation of salary at junior colleges of .79, implying that a uniform salary schedule does not exist for parttimers.

It is assumed that the supply curve for both FTF and PTF is perfectly elastic; at the going wage the college can hire additional faculty without affecting the average wage. On the demand side, the college is assumed to have monopsonistic power in the PTF labor market, and the demand is the marginal revenue product curve. Firms with monopsony power facing a perfectly elastic supply curve generally occur only in a metropolitan area where a large number of well-educated persons exists. A monopsony market structure in which the monopoly firm faces an upwardsloping labor supply curve is more likely to occur in rural areas where there is a limited supply which can only be brought forth by offering a higher wage.

Given these characteristics of PTF and FTF, the supply of labor of each type of faculty can be viewed differently from the view taken by other studies on this subject. The determination of numbers of people and hours of work is usually approached from the supply side. Employees are viewed as facing a price (wage') andadjusting their hours supplied to 1t. However, the approach taken in this dissertation views the supply of both PTF and FTF as perfectly elastic and concentrates on an examination of the demand side. 
The problem the college faces is treated as a constrained optimization problem. Optimization is viewed in two ways: first, the college can plan to produce a particular level of output and then attempt to minimize cost subject to this level of output. Second, the college can determine the cost level and attempt to maximize output subject to this cost. Development of the model takes place in a manner which expresses the simple relationships and gradually adds complexity in order to approximate more closely actual labor costs and constraints at community colleges.

$\operatorname{cosTS}$

Initially, the assumption is made that the college uses only one type of labor. Because the college is providing a service, there are the usual difficulties in measuring output. The model incorporates assumptions regarding the relationship between labor input and the college output. Support for these assumptions is from empirical research which is cited and discussed in a later section.

The college demands labor input to produce output. This labor is a combination of numbers of persons (N) and hours worked per person (H). The combination of the two is expressed as:

$$
L=\mathrm{f}(\mathrm{N}, \mathrm{H})
$$

where $L$ is labor flow specified for a particular time period (Rosen 1.968). In this model, the college produces output (Q) per time period which is defined as the labor input times a weight (P) which is interpreted here as productivity and further defined and expanded upon in a later 
section:

$$
Q=P N H=P L
$$

The college also examines labor costs. In its simplest form, the college faces the following variable costs (V):

$$
\mathrm{V}=\mathbf{W H}
$$

where $\mathrm{w}$ is the wage.

The college looks at its labor inputs not only in relation to the wage it pays but also at other costs of labor. This model includes two other costs; the first is called fringe benefits and includes a number of non-wage payments made to labor or on behalf of labor to government or some other agency. Many of these costs are fixed in the sense that they do not increase with the wage level but are associated with the employee rather than with the hours worked.

The other non-wage cost included in this model is a turnover cost. This is an investment cost of labor in the sense that it is a one-time expenditure on labor. In economic terms, investment means an addition to or replacement of real, as opposed to monetary, assets including factories, machinery, houses, inventories, and other capital. The term "investment" is used here in a way which parallels this usage, except that the firm is making new or replacement investment in its labor force. The investments include expenditures on individuals for hiring, training, and termination. From the college's standpoint, these costs are a capital expenditure because the college expects labor to be more productive* as a result of the investment.

*Terminating a faculty does not necessarliy make the individual more productive although it may make the group more productive. It is a fixed cost of labor and, as such, is included as an investment. 
The expression $(1+.5 r)$ is an adjustment for the opportunity cost of having funds tied up in the investment of faculty rather than in another earning investment. Because the investment can be made at any time during the year, the use of .5 averages the interest rate $(r)$ over one year. The turnover costs can be expressed as $q \operatorname{TN}(1+.5 r)$. The investment cost to the college is component $\mathrm{qTN}$, the rate at which employees quit (q), multiplied by two factors: the cost of each turnover $(T)$ and the number of employees $(N)$.

The costs are combined to form an equation in the following manner where TC is the total cost of faculty per time period:

$$
\begin{aligned}
& \mathrm{TC}=\mathrm{FN}+\mathrm{TNq}(1+.5 \mathrm{r})+\text { wHN } \\
& \text { where: } \quad \mathrm{F} \text { is the fringe cost per instructor } \\
& \mathrm{N} \text { is the number of faculty members } \\
& \mathrm{T} \text { is the turnover cost per instructor } \\
& \mathrm{q} \text { is the quit rate } \\
& \mathrm{I} \text { is the interest rate } \\
& \mathrm{W} \text { is the wage per hour worked, and } \\
& \mathrm{H} \text { is the hours per faculty member. }
\end{aligned}
$$

The expression states that the total cost (TC) of faculty to the college is a combination of the cost of fringe benefits, turnover costs as adjusted with the quit rate and the interest rate, and the wage costs, which combination is itself multiplied by the number of hours worked by the employees. The total cost is then derived by multiplying each cost component by the number of faculty the college employs. 


\section{PRODUCTIVITY}

Costs are not the only consideration. In order to make a rational choice about the optimum use of resources, the productivity of the inputs must be examined. The college would prefer to hire those with higher productivity if the costs of both full-time and part-time instructors were identical and "other things" were also the same. Presumably, as noted earlier, FTF have higher productivity on the average than PTF, and therefore, ceteris paribus, would be preferred.

At this point a slight digression is in order. The concept of labor productivity has a specific meaning: productivity of the marginal worker is measured by the increase in ouput if, given the fixed inputs, the amount of the variable input, labor, is increased. As long as the firm is perfectly competitive, produces a measurable ouput, and "other things" remain the same, productivity is relatively easy to measure. Application is not as simple and straightforward as the above paragraph suggests because all of the conditions are rarely met. In addition, other problems arise when attempting to apply the concept to an institution which produces a service rather than a good. The community college produces teaching services and, while it is not impossible to measure the amount of a service produced, there are several reasons why the resultant measure is subject to controversy. One of the most important reasons is the lack of agreement on what a college, or any school, actually produces. Furthermore, once a definition of the ouput has been decided upon, use of variables to measure this ouput is another difficult and controversial task. 
As a result, there is little agreement among soclal scientists regarding how to measure the "marginal productivity" of teachers. While research in the area of educational economics has attempted to deal with the problems of definition and measurement of both school systems and the largest input of schools, teachers, it has tended to concentrate on the public school system, especially grade schools where data are more readily available and are collected with greater ease due to the structure of classroom teaching. However, even here results have been limited and controversial (Guthrie 1970, Hanushek 1970, Levin 1970, and Owen 1972).

As an alternative to the approach taken by the economics of education literature, the study of human resources has consistently revealed certain relationships between the education of individuals and their resultant output. Education can be thought of as an "investment" in an individual, which results in a return to that individual in the form of greater productivity and higher wages and income. Empirical research in the area of human resources indicates that there is a positive correlation between education and income: those who are willing to invest in this intangible resource generally increase their potential future real income.

The study of education as an investment began with an examination of the effect of formal education on income levels. In a pioneering article entitled "Investment in Human Capital" by Schultz (1961), the author discussed the importance of labor as a factor of production. A considerable amount of research was subsequently generated in an attempt to examine the relationship between education, income, and the productivity of workers. As research proceeded it became increasingly 
evident that there were a number of other sources of human capital in addition to formal education including informal training of all kinds, especially on-the-job training (OJT), information, health, and other intangible forms of human activity. While technical difficulties exist which make precise empirical measurement difficult, research has indicated there is a positive relationship.

The conclusion from empirical research in human resources is that education and training do result in higher productivity among those willing to invest. While these results have been subject to some controversy, there is little disagreement with the general conclusion. Therefore, the approach in this dissertation follows the theory of human resources.

The colleges themselves, as well as other educational institutions, appear to support the hypothesis that education and training are positively correlated with higher productivity. The salary schedule for full-time instructors rewards higher educational attainment and greater internal and external experience with higher salaries.

The theory of human resources suggests that there is a relationship between inputs and outputs. It was expressed earlier with equation 2.2:

$$
Q=P N H=P L
$$

As an initial simplifying assumption, faculty are assumed to have equal productivity up to some maximum number of (equal-sized) classes and hours of work. The model makes no assumptions regarding the productivity of FTF in relation to those who are part-time, although there are a priori reasons to believe that the former group has higher productivity. 
Other characteristics of FTF and PTF follow. Those who are parttime $\left(\mathrm{N}_{b}\right)$ work $\mathrm{H}_{b}$ hours per term, while full-time instructors $\left(\mathrm{N}_{a}\right)$ work $\mathrm{H}_{\mathrm{a}}$ hours per term. The labor inputs are combined by the college to produce output (Q). Expanding its earlier form (1.1), the output equation becomes:

$$
\mathrm{Q}=\mathrm{N}_{\mathrm{a}} \mathrm{H}_{\mathrm{a}} \mathrm{P}_{\mathrm{a}}+\mathrm{N}_{\mathrm{b}} \mathrm{H}_{\mathrm{b}} \mathrm{P}_{\mathrm{b}}
$$

which states that instructors have productivity expressed by the term $P_{a}$ for full-time and $P_{b}$ for part-time instructors. The numbers of faculty, hours of work, and productivity of the two faculty groups can be combined to produce output. In order to simplify computations, full-time instructors are given a productivity weight equal to 1.0 and the part-time instructors are given a weight that varies according to the calculations, as described in the study design.

\section{OPTTMIZATION}

Given the cost and productivity measures, the rational firm combines the two kinds of labor such that costs are minimized subject to the above output constraint, or output is maximized subject to a cost constraint. Using model 2.4 as a basis and expanding it to recognize the two classes of instructors, the total cost is:

$$
\begin{aligned}
T C=F\left(N_{a}+N_{b}\right)+ & (1+.5 r) q_{a} T_{a} N_{a}+(1+.5 r) q_{b} T_{b} N_{b} \\
& +w_{a} N_{a} H_{a}+w_{b} N_{b} H_{b}
\end{aligned}
$$

The total cost is an amount set by the college School Board or other administrative body.

The problem can be solved by use of linear programing since the conditions the model attempts to approximate can be assumed to be linear 
or approximately linear. The FTF and PTF were shown to be perfect substitutes for the teaching function but not perfect substitutes for each other. However, the differences between the FTF time allocation and that for PTF are relatively small: time spent in teaching-related activities differed by a maximum of ten percentage points at college $\mathrm{A}$ to as little as two points at College C. (See Table 5, Chapter IV.) Thus, for small changes in the two groups can be considered nearly perfect substitutes for one another; however, extreme changes (for example, if al1 FTF were replaced with PTF) may have an adverse influence on the college services and may not be realistic. These extreme changes will be discussed, however, and can be considered the minimum or maximum limit. The model must be modified in order to make it linear. The part of the model which is non-linear is the section in which the two variables $\mathrm{N}$ and $\mathrm{H}$ are multiplied by each other. Rather than expressing $\mathrm{H}$ as a variable, it is used as a constant: the average hours of work per term. Thus, for linear programming purposes the objective function becomes a cost minimizing function of the form:

$$
\begin{aligned}
\mathrm{TC}=\mathrm{F}_{a} \mathrm{~N}_{\mathrm{a}} & +\mathrm{T}_{\mathrm{a}} \mathrm{N}_{a} \mathrm{q}_{\mathrm{a}}(1+.5 r)+\mathrm{w}_{a} \mathrm{~N}_{a} \mathrm{H}_{\mathrm{a}}+\mathrm{F}_{b} \mathrm{~N}_{b} \\
& +\mathrm{T}_{b} \mathrm{~N}_{b} \mathrm{q}_{b}(1+.5 r)+\mathrm{w}_{b} \mathrm{~N}_{b} \mathrm{H}_{b}
\end{aligned}
$$

There are several constraints to this model. The college must produce at least a minimum amount of output:

$$
Q \geq \mathrm{N}_{a} \mathrm{H}_{a} \mathrm{P}+\mathrm{N}_{b} \mathrm{H}_{b} \mathrm{P}_{b}
$$

For full-time faculty, the combination of numbers of persons and hours worked per instructor is fixed at the full-time schedule $\left(s_{a}\right)$, and the part-time faculty work a part-time schedule $\left(s_{b}\right)$. In addition, there is a minimum number of FTF which is specified as $\mathrm{N}_{0}$ : 


$$
\begin{aligned}
& \mathrm{N}_{a} \mathrm{H}_{\mathrm{a}}=\mathrm{S}_{\mathrm{a}} \\
& \mathrm{N}_{\mathrm{b}} \mathrm{H}_{\mathrm{b}}=\mathrm{S}_{\mathrm{b}} \\
& \mathrm{N}_{\mathrm{a}} \geq \mathrm{N}_{0}
\end{aligned}
$$

There is a minimum amount of work that must be performed:

$$
\mathrm{Q} \geq \mathrm{Q}_{\mathrm{O}}
$$

The non-negative requirements are as follows:

$$
\begin{aligned}
& \mathrm{N}_{\mathrm{a}} \geq 0 \\
& \mathrm{~N}_{\mathrm{b}} \geq 0 \\
& \mathrm{H}_{\mathrm{a}} \leq 0 \\
& \mathrm{H}_{\mathrm{b}} \geq 0
\end{aligned}
$$

The model can also be expressed as an output maximization problem in which the objective function is of the form:

$$
\mathrm{Q}=\mathrm{N}_{a} \mathrm{H}_{a} \mathrm{P}_{a}+\mathrm{N}_{b} \mathrm{H}_{b} \mathrm{P}_{b}
$$

and the constraints are as follows:

$$
\begin{aligned}
T C \leqq F_{a} N_{a} & +T_{a} N_{a} q_{a}(1+.5 r)+w_{a} N_{a} H_{a}+F_{b} N_{b} \\
& +T_{b} N_{b} q_{b}(1+.5 r)+w_{b} N_{b} H_{b}
\end{aligned}
$$

which is the objective function of the previous cost minimization problem, expressed as a "less than or equal to" constraint. The previous constraints are also part of the problems as stated this way:

$$
\begin{aligned}
& \mathrm{N}_{b} \mathrm{H}_{\mathrm{b}}=\mathrm{S}_{\mathrm{b}} \\
& \mathrm{N}_{\mathrm{a}} \geqq \mathrm{N}_{0} \\
& \mathrm{Q} \geqq \mathrm{Q}_{0} \\
& \mathrm{~N}_{\mathrm{b}} \geqq 0
\end{aligned}
$$


The results show the optimum number of faculty for each type. These results are compared with the actual number of hours worked at each community college to see if the colleges act in the way the model predicts.

Linear programing allows simulation of various kinds of conditions and situations. While the actual costs are gathered and optimization is determined under current cost conditions given the model's assumptions, it is possible to determine optimization with simulated costs or constraints as well. This research examines not only the costs and optimum conditions in the current situation, but also the effects of a number of simulated costs, conditions, and constraints.

\section{STUDY DESIGN}

The colleges chosen for this study are the largest community colleges in a Standard Metropolitan Statistical Area (SMSA). They are identified only as College A, College B, and College C.* All of these are public community colleges which are located within and are influenced by the urban environment. The study concentrates on specific sections of each college: those subject areas which are geared mainly to lower division college (IDC) transfer programs. By excluding other parts of the community college, problems involving the great differences between LDC departments and other departments have been eliminated. The LDC division generally differs from the rest of the college in a number

*Further identification is felt unnecessary. However, the author will provide this information to those who inquire. 
of ways including hiring practices, class size and procedures, type of instruction, and level of education of the faculty.

Given the specific departments studied within the college, and the model which expresses the relationships among the variables, two major areas of data collection can be identified. These are (1) information on numbers, hours worked, and various costs of labor, and (2) information on the labor input as a proxy for productivity. The purpose of this section is to operationalize the variables in a way which facilitates the actual data-gathering process.

Numbers, Hours Worked, and Costs of Labor

Numbers of Faculty. These variables measure the average number of instructors employed per quarter based on the academic year.

Average Hours Worked. This variable measures the number of hours worked of FTF $\left(\mathrm{H}_{a}\right)$ and PTF $\left(\mathrm{H}_{b}\right)$ each term. Data were gathered by questionnaire. All work performed by the instructor was included: class preparation, in-class instruction, and other work.

Quit Rates. The percent of FTF and PTF terminated each term ( $q_{a}$ and $\mathrm{q}_{\mathrm{b}}$ ), averaged over three academic years, is used as a measure of quit rate. The use of more than one year reduces the possibility that one exceptional year is used as a basis for the estimates.

For FTF a quit has a clear meaning: a FTF member formally terminates the employment relationship with the college. For those who are part-time, a quit is not as easily defined since PTF can be hired for one quarter, quit for several terms, then return two or three quarters to teach again. Thus, it becomes necessary to define a quit for PTF 
as one whose name appears during one year but does not reappear during the following sample years.

Interest Rate. While the interest rate $(r)$ is an adjustment for the opportunity cost of one-time labor turnover, it is defined to recognize no difference between FTF and PTF. This is a simplification which has little effect on the final result. The interest rate on funds the college has invested in short-run funds or securities provides an interest figure for the model.

Wage Rate. The wage rate is the payment directly to the instructors on the basis of hours worked, classes taught, or some other basis. In the case of FTF $\left(w_{a}\right)$, payment is made on the basis of a specific number of duties including advising, counseling, and other faculty responsibilities. The wage is usually recorded for an academic year.

PTF receive a wage $\left(w_{b}\right)$ based on a specific class or classes. No special sections or workshops are included in the sample. Therefore, a11 PTF payments represent flat fees for each class taught.

Supplementary Compensation Expenditures. Supplementary compensation expenditures or fringe benefits are payments exclusive of the wage payment made to FTF $\left(F_{a}\right)$ and PTF $\left(F_{b}\right)$. Most of these are quasi-fixed in the sense that they vary with the number of workers rather than the number of hours worked.

Fringe costs include the following categories:

(A) Payments to government funds:

(1) Social Security Compensation (OASDHI)

(2) Unemployment Compensation (under the assumption of a quit rate equal to zero) 
(3) Workman's Compensation

(4) Public Employees Retirement System (PERS)

(5) Other

(B) Payments directly to employees

(1) Sick Leave

(2) Bonus Payments

(3) Other Payments

(C) Payments for Health and Welfare, exclusive of government funds

(1) Health Insurance

(2) Dental Insurance

(3) Life Insurance

(4) Private Retirement Plan Payments (other than PERS)

(5) Other payments

(D) Payments to Internal Funds

(1) Vacation Funds

(2) Savings Funds

(3) Sabbatical Leave Funds

(4) Other Payments

Turnover Costs. This is the cost of hiring, training, and terminating of both full and part-time faculty. Turnover costs are gathered by questionnaire and include the following:

(A) Cost of hiring the part and full-time instructor to the department, including recruitment costs as measured by the average number of labor hours by administrators and faculty acting in administrative roles while recruiting, screening, and interviewing to fill the "typical" vacancy. 
(B) Training and orientation costs per term, including average number of hours spent by administrators or faculty on activities relating to orientation and training for the average part-time and full-time faculty. Costs include any instructor time or materials used in the training process.

(C) Termination costs, including cost of administrative time involved in the termination process and any direct payments to the instructor such as severance pay.

(D) Additional turnover costs, including the increase in the cost of unemployment compensation as a result of terminations.

Since it was discussed earlier, it is only noted here that the cost of "recalling" a PTF member is different from hiring a faculty who has never worked for the college before. (See pp. 34-35). Data were collected to recognize these differences.

\section{Productivity}

In order to operationalize productivity, the salary schedule of the full-time faculty is applied to both the full-time and the part-time faculty. The colleges in this sample pay their part-time faculty on the basis of number of classes taught or for the number of hours of classwork rather than using education and experience as a basis for pay as is the case with the FTF. The college acts as if the part-time faculty are a relatively homogeneous group and that the cost involved in offering different wages to those with various background characteristics is not worth the additional benefit. In other words, variations in wage rates are not necessary to bring forth additional quantity supplied because the college faces a perfectly elastic supply. 
The assumption is made in this dissertation that the full-time salary schedule of the college accurately measures productivity differences of FTF and can also be used to measure the productivity of the PTF. The salary schedule is based on several measurable items: education, experience, and professional development. Education level is rewarded in the form of a higher wage to those who have acquired greater education. Experience is rewarded in two separate forms: training received outside the college is rewarded by a higher wage up to a limited number of years. Beyond that, the college does not reward individuals for additional external on-the-job training. The college rewards training in a second way, however, by paying those who engage in training at the college. It is apparently assumed by the community college administration that those who stay with the college learn through the experience of internal on-the-job training. The college rewards these individuals by increases in wage levels that are associated with years worked at the college. The reward system is consistent with the findings of research on human capital (see pp. 28-29).

It follows that the term productivity $(P)$ is derived in the following way: the FTF salary is examined to determine the percentage increase in salary attributable to each of the activities for which the college rewards FTF. These values are then applied to the PTF to determine this group's productivity.

The productivity values can be derived in two ways: first, by using a regression analysis to determine what values the college places on the various characteristics of the FTF. The FTF salary is used as the dependent variable with education and experience as the independent 
variables. The assumption is made that the FTF salary schedule accurately reflects the productivity of salary.*

Using data collected on the educational and experience background of PTF, the values collected on the FTF characteristics are applied to the PTF. The resulting estimates provide productivity values for each PTF; they can be used to derive an average for the PTF and then compared to the FTF to produce a relative difference between the two groups as explained below.

A second method involves using the salary schedule for FTF to estimate the value of the background characteristics of the PTF. This method involves two steps: first, the values the college places on each characteristic are determined from the FTF salary schedule. Second, the characteristics of the PTF are determined independently. Each PTF is evaluated according to background characteristics to determine the appropriate salary level the faculty would earn according to this schedule. An average hypothetical salary can thus be determined for each PTF for each college.

Using either of the above methods, the average salary of the FTF is valued as an index 1.0 while the average hypothetical PTF salary is valued according to the independent estimates. These estimates of PTF salary are independent in the sense that the values are different from the actual salary of PTF if they worked full-time at the current FTF wage level. These hypothetical figures of PTF salary represent estimates of productivity of PTF in relation to FTF.

*Discussed earlier on p. 29. 
CHAPTER III

\section{DATA GATHERING}

Data were gathered from various sources at the three community colleges: from the personnel offices, college records, and the faculty. Responses to two questionnaires provided most of the information. One, mailed directly to both full-time faculty (FTF) and part-time faculty (PTF) at each community college, asked questions regarding the educational and experience backgrounds and the current employment situation of each faculty member. A second questionnaire went to the personnel offices and was mainly concerned with gathering information on turnover costs. (See Appendix A for the questionnaires.)

Additional data were gathered from records available at each college and from state government records. This third source of data was deemed necessary when it was determined that certain data collected by questionnaire were inaccurate or inadequate, or could not be collected by questionnaire.

The faculty questionnaire provided demographic information and estimates by faculty of the allocation of their working time to various activities. While the questionnaire was presented to each college in the same general form, minor changes, such as changing the school name on both the questionnaire and the cover letter to reflect the individual college, were necessary.

Before the actual data gathering could begin, it was necessary to generate a list of faculty to serve as the study population. The study population was generated by a three step process: first, the type 
of class to be included in the study was established; second, the faculty who teach these classes were identified; and third, faculty were further identified as full-time or part-time depending on the number of classes they taught as well as other criteria as defined below.

Since the faculty were included or excluded on the basis of the type of classes they taught, it was necessary to generate a list of "included" classes. These classes are usually considered traditional subjects and generally require a college education as a prerequisite for teaching them. There are a number of reasons why traditional lower division college classes (LDC) were chosen for this study while other divisions of the college.were excluded. First, the population was limited to faculty who teach LDC classes because these faculty have similar qualifications for their positions, usually a master's degree. Second, the IDC classes chosen for this study are included in most commity college curricula and are a part of the curriculum of each college in this study. Other types of classes (and therefore faculty) were excluded because even though they may be college transfer classes, they are not a common part of all college curricula. Third, LDC classes have the same general format and content at all colleges, in contrast to vocational areas and community education classes which are diverse in subject area and content as we.11 as organization and presentation.

All classes included in this study were divided into four groups. While the classification system may differ from that used by the individual college, it generally followed traditional lines. The four subject areas were: business administration, social science, humanities, and science. The business administration group included such classes as 
accounting, business math and law, marketing, advertising, and finance classes. Most secretarial classes were excluded with the exception of those classes in which the instructor also taught other business classes. The social science group included sociology, psychology, economics, geography, political science, and anthropology. Music, art, philosophy, speech, English, literature, drama, foreign language, and history were included in the humanities group. The science group included math, biology, botany, chemistry, geology, and physics.

As the above list illustrates, a large number of classes and therefore faculty were excluded from the study. Some college transfer classes, including the entire group of health and physical education classes, were excluded because of the differences in the meeting hours of these classes. Since they are not offered at all colleges, special area classes and workshops such as government services, criminal justice, most law classes, health services classes, home economics, real estate, and journalism were excluded.

Vocational classes and therefore faculty were excluded because of differences between the faculty and those who teach LDC classes in regard to educational background and class presentation and organization. Vocational classes included automotive, machine shop, and engine repair classes. Technical classes also were excluded: architecture, drafting, engineering, electronics, food sciences, and all other technical classes. For the same reasons, other class offerings such as basic skills classes and community education classes were not included.

An estimate of the proportion of faculty eliminated can be made by approximating the number of students enrolled in each area. Assuming 
that the student-faculty ratio is approximately constant throughout the college, the number of faculty in each area can be estimated from published figures of full-time equivalent (FTE) student enrollment. All three colleges offer a combination of LDC classes, community education classes, and vocational-technical classes; because of the community-based administration, however, each college offers a different "mix" of these three areas. College B has the greatest emphasis on LDC classes with 41 percent of the FTE enrollment in this area. Colleges $A$ and $C$ each have approximately one-third of their students in this area. (See Table I.) Given these proportions, at least two-thirds to two-fifths of the college faculty is excluded by the study design in each case, assuming that the LDC classes excluded form a relatively small part of the total LDC classes.

TABLE I

TOTAL AND PERCENT LDC AND FTE ENROLLMENT

Total Number

College

A

B

C

$$
\text { FTE Students }
$$

$$
13,092
$$$$
6,058
$$$$
3,310
$$

Total Number LDC FTE Students

$$
4,100
$$$$
2,400
$$$$
1,100
$$

Percent LDC Students $33 \%$

34

Source: Oregon Department of Education, 1979.

The study population was derived from lists of those teaching IDC classes. No attempt was made to exclude faculty who may also teach an occasional non-college transfer or special interest class. Since FTF and PTF teach at each of the three colleges, six groups of faculty were represented. From these groups, a random sample was generated to which the faculty questionnaire was sent. After a second mailing, the response 
was 45 to 50 percent of the sample. Table II shows the size of the population, the number in each sample, and the number and percent of response for each group.

TABLE II

POPULATION, SAMPLE, AND RESPONSE BY COLLEGE

$\begin{array}{llll}\text { Total } & \text { Sample } & \text { Number } & \text { Percent } \\ \text { Population } & \text { Size } & \text { Responding } & \text { Responding }\end{array}$

$\begin{array}{ccccc}\begin{array}{c}\text { College A } \\ \text { FTF }\end{array} & 134 & 49 & 23 & 47 \% \\ \text { PTF } & 229 & 97 & 47 & 48 \\ \text { College B } & & & & \\ \text { FTF } & 77 & 50 & 25 & 50 \\ \text { PTF } & 86 & 98 & 44 & 45 \\ \text { College C } & & & & \\ \text { FTF } & 50 & 40 & 18 & 45 \\ \text { PTF } & 53 & 30 & 14 & 47\end{array}$

Source: derived from faculty questionnaire and college records.

The faculty questionnaire was designed to gather information on faculty which could not be obtained from other sources. The questionnaire sought three types of information: first, demographic information such as age and sex, as well as information on whether the individual faculty member was ful1-time or part-time and the department to which the individual belonged, was gathered. Data on the distribution of faculty by department were discarded when it was determined the sample size was too small; little was lost, however, because the dissertation's focus is on college-wide rather than department policy.

The second group of data gathered by means of the faculty questionnaire was current work information. The data, focused on the length of employment at the college, salary earned, and hours worked by the faculty in each activity in an "average" week during the term. 
It was the task of the individual faculty member to determine what average meant, as some weeks take more time than others due to, for example, lecture preparation or examination schedules. Because of the way the question was originally asked, salary information gathered by the faculty questionnaire was determined to be too ambiguous for purposes of this study. Some faculty responded to the question by quoting takehome pay, some listed their gross salary, and still others quoted a figure which included summer pay or payment for additional work. Therefore, information on wages was gathered from payroll records. Information on length of employment was collected by requesting the number of terms which the faculty had taught at the college, excluding summer terms. The figure on years taught was not as accurate a figure as terms taught, especially in the case of part-time faculty who often are not employed a full year.

The third group of data gathered from the faculty questionnaire was background information. Faculty were asked to respond to questions about the educational and job experience they had had prior to college teaching and were asked if they currently hold another job. This information is valuable for two reasons: in contrast to many other studies which estimate the background of workers by use of their age, years of schooling, and number of children if they are female, this questionnaire provides actual information on work experience. Second, it identifies part-time experience, which has only rarely been studied. The second questionnaire was specifically designed to identify and estimate the costs involved in hiring, training, and terminating faculty. This questionnaire was delivered to the personnel offices of 
the three colleges. In each case, the director of the office or another person directly involved in faculty turnover decisions filled out the questionnaire. A detailed discussion with the three respondents provided each with an explanation and clarification of the purpose of the study and supplied the background information so that each could fill out the questionnaire in conformance with the other colleges. Each individual used dollar outlay information from their files and made estimates of other costs based on time involved in the activity, materials, and other expenses where applicable.

The estimates in this study do not represent all costs associated with the operation of a personnel office (the cost of office space, for example); however, the estimates do reflect the average cost of turnover of faculty using administrative and staff time and materials.

While the two questionnaires supplied the bulk of the information on costs and productivity measurement, additional data were collected from college publications and other printed records. Each college keeps records differently, so it was necessary to use somewhat different sources of data on the faculty of each school; however, these deviations were minor and rare.

One major piece of data gathered from college records was a count of the total number of faculty in each group during an average school term for the 1977-78 academic year. To calculate these figures, it was necessary to tally the number of faculty who teach each school term for a year. These figures then yielded an average number of instructors per term for the 1977-78 school year. The source of the data varied among the schools: college A publishes 1ists of faculty employed each quarter, 
while college B had lists of faculty from personnel office records. College C had computer printouts of class records.

Full-time faculty are defined as those instructors who teach at least two terms on a full-time basis. This includes both permanent instructors and temporary faculty who hold a contract to teach a fulltime schedule. Full-time faculty "on leave" are excluded from this count.

The number of part-time faculty is a count of those who teach on a part-time basis, usually identifled by association with a particular class or classes. Part-time faculty may teach more than one class, but their specific duty is only teaching and its associated responsibilities. The number of PTF per term was derived in the same way the full-time figure was calculated, using an average over the 1977-78 academic year.

While the number of faculty was a relatively straightforward piece of datum, the turnover of faculty was more difficult to retrieve. Calculation of turnover began with a modification of the count of the number of faculty; however, three additional figures were needed: the base, the new hires, and the quits. The base was comprised of those faculty who stayed with the college in any role for the three years, 1977-78, 1976-77, and 1975-76. In other words, if an individual name appeared on the faculty 11st all three of the above years, it was included in the base.

The number of faculty who quit was used to establish the base. In the case of a full-time faculty member, a quit can be defined quite clear1y. A formal hiring and termination process takes place even in the case of a full-time instructor who is temporary (for example, an instruc- 
tor who has a one-year appointment). Very few quits or new hires took place in this sample among full-time instructors. An individual who quit as an instructor but continued to be associated with the college in some other function, as in the case of a full-time faculty member who accepts an administrative position, was not considered a quit by the definition used in this study.

In the case of PTF, a quit was defined over a period of three years. If the individual's name appeared at any one term in this time period, and did not reappear, the individual was considered a quit, regardless of why the person terminated the employment relationship. New hires were considered as those appointed to the faculty on a permanent or temporary position. Those who transferred from administrative positions within the college to faculty assignments were not considered new hires for purposes of this research. This differs from the earlier definition of the number of faculty; the rationale is that these transfers are not true turnovers. Administrators who hold faculty positions for at least two years were included in the base; those who held a position only one year were excluded. New hires included those employed by the college on a one-year appointment or other temporary basis.

Once the base was established and new hires and quits were counted, the turnover rate ( $T$ ) could be calculated by the following simple formula: $T=\frac{B(N-g)}{h}$

It states that turnover is a ratio of the base (B) which is the number of faculty (N) adjusted by those who quit (q), all divided by the new hires (h). All figures were from a three-year period in order to minimize the 
effect of any one year's abnormality.

Data on supplementary compensation expenditures were collected by means of in-house studies which each college gathers on the total cost of fringe benefits disbursed to faculty. The in-house studies record the type and cost of each benefit and then calculate its percent of the wage.

The population upon which the in-house studies are performed differs from those of this study by including all full-time faculty and all part-time faculty within each college. The population in this dissertation is a subset of the total college faculty; however, there is no reason to believe that the fringe benefits of the total faculty differ significantly from those chosen from this study. Therefore, the inhouse studies of fringe benefits were used.

All three in-house studies estimate the cost of fringe benefits based on the cost of each individual benefit item. The employer contributions to Social Security (FICA) and the Public Employees Retirement System Pension Fund (PERS) are the largest and are recorded as a percentage of the average wage. Other contributions are to the State Accident Insurance Fund (SAIF) and health and dental insurance and other payments such as life and disability insurance. Health, dental, and other payments are usually a fixed amount regardless of wage. Fringe benefits of full-time employees include all of the above, but part-time employees receive only Soclal Security, SAIF, and in some cases, the Public Employees Retirement System. As a general rule, very few parttime employees belong to RERS, and thus employee contributions to this fund for part-time employees are so small as to be insignificant. 
One final piece of information was determined necessary: an appropriate interest rate. For purposes of this dissertation an interest rate is necessary in order to adjust for the opportunity cost to the college of having funds tied up in one investment, specifically the investment in faculty, rather than in another.

An attempt was made to find an interest rate for each college which was comparable in source among the colleges. However, each college loans funds to a number of different organizations and institutions for various purposes. One institution was a common depository for all colleges, however, and that was the State Investment Pool.

TABLE III

STATE INVESTMENT POOL INTEREST RATES

FOR VARIOUS MONTHS, 1977-78

$\underline{\text { Year }}$

1977

1978
Month

September

October

November

December

January

February

March

April

May

June
Interest Rate

6.17

6.34

6.65

6.70

6.88

7.30

6.99

7.09

7.11

7.30

Source: Oregon State Treasury Department, 1977-78. 
The state provides a short-term investment service to local governmental units and school districts, which is available to each college. The purpose is to pool funds of small governmental units and, theoretically, to provide them with access to more attractive interest rates. Use of the interest rate from the account has two advantages from the point of view of this dissertation. First, the Pool invests some funds from all of the colleges in the sample, so it meets the criterion of alternate investment funds. Second, it records a specific identifiable interest rate. These criteria are lacking from other sources.

The Pool records interest rates for a monthly period. Since the market and size of the Pool did not change substantially during the time period from September 1977 through June 1978, a simple average was calculated from the percent given each month, rendering 6.85 percent. (See Table III.)

This chapter has provided information on the sampling and data gathering procedures. The data gathered by these procedures provide the empirical base for the dissertation. 
CHAPTER IV

DEMOGRAPHIC CHARACTERISTICS

This chapter and the following one identify and discuss not only what differences exist between full-time faculty (FTF) and part-time faculty (PTF) but also why such a division is evident and conspicuous. The discussion of differences is divided into two areas. In this chapter, differences related to the characteristics of the individuals belonging to each of the two groups are discussed. These include age, sex, education, and background experience as well as hours devoted to teaching and non-teaching.

The second group of differences between the two types of faculty includes the cost to the college and the value of the work performed for the college. Both types of differences are the result of the position the individual holds at the college, whether full-time or part-time. Costs and productivity are discussed in Chapter V.

The labor market for community college instructors is best described as "segmented." The concept of a "dual labor market" was originally described by Doeringer and Piore (1971) as two markets for labor, one primary and the other secondary. These markets differ from one another in two ways: first, the jobs in the two sectors are different from one other, and second, the individuals who hold the jobs in the primary sector are different from those in the secondary sector. As used here, the term describes two labor markets, one full-time and the other part-time, which exist at the same institution and provide similar services. The differences between the labor markets are similar to the 
division between the primary and secondary labor markets. The primary labor market of Doeringer and Piore is made up of a series of internal labor markets in which formal and informal rules and procedures govern many aspects of the job. The FTF labor market is similar to this market in that wages and fringe benefits are high, employment is stable, and workers enjoy advancement, equity, and good working conditions.

When compared to the labor market for FTF, that for PTF has relatively low wages and fringe benefits, few chances for advancement, and employment instability. Within the secondary labor market, Doeringer and Piore hypothesized that internal labor markets do not exist or are weak, and that informal rules and procedures can lead to arbitrary decisions. The concept was originally applied to the relatively uneducated workers in jobs which are usually considered undesirable by those researching the problem (if not the workers). While teaching at a community college is of ten considered a relatively high status occupation with good working conditions, excellent pay, desirable tasks, and highly educated workers, application to the full-time and part-time labor market does not strain the theory for two reasons: first, the appearance of high status for the part-time faculty labor market is not a picture. of reality and second, the term as applied here describes a specific firm in which two types of labor exist and yet provide the same service. Major differences between the two faculty groups exist, and these will be discussed in this chapter.

NUMBER AND TIME ALLOCATION

Following a nationwide trend, PTF at the three community colleges 
outnumber FTF. The percent and total number of faculty in each group is listed in Table IV. As can be seen, the PTF comprise from 60 percent to 80 percent of the total faculty. The study population, faculty who teach lower division college classes, is only a portion of the faculty at the college, but representation from each group is similar to that of the total faculty. The PTF outnumber the FTF and comprise from 50 percent to 60 percent of the total faculty. (See Table V.)

TABLE IV

TOTAL FACULTY EMPLOYED BY COLLEGES BY NUMBER

AND PERCENT, OCTOBER 1978

\begin{tabular}{cccccccc} 
College & $\begin{array}{c}\text { Fu11-Time Faculty } \\
\text { Number }\end{array}$ & $\begin{array}{c}\text { Percent } \\
\text { A }\end{array}$ & 332 & $20.3 \%$ & $\begin{array}{c}\text { Part-Time } \\
\text { Number }\end{array}$ & $\begin{array}{c}\text { Faculty } \\
\text { Percent }\end{array}$ & \multicolumn{2}{c}{$\begin{array}{c}\text { Total } \\
\text { Number }\end{array}$} & $\begin{array}{c}\text { Faculty } \\
\text { Percent }\end{array}$ \\
B & 162 & 34.7 & 1302 & $79.7 \%$ & 1532 & $100 \%$ \\
C & 130 & 38.9 & 305 & 65.3 & 467 & 100 \\
& 130 & 204 & 61.1 & 334 & 100
\end{tabular}

Source: American Association of Junior Colleges, 1979.

Although the college employs more PTF than FTF, the FTF have exposure to a greater number of students. Of the LDC classes included in this study, the FTF taught an average of 4.3 classes at College A, 4.4 at College B, and 4.2 at College C. The PTF taught fewer classes, 1.7, 1.4 , and 1.7 respectively. Using these figures the in-class student contact hours can be calculated. In all cases, the PTF teach fewer total classes than the FTF: at the three colleges the PTF teach 40 percent, 27 percent, and 30 percent of the total classes while the FTF teach the remainder. (See Table XLIX in Appendix C.) 
TABLE V

NUMBER AND PERCENT OF FACULTY IN STUDY POPULATION

\begin{tabular}{cccccccc} 
College & $\begin{array}{c}\text { Ful1-Time } \\
\text { Number }\end{array}$ & $\begin{array}{c}\text { Faculty } \\
\text { Percent }\end{array}$ & $\begin{array}{c}\text { Part-Time } \\
\text { Number }\end{array}$ & $\begin{array}{c}\text { Faculty } \\
\text { Percent }\end{array}$ & \multicolumn{2}{c}{$\begin{array}{c}\text { Total Faculty } \\
\text { Number }\end{array}$} & $\begin{array}{c}\text { Percent } \\
\text { A }\end{array}$ \\
& 134 & $36.9 \%$ & 229 & $63.1 \%$ & 363 & $100 \%$ \\
B & 77 & 47.2 & 86 & 52.8 & 163 & 100 \\
C & 50 & 48.5 & 53 & 51.5 & 103 & 100
\end{tabular}

Source: data gathered from college records.

A better representation of the relative work load of the two faculty groups is the total number of hours of work performed by each group, a figure that can be derived from Table VI. The total number of FTF and PTF (columns one and two) when multiplied by its respective average weekly hours of work (columns three and four) gives an estimate of the total hours of work performed each week. The total hours of work performed per term by each group (columns five and six) are calculated from the estimates of weekly work by assuming a standard 11-week session.

1 Estimates of the relative work load of FTF and PTF are in the last two columns of Table VI. Although it was shown earlier that the PTF outnumber the FTF, the estimates in Table VI illustrate that the FTF are responsible for a relatively greater work load at each college. The PTF perform from one-fifth to nearly one-third of the LDC faculty work while the rest is performed by the FTF.

These estimates illustrate that while the PTF perform relatively less work than do the FTF, the contribution of the PTF is substantial. An assessment of the total work load currently carried by PTF can be 
TABLE VI

WEEKLY AND TOTAL HOURS OF WORK PER TERM BY FTF AND PTF

\begin{tabular}{|c|c|c|c|c|c|c|c|c|}
\hline \multirow[b]{2}{*}{ College } & \multirow{2}{*}{$\begin{array}{l}\text { Numbe } \\
\text { FTF } \\
\end{array}$} & culty & \multicolumn{2}{|c|}{$\begin{array}{l}\text { Average Weekly } \\
\text { Hours of Work }\end{array}$} & \multicolumn{2}{|c|}{$\begin{array}{l}\text { Total Hours of } \\
\text { Work per Term* }\end{array}$} & \multicolumn{2}{|c|}{$\begin{array}{l}\text { Percent Total } \\
\text { Hours of Work }\end{array}$} \\
\hline & & PTF & FTF & PTF & FTF & PTF & FTF & PTF \\
\hline $\mathbf{A}$ & 134 & 229 & 42 & 11 & 61,908 & 27,709 & $69 \%$ & $31 \%$ \\
\hline B & 77 & 86 & 44 & 11 & 37,268 & 10,406 & 78 & 22 \\
\hline C & 50 & 53 & 41 & 16 & 22,550 & 9,327 & 71 & 29 \\
\hline
\end{tabular}

*This assumes an eleven-week term.

Source: derived from faculty questionnaire. See Appendix A. 
made by estimating the impact of removing all PTF positions. Assuming the college maintains the total hours of work performed (although not necessarily the total output produced), the cost of replacing its entire PTF with FTF can be made with information in Table VI. If college $A$ is used as an example, it would replace the 27,709 hours per term of work now performed by the PTF who work an average of eleven hours per week. Given that FTF work an average of 42 hours each week, College A would require 60 FTF replacements for the currently employed 229 PTF, or approximately 45 percent additional FTF. Estimates of replacement faculty are listed in Table VII as number (column three) and percent of faculty (column four).

TABLE VII

FULL-TIME FACULTY REQUIRED TO REPLACE

PART-TIME FACULTY

\begin{tabular}{|c|c|c|c|c|}
\hline College & $\begin{array}{l}\text { Current } \\
\text { FTF }\end{array}$ & $\begin{array}{r}\text { Number } \\
\text { PTF }\end{array}$ & $\begin{array}{l}\text { Number of FTF } \\
\text { to Replace PTF }\end{array}$ & $\begin{array}{l}\text { Additional FTF as } \\
\text { Percent of Current FTF }\end{array}$ \\
\hline A & 134 & 229 & 60 & $45 \%$ \\
\hline B & 77 & 86 & 22 & 29 \\
\hline C & 50 & 53 & 21 & 42 \\
\hline
\end{tabular}

Source: calculated with data gathered from faculty questionnaire.

This table is calculated with the assumption that the number of hours PTF are employed is replaced with FTF. The actual number of productive hours would increase if FTF replaced PTF because FTF are more productive than PTF.

The basic difference between the two types of faculty is that one group is full-time while the other is part-time. Farlier analysis in- 
dicated that the FTF spend more hours in the classroom and more total hours working for the college than do the PTF, not only per person but for each group as a whole.

The differences are more complex than merely the number of hours spent working for the college. The FTF allocate their working time for the college in a way which is different from the PTF. While teaching and its related activities are the primary function of all full-time instructors at community colleges, they perform additional functions, including developing course work and curriculum, and organizing and attending meetings.* (See Appendix B .)

The three community colleges pay for and expect FTF to provide the additional functions noted above. In contrast, PTF have only a limited responsibility. While there are some differences in the execution of the policy surrounding PTF, in general they are paid to teach and to perform its related functions, and they are not paid for additiona1 activities.

Teaching-related activities for FTF include lecturing or other in-class presentations, preparation and follow-up of in-class activities, and advising and counseling students.' ${ }^{\prime}$ At all three colleges, FTF spend an average of 85 percent of their time in teaching-related activities, while the PTF average 86 to 96 percent of their time in these activities. (See Table VIII.) The non-teaching related activities are those which, to a large extent, provide the continuity and stability for the college: course development, organization of and participation at meetings, and

*Mean hours of teaching-related activities are the first four columns of Table XLVI, Appendix C. 
other activities. FTF spend approximately 15 percent of their time in these activities.

TABLE VIII

MEAN TIME IN TEACHING AND NON-TEACHING-RELATED ACTIVITIES

\begin{tabular}{lcl} 
Time in Teaching- & Time in Teaching \\
Related Activities & Related Activities & $\begin{array}{l}\text { Time Non-Teaching Re- } \\
\text { lated Activities }\end{array}$ \\
Hours Percent & Hours Percent & Hours* Percent \\
\hline
\end{tabular}

College A

$\begin{array}{ccccccc}\text { FTF } & 35.6 & 84.4 \% & 6.6 & 15.6 \% & 42.3 & 100.0 \% \\ \text { PTF } & 10.6 & 94.6 & .6 & 5.3 & 11.2 & 100.0\end{array}$

College B

$\begin{array}{lrrrrrr}\text { FTF } & 37.7 & 85.7 & 6.3 & 14.3 & 44.1 & 100.0 \\ \text { PTF } & 10.9 & 94.0 & .7 & 6.0 & 11.1 & 100.0\end{array}$

College C

$\begin{array}{lllllll}\text { FTF } & 33.6 & 84.0 & 6.4 & 16.0 & 40.6 & 100.0\end{array}$

$\begin{array}{lllllll}\text { PIF } & 13.7 & 85.6 & 2.3 & 14.4 & 15.9 & 100.0\end{array}$

Source: derived from faculty questionnaire.

* May not add due to rounding.

Because PTF receive no payment for non-teaching activities, it would be expected that they would not engage in these functions. In fact, of all PTF time, less than 6 percent at Colleges A and $B$ and nearly 15 percent at college $C$ is spent at non-teaching activities for which these faculty receive no monetary reimbursement. PTF probably engage in non-paid activities for at least two reasons. First, non-teaching college-related activities may make PTF feel they are more completely fulfilling their role as educators. In this sense, PTF recelve non- 
monetary rewards for those activities for which there is no dollar payment. Second, students often do not make the distinction between PTF and FTF and thus students request and PTF render services for which the college does not pay PTF. Abel (1977) found that the PTF in her sample were more likely to engage in non-paid college-related activities if they held their classes during the day, or at an on-campus location, or had access to office space. The dissertation questionnaire did not request information on class time, location, or office space, and includes PTF with various teaching arrangements, but the characteristics of the colleges differ from one another. The sample from College $C$, for example, teaches primarily on-campus, and this is reflected in the high percentage of faculty time in non-teaching activities.

The above discussion of the time allocation differences between FTF and PTF showed that the FTF generally spend relatively less time teaching and on related activities than do PTF. In total hours, of course, the average FTF member spends more time in all activities than does the PTF member. At all of the colleges, the total number of hours worked by FTF is considerably greater than that worked by PTF as can be seen from Table VII (column five). For example, the PTF at College B spend an average of 11 hours per week working, compared to 44 by FTF. If total time spent by PTF is calculated as a percentage of FTF time, it can be seen that the PTF work 25 percent of FTF hours at College B. At Colleges $A$ and $C$, the pattern is the same: the PTF work 27 percent and 39 percent of the time worked by FTF. 


\section{EMPLOYMENT STABILITY AND INSTABILITY}

Numbers alone are not enough to show that two labor markets exist; other characteristics are necessary to show that the FTF and PTF division is more than a convenient classification. Doeringer and Piore (1971) and Osterman (1975) suggested that one of the more important differences between the primary labor market and secondary labor market is the employment stability of the former and the instability of the latter. When the average length of continuous employment of FTF and PTF at the college is compared, the FTF are seen to have been employed much longer: 9 years at College A for FTF and 3 years for PTF. At Colleges $B$ and $C$ the FTF have been employed approximately 7 years, compared to 3 years for the PTF. (See Table IX.)

TABLE IX

AVERAGE LENGTH OF EMPLOYMENT IN TERMS, STANDARD DEVIATION, AND COEFFICIENT OF VARIATION

\begin{tabular}{lll} 
Mean Length of & $\begin{array}{l}\text { Standard } \\
\text { Employment in Terms }\end{array}$ & $\begin{array}{l}\text { Coefficient of } \\
\text { Variation }\end{array}$ \\
\hline
\end{tabular}

College A

FTF

28.1

8.7

$31.0 \%$

PTF

10.3

10.0

96.7

College B

$\begin{array}{llll}\text { FTF } & 20.2 & 8.2 & 40.6 \\ \text { PTF } & 10.7 & 9.2 & 86.0\end{array}$

College C

$\begin{array}{rrrr}\text { FTF } & 19.8 & 10.1 & 51.0 \\ \text { PTF } & 7.9 & 10.1 & 127.8\end{array}$

Source: calculations from data gathered with faculty questionnaire. 
Further examination of Table IX reveals another pattern of variation between the two groups of FTF and PTF. The standard deviation of the length of time employed at the college is similar: between 8 and 10 quarters for both groups at all three colleges. This suggests that the PTF have a greater variation in their employment tenure than do the FTF because the average length of quarters is so much longer for FTF than for PTF. An examination of the coefficient of variation shows that the time variation for the FTF is much less than that among the PTF. For the PTF, the coefficient of variation is approximately 90 percent to over 100 percent, suggesting a large variation of length of employment within this group.

A further measure of employment stability of faculty is the cumulative percent hired of faculty currently employed, as shown in Table X. The FTF have been employed by the college longer than the PTF; depending on the college, between 39 percent and 70 percent of the FTF had been hired by the 1970-71 academic year while significantly fewer, between 7 percent and 19 percent of the PTF, were hired by that same year. By the 1976-76 academic year, at least 83 percent of the FTF had been hired while there was no case in which even 50 percent of the PTF was hired.

\section{EDUCATION AND EXPERIENCE}

The model assumes two perfectly elastic supplies of labor, one schedule for FTF and another for PTF. Each college has minimum educational and experience background requirements for all faculty whether full-time or part-time. The standards can be considered flexible; the 


\section{TABLE X}

CUMULATIVE PERCENT HIRED OF FACULTY CURRENTLY EMPLOYED

\begin{tabular}{lcccccc} 
& \multicolumn{2}{c}{ College A } & \multicolumn{2}{c}{ College B } & \multicolumn{2}{c}{ College C } \\
Year & \multicolumn{1}{c}{ FTF } & PTF & FTF & PTF & \multicolumn{1}{c}{ FTF } & PTF \\
$1964-65$ & $4.3 \%$ & $2.1 \%$ & & & & \\
$1965-66$ & 13.0 & 2.1 & & & & $7.1 \%$ \\
$1966-67$ & 30.4 & 4.3 & $3.9 \%$ & & $11.1 \%$ & 7.1 \\
$1967-68$ & 39.1 & 4.3 & 11.7 & $2.3 \%$ & 27.8 & 7.1 \\
$1968-69$ & 47.8 & 8.5 & 11.7 & 7.0 & 33.3 & 7.1 \\
$1969-70$ & 69.6 & 12.8 & 15.6 & 14.0 & 38.9 & 7.1 \\
$1970-71$ & 69.6 & 14.9 & 40.0 & 18.6 & 75.6 & 7.1 \\
$1971-72$ & 78.3 & 14.9 & 60.0 & 20.9 & 75.9 \\
$1972-73$ & 91.3 & 21.3 & 75.3 & 23.3 & 72.2 & 7.1 \\
$1973-74$ & 91.3 & 23.4 & 84.4 & 30.2 & 77.8 & 7.1 \\
$1974-75$ & 100.0 & 36.2 & 84.4 & 35.0 & 77.8 & 28.6 \\
$1975-76$ & & 48.9 & 92.2 & 48.8 & 83.3 & 35.7 \\
$1976-77$ & & 74.5 & 92.2 & 81.4 & 83.3 & 42.9 \\
$1977-78$ & & 100.0 & 100.0 & 100.0 & 100.0 & 100.0
\end{tabular}

Source: derived from data gathered with faculty questionnaire. 
college is often willing to substitute education for experience or experience for education if necessary. The wage differential between the two faculty groups, full-time and part-time, is dependent on the productivity differential between the groups as perceived by each college. If the colleges perceive a small difference in productivity between FTF and PTF, then the wages of faculty may not differ substantially. If a large difference in the average productivity is perceived, then the college may find that although there are many PTF applicants, they will be less productive than the FTF applicant group.

Based only on the offering wage, that is, the wage per hour of work performed by the average current ful1-time and part-time instructor of the college, some conclusions can be made regarding the applicants of each labor market. The conclusions are also based on the assumption that applicants are aware of the time involved in teaching a class or classes and these applicants would allocate their time approximately the same as those currently teaching. The before-tax wage per hour, excluding fringe benefits, is shown for the college in Table XI. The per hour full-time wage appears substantially higher than the part-time wage. This wage differential reflects the productivity differential between the faculty groups. 
TABLE XI

WAGE PER HOUR

\begin{tabular}{|c|c|c|c|}
\hline College & Fu11-time Faculty & Part-time Faculty & $\begin{array}{l}\text { Percent PTF Wage } \\
\text { of FTF Wage }\end{array}$ \\
\hline A & $\$ 12.88$ & $\$ 7.36$ & $57.1 \%$ \\
\hline B & 12.47 & 6.12 & 49.1 \\
\hline C & 13.63 & 6.03 & 36.9 \\
\hline
\end{tabular}

Source: derived from faculty questionnaire and college records.

The data indicate that the productivity of the FTF as measured by eductional attainment is different from the PTF. All of the FTF at each of the three colleges hold at least a master's degree; however, there are substantial numbers of PTF who hold less than this advanced degree. At College A, 26 percent of the PTF hold less than a master's degree while at Colleges B and C, 20 percent and 14 percent of the PTF hold less than a master's degree. (See Table XII.) In a study of part-time faculty at a California community college, Lombardi (1975) found a similar pattern of degrees held between full-tlme and part-time faculty teaching in baccalaureate programs. Of the full-time instructors in his study, 95 percent held a master's degree or better while less than 85 percent of the parttime faculty held this advanced degree.

TABLE XII

PERCENT OF FACULTY HOLDING AT LEAST A MASTER'S DEGREE

College

A

B

C
Fu11-time Faculty

$100 \%$

100

100
Part-time Faculty $74 \%$

80

86

Source: derived from faculty questionnaire. 
If wage rates reflect productivity, the productivity differences between the FTF and PTF will be large, as measured by experience levels. The first measure of experience differences between the faculty is the total experience of the faculty at all levels and from all sources of teaching and professional experience. This measurement includes experience both within and outside the community college. The fact that the FTF are employed full-time within the college while the PTF are not does not bias the results toward the FTF because all work experience is included in these figures. For example, the experience of a PTF member who is employed full-time outside the college is included. By including all experience, faculty can be examined and compared at a point in time. Table XIII shows that, as with education, the FTF have a greater amount of full-time job experience. This is consistently the case at all colleges; the FTF have 33 percent to 60 percent more total job experience depending on the college. The opposite is true of part-time job experience; PTF have more total part-time job experience from all sources with the exception of College C. While these figures include part-time teaching at the college, this source accounts for approximately half or slightly less of the total part-time experience of the PTF.

If teaching experience only is examined, it can be seen from Table XIV that FTF have had much more full-time teaching experience than the PTF. This result is expected because the FTF are currently employed on a full-time basis while the PTF may not be. A surprising number of quarters of full-time teaching has been accumulated by the PTF; that is the result of many PTF who are currently employed full-time as 
TABLE XIII

FULL-TIME AND PART-TIME JOB EXPERIENCE FROM ALL SOURCES BY FTF AND PTF

Mean Number of Quarters of Fu11-Time Job Experience from All Sources

\begin{tabular}{cccc}
\cline { 2 - 3 } College & \multicolumn{1}{c}{ FTF } & PTF & Percent PTF of FTF \\
\cline { 2 - 4 } A & 52 & 26 & $50.0 \%$ \\
B & 33 & 13 & 34.4 \\
C & 30 & 20 & 66.7
\end{tabular}

Mean Number of Quarters of Part-Time Job Experience from All Sources

\begin{tabular}{ccc}
\hline FTF & PTF & Percent PTF of FTF \\
\hline 13 & 22 & $167.2 \%$ \\
16 & 33 & 206.3 \\
20 & 16 & 80.0
\end{tabular}

Source: derived from faculty questionnaire.

Note: all data for teaching experience exclude summer term. 
instructors at local high schools.* As expected, the PTF have accumulated more part-time teaching experience than the FTF. PTF are, of course, currently employed part-time. +

While past experience differentiates the two faculty groups, the current job is the major distinction for the purposes of this research. The FTF at all colleges by definition teach full-time while the PTF teach part-time. While this difference is obvious, what is not so obvious is what the faculty do with their non-teaching time. Since the FTF at all three colleges teach full-time, their non-teaching time is limited.

The PTF differ from the FTF in this important way: many of the non-teaching activities in which the PTF engage occupy a major part of the individual's time. In fact, the college teaching which is a major activity of the FTF is often considered an extracurricular activity by the PTF.

While the FTF can be characterized as all teaching full-time and almost never engaging in other activities besides teaching, the PTF can be characterized as teaching part-time and almost always engaging in other activities. The PTF can be divided into two groups: the first is comprised of those who teach only part-time. These individuals often hold at least one other part-time job besides teaching at the college. The second group is the moonlighters, who teach at the college but who are employed full-time elsewhere. Table XV shows the number and percent of each group.

* See later section on moonlighting.

+It is possible for FTF to be employed "part-time," $1 . e$. , to be moonlighting at the college; however; data were not collected on this subject. 


\section{TABLE XIV}

TEACHING EXPERIENCE FROM ALL SOURCES BY FTF AND PTF

\begin{tabular}{cccc} 
& \multicolumn{3}{l}{$\begin{array}{l}\text { Mean Number of Quarters of } \\
\text { Full-Time Teaching Experience }\end{array}$} \\
\cline { 2 - 3 } College & FTF & PTF & Percent PTF of FTF \\
\cline { 2 - 3 } A & 47 & 12 & $25.5 \%$ \\
B & 28 & 6 & 21.4 \\
C & 28 & 12 & 42.8
\end{tabular}

\begin{tabular}{ccc}
$\begin{array}{l}\text { Mean Number of Quarters of } \\
\text { Part-Time Teaching Experience }\end{array}$ \\
\hline FTF & PTF & Percent PTF of FTF \\
\hline 8 & 11 & $137.5 \%$ \\
9 & 25 & 277.8 \\
8 & 13 & 162.5
\end{tabular}

Source: derived from faculty questionnaire.

Note: all data exclude summer term. 
TABLE XV

NUMBER AND PERCENT OF MOONLIGHTERS AND

EXCLUSIVE PART-TIMERS

\begin{tabular}{|c|c|c|c|c|c|c|}
\hline \multirow[b]{2}{*}{ College } & \multicolumn{2}{|c|}{ Moonlighters } & \multicolumn{2}{|c|}{$\begin{array}{l}\text { Exclusive } \\
\text { Part-timers }\end{array}$} & \multirow{2}{*}{$\begin{array}{l}\text { Unknown } \\
\text { Number }\end{array}$} & \multirow[b]{2}{*}{ Percent } \\
\hline & Number & Percent & Number & Percent & & \\
\hline A & 22 & $46.8 \%$ & 19 & $40.4 \%$ & 6 & $12.8 \%$ \\
\hline B & 12 & 27.3 & 26 & 59.1 & 6 & 13.6 \\
\hline C & 4 & 28.6 & 8 & 57.1 & 2 & 14.3 \\
\hline
\end{tabular}

Source: derived from faculty questionnaire.

A division of the PTF into two groups provides additional tools of analysis. When examined in this way, differences which at first appeared small or non-existent are seen as substantial. Age differences appear when the PTF aredivided into two groups. There may be no a priori reason to assume that the PTF are younger than the FTF; however, there are reasons to believe that moonlighters are older than exclusive part-timers. Because the moonlighters are persons currently employed full-time, they are similar to the FTF in their work-life pattern. The exclusive parttimers are probably younger than either the FTF or the moonlighters because they are more of ten just beginning a career or combining a parttime job with school or raising a young family.

Table XVI shows the mean age of the FTF and the total PTF in the first two columns. While the PTF are younger than the FTF in every case, the difference between those who moonlight (column three) and those who are exclusive part-timers (column four) is distinct between the two groups of part-timers. The moonlighters and the FTF are older than the exclusive part-timers in every case. 
TABLE XVI

MEAN AGE OF FACULTY GROUPS

\begin{tabular}{|c|c|c|c|c|}
\hline College & FTF & $\begin{array}{l}\text { Total } \\
\text { PTF }\end{array}$ & Moonlighters & $\begin{array}{l}\text { Exclusive } \\
\text { Part-timers }\end{array}$ \\
\hline A & 45.8 & 39.5 & 42.1 & 35.9 \\
\hline B & 40.2 & 36.8 & 40.7 & 34.4 \\
\hline C & 40.7 & 34.1 & 35.9 & 31.3 \\
\hline
\end{tabular}

Source: derived from faculty questionnaire.

The eomposition by sex of the FTF can be expected to favor males. Generally, males tend to dominate in jobs in higher education. If, for example, the percentage female is compared at the lower grades through high school and into college, it can be seen that there is a higher percentage women in the lower grades but at higher grades and college, the percentage female declines noticeably. In the 1970 Census, 98.1 percent of all instructors in pre-kindergarten and kindergarten were female while in elementary school the composition was 84 percent female. In secondary school there was an equal division of males and females, but in college women comprised only 29 percent of all instructors. (See Table XVII.) 
TABLE XVII

COMPOSITION BY SEX OF INSTRUCTORS AT VARIOUS LEVELS

OF EDUCATION UNITED STATES, 1970

Institution

College and University

Secondary School

Elementary School

Pre-Kindergarten and Kindergarten
Percent Male

$71.4 \%$

50.9

16.1

1.8
Percent Female

$28.6 \%$

49.1

83.9

98.1

Source: United States Bureau of the Census, 1970.

While institutions of higher education employ more males, as the above pattern illustrates, it is not necessarily the case that men will outnumber women among the PTF. Those who hold part-time jobs tend to be female more often than male (Owen 1977); however, the sexual composition of the PTF will not be the same as the FTF; the PTF constitutes those who moonlight as well as those who are exclusively part-time; therefore, the aivision by sex can be expected to mirror the composition of the outside activities of these faculty. PTF who moonlight can be expected to be more heavily male and those who work only part-time more heavily female. Because of their family responsibilities, which continue even after the women's movement of the 1970's, women generally find it impossible to moonlight. For the same reasons, a full-time job would of ten require too many total hours of work, so a woman finds it easier to hold one or two part-time jobs in combination with family responsibilities. The pattern of male-female among the PTF will, therefore directly mirror the composition of the division of faculty into moonlighters and exclusive part-timers. 
The data on composition by sex show that the FTF and PTF are approximately one-third to nearly one-half female. At Colleges $\mathrm{A}$ and $\mathrm{C}$, there is a higher percentage of females among the FTF than among its PTF. There does not appear to be a clear pattern, however, until the PTF are divided into moonlighters and exclusively part-timers. The data show that women apparently find it difficult to moonlight; less than 25 percent of this group at each college is female. Women also seem to find it easier to work only part-time as over 60 percent of the exclusive part-timers at each college are female. (See Table XVIII.)

TABLE XVIII

PERCENT FEMALE OF FACULTY GROUPS

\begin{tabular}{|c|c|c|c|c|}
\hline College & FTF & $\begin{array}{l}\text { Total } \\
\text { PTF }\end{array}$ & Moonlighters & $\begin{array}{l}\text { Exclusive } \\
\text { Part-timers }\end{array}$ \\
\hline$A$ & $35 \%$ & $30 \%$ & $14 \%$ & $63 \%$ \\
\hline B & 40 & 48 & 25 & 62 \\
\hline $\mathrm{C}$ & 44 & 43 & 25 & 75 \\
\hline
\end{tabular}

Source: derived from faculty questionnaire.

As the above data illustrate, the composition of the PTF varies from the FTF as well as within the PTF itself. The source of PTF to the community college in a metropolitan area, however, is not only diversifled but is large relative to the demand for 1t. This also seems to be the case with community colleges in the United States as a whole (Tuckman and Caldwell 1979). Those who are avallable to teach part-time come from a number of sources: moonlighters, qualified full-time employees who make themselves available to teach night classes; homemakers, qualified persons, usually women, who have other responsibilites 
but wish a part-time job; retired persons; and university students (Tuckman 1978). The group of those available to teach part-time is probably greater than those willing to teach full-time; those who moonlight may not be willing to change positions (some are earning more than the full-time faculty); retired persons, homemakers, and students may not be willing or able to teach full-time; and some of the PTF would not be employed by the college because usually a master's degree is a minimum requirement and some PTF do not hold such a degree. The above argument leads to the conclusion that there is a perfectly elastic supply of PTF.

There is also a perfectly elastic supply of FTF. The number of persons with master's degrees has continued to grow in the 1970's even though the growth of demand has slowed (Cartter 1976, Freeman 1976). The market for teachers tends to follow the classic cobweb feedback system which is generally associated with the market for corn and hogs (Carter 1976). There are lags in the response to changes in market conditions. The shortage of teachers which existed in the 1960's helped to attract students, but because of a number of reasons, including demographic changes and weakening of the economy, the conditions of shortage of the 1960 's changed in the 1970's to surplus for college-trained labor including teachers. While there continues to be a large number of individuals willing to work as full-time instructors, the demand for teachers has decreased rather dramatically (Freeman 1976). Teachers who invested in a college education continue to hold their degrees and in many cases hold a "transitional" job waiting for a teaching fob. Thus the total supply of teachers and other college graduates does not decrease easily or quickly. 
These large numbers of persons who are qualified and willing to teach full-time help form conditions for FTF which can be approximated by a perfectly elastic supply curve. 


\section{CHAPTER V}

\section{COSTS AND PRODUCTIVITY}

This chapter examines the differences between full-time faculty (FTF) and part-time faculty (PTF) on the basis of the differences of the activities and faculty support costs rather than the individuals holding the positions. The differences include the costs incurred by the college in hiring both types of faculty as well as in productivity as viewed by the assumptions and definitions in this dissertation.

$$
\operatorname{cosTS}
$$

\section{Wage Costs}

FTF earn more on an absolute basis than PTF because as a group they work more total hours, but the FTF also earn more on a relative basis, that is, more dollars per hour, as was shown earlier (see Chapter IV).

To a large extent, it appears that the differentiation of wage rates between FTF and PTF is the result of the wage structure and policy differences. The wage rates of FTF do not adjust easily to external conditions but are rigid, adjusting downward only as the result of other costs and wages going up faster than the FTF wages. Resistance to downward adjustment is the result of administrative rules and procedures which surround the FTF and insulate it against changes in economic conditions. Upward adjustments, on the other hand, do occur. Wage levels are assoclated with each individual faculty member rather 
than with the group, and are adjusted upward in response to unionmanagement agreements for cost-of-living raises or other wage adjustments, as stated in the contract, as long as the individual is employed. Thus, wage levels for FTF as a whole rise as long as turnover within the group remains low. PTF are much more subject to external economic conditions, and wage levels are more easily adjusted to labor market conditions since wages are associated not with the individuals in the group, but rather with the group as a whole.

Most regulations and rules are formally stated in the FTF manual. In addition, a union of FTF exists which acts as a bargaining unit for the FTF in all major decisions. The union contract specifies procedures concerning allocation, wages, and other economic and noneconomic matters, and acts to structure and regulate hiring, allocation, mobility, and pricing of FTF. In this way, the FTF group forms an internal labor market by which it insulates itself against outside competitive forces (Doeringer and Piore 1971).

The PTF situation is in marked contrast to that of the FTF. There is no union to represent the PTF, and there are few written rules and regulations. The contract which the PTF member signs guarantees to the college that the individual will teach a specified class; however, the contract does not guarantee that the PTF member will have a class to teach. Enrollment or other problems can force cancellation of the class, and the college can terminate the PTF at any time. The contract guarantees only that if the PTF member teaches the class, payment will be forthcoming.

The impact of written rules and internal structures on wage levels 
is difficult to measure empirically because the effects of these structures are difficult to separate from the effects of other variables, for example, human resource variables such as education and experience. A wage advantage may exist for the FTF which is unionized over the PTF which is not unionized.

The subject of the effect of unionization on wages at institutions of higher education has not been extensively studied (although it has been extensively discussed). Studies on the topic show mixed results, but appear to lend support to the view that unionization does not have a substantial impact on wages (although there appears to be an initial impact). When the union is first established, wage gains are made by the newly unionized faculty relative to colleges which have non-unionized faculty. During subsequent years, the initial gains appear to erode and the wage difference between unionized and non-unionized colleges declines and in some cases disappears. (See Garbarino and Aussieker 1975, Birnbaum 1974, Leslie and Hu 1977, and Marshall 1979). It has been argued that union activity can affect wages of non-union workers; thus, faculty at non-unionized colleges may benefit from the "threat effect," by employers raising wages comparably to prevent unionization. However, it can be argued equally well that the impact of union activity is that of a "crowding effect." If unions are able to effect wage increases at some colleges, this may lead to a decrease in quantity demanded at the unionized college and an increased supply of faculty at non-unionized colleges. These alternative hypotheses have not been empirically tested with institutions of higher education because the length of unionization has been short. Study of this impact is left for further research. 
The significance of the wage cost differences between the two faculty groups can be seen in the cost of replacing the PTF with FTF. An earlier discussion classified the duties of the two faculty groups, illustrating that the FTF spend relatively less time teaching than do the PTF, although the differences between the two in terms of duties are assumed similar enough that the two groups can substitute for one another. The substitution does not occur on a one-to-one ratio because the two groups of instructors do not work the same hours each week and are not equally productive in those hours. Table VII shows the number of FTF needed to replace PTF in terms of number of hours worked each week if the college eliminated all PTF positions. The second issue, that of productivity, is addressed later in this chapter.

Using the information from Table VII and wage data, the cost of replacing the number of hours produced by the PTF with FTF is seen in Table XIX. The table shows the current wage cost to the colleges of FTF (column one) and PTF (column two) and the total wage cost of both groups (column three). The cost of replacing the PTF with FTF (column four) is greater than the cost of employing the PTF, hence the total wage cost of a faculty which is all full-time (column five) is greater than the current faculty which is a mix of full-time and part-time. The wage savings of using the current mix, shown in column six as an amount and column seven as a percent, is 12.5 percent to 22.6 percent depending on the college. 
TABLE XIX

WAGE COST PER TERM OF FTF AND PTF WORKING CURRENT HOURS AND HYPOTHETICAL WAGE COST IF FTF REPLACED PTF*

\begin{tabular}{|c|c|c|c|c|c|c|c|}
\hline \multirow[b]{2}{*}{ College } & \multirow{2}{*}{$\begin{array}{l}\text { Current } \\
\text { FTF }\end{array}$} & Total Wage & Costs & \multicolumn{2}{|c|}{$\begin{array}{l}\text { Total Wage Cost if Use } \\
\text { FTF to Replace PTF** }\end{array}$} & \multicolumn{2}{|c|}{$\begin{array}{l}\text { Total Wage Savings if Use } \\
\text { Current FTF/PTF mix** }\end{array}$} \\
\hline & & PTF & Tota1 & Replacement & Tota1 & Amount & Percent \\
\hline A & $\$ 797,375$ & $\$ 205,938$ & $\$ 1,001,313$ & $\$ 356,892$ & $\$ 1,154,267$ & $\$ 152,954$ & $15.3 \%$ \\
\hline B & 464,732 & 63,685 & 528,417 & 129,763 & 594,495 & 66,078 & 12.5 \\
\hline C & 307,357 & 46,920 & 354,277 & 127,141 & 434,498 & 80,221 & 22.6 \\
\hline
\end{tabular}

Source: columns one and two derived from data gathered from college records and with the faculty questionnaire.

*All analysis is based on a standard 11-week term.

**The number of hours worked by PTF is replaced by FTF. Because FTF are more productive, total output increases; however, these estimates disregard the increase from this source. 


\section{Fringe Benefits and Total Compensation}

For many workers, fringe benefits are a tax-free source of indirect monetary income. Faculty who worked a nine to ten-month year at two-year public institutions of higher education in the 1975-76 academic year received fringe benefits of approximately 15.1 percent of their wage (Beazley 1977). The FTF of this dissertation sample averaged a somewhat higher percent of fringe benefits, with fringe benefits equal to over 20 percent of the wage at all three colleges. PTF do not receive comparable fringe benefits; when calculated as a percentage of wage, they are paid less than one-half of the fringe benefits paid to FTF, as Table XX indicates.

\section{TABLE XX}

FRINGE BENEFITS AS PERCENT OF HOURLY WAGE

\begin{tabular}{lcc} 
College & Full-time Faculty & Part-time Faculty \\
A & 22.64 & 10.0 \\
B & 21.50 & 8.5 \\
C & 24.50 & 11.5 \\
\multicolumn{2}{c}{$\begin{array}{c}\text { Source: } \\
\text { records. }\end{array}$} & data derived from faculty questionnaire and college
\end{tabular}

The fringe benefits received by the PTF differ from those received by FTF not only in relative amount of benefit types but also in benefits received. Only compulsory fringe benefits are paid to or for the PTF: insurance premiums for Social Security, workman's compensation, and unemployment. In contrast, FTF receive the compulsory benefits and additional benefits due to their status as full-time instructors. The additional benefits, paid by the college, are payments 
for insurance: medical and dental, life, long-term disability, and retirement in addition to Social Security.

The lack of non-compulsory fringe benefits for PTF appears to result from at least three factors: first, turnover among the PTF is high which results in a low or negative return for efforts to attain additional benefits by the PTF. In other words, because there is no organization or union through which PTF can speak, the task of organizing other faculty, then demanding benefits, is not worth the effort to the individual PTF who may leave the job even before the additional dollars of compensation start to flow. Second, the PTF as a group do not all have the same goals and needs: some are moonlighters who hold other full-time jobs where fringe benefits are provided. These PTF do not perceive a need for additional benefits. Other PTF who do not hold full-time jobs but work exclusively part-time may or may not find It advantageous to have fringe benefits as part of their compensation packages. These individuals may be covered through spouses who work full-time, by retirement benefits, or by the university in which they are enrolled. Others who rely exclusively on part-time teaching for income may prefer compensation in the form of dollars rather than benefits. Third, the college itself may hesitate in offering fringe benefits because of the expense of covering PTF. The short tenure of many PTF and the various hours of teaching by each individual may make the expense of record-keeping greater than the additional satisfaction among the part-time instructors.

The wage cost of the FTF is greater than that of the PTF as was established earlier (see Table XI). It is also true that the cost of 
fringe benefits per hour to the college is greater for the FTF than for the PTF. Fringe benefits were shown earlier in Table XX as a percentage of the wage of each group; the fringe benefits are shown in Table XXI as an amount per hour (column three). The table 11lustrates that the FTF at each college not only earn higher wages per hour than the PTF (the PTF wage per hour varies from almost 40 percent to 57 percent of the FTF wage per hour (column two), but the FTF also receive fringe benefits that are greater than those received by the PTF. The PTF earn fringe benefits per hour of 17 percent to 25 percent of the fringe benefits paid by the college to the FTF.

TABLE XXI

WAGES, FRINGE BENEFITS AND TOTAL COMPENSATION PER HOUR

\begin{tabular}{|c|c|c|c|c|c|}
\hline $\begin{array}{l}\text { Wage } \\
\text { per }\end{array}$ & Percent & $\begin{array}{l}\text { Fringe } \\
\text { Benefits }\end{array}$ & Percent & $\begin{array}{l}\text { Total } \\
\text { Comp- } \\
\text { ensation }\end{array}$ & Percent \\
\hline & PTF of FTF & er Hour & $F$ of FTF & per Hour & PTF of FTF \\
\hline
\end{tabular}

College A

$\begin{array}{rrrrrrr}\text { FTF } & \$ 12.88 & & \$ 2.92 & & \$ 15.80 & 51.3 \% \\ \text { PTF } & 7.36 & 57.1 \% & .74 & 25.3 \% & 8.10 & \text {. }\end{array}$

College B

$\begin{array}{rrrrrrr}\text { FTF } & 12.47 & & 2.68 & & 15.15 & \\ \text { PTF } & 6.12 & 49.1 & .52 & 19.4 & 6.64 & \end{array}$

College C

$\begin{array}{rrrrrrr}\text { FTF } & 13.63 & & 3.34 & 16.97 & 33.1 \\ \text { PTF } & 5.03 & 36.9 & .58 & 17.4 & 5.61 & \end{array}$

Source: data in columns one and three derived from faculty questionnaire and college records. 
Combining wages and fringe benefits results in the total compensation to the faculty by the college (column five). The above discussion illustrates that the FTF are paid higher wages and receive more fringe benefits than the PTF, thus the total compensation paid to the FTF is greater than that paid to the PTF. In all cases the amount received by both faculty groups at all three colleges is increased but the difference between the FTF and PTF is further accentuated when total compensation is examined rather than wages alone. Using total compensation per hour, the PTF are paid from one-third to slightly more than one-half that paid to FTF (column six).

The significance of the difference in cost between the two faculty groups can be illustrated in two ways: by examining a hypothetical 40-hour week and by projecting the cost of replacing the PTF with FTF. In the first example, if all faculty worked a 40-hour week and 11-week term, the differences between the two groups could be compared on a standard basis. At College A, a hypothetical average FTF member would cost the college $\$ 6,952$ while the PTF working the same hours would cost $\$ 3,564$. At College $B$ the difference in cost between the two faculty is $\$ 6,666$ for the FTF and $\$ 2,922$ for the PTF. At College $C$, the FTF would cost $\$ 7,467$ compared to $\$ 2,468$ for the PTF. These figures show that the PTF costs the college much less than the FTF. The analysis disregards the change in total output due to productivity differences between the two faculty groups.

In the second example, if all FTF were used instead of the current mix of FTF and PTF, and if FTF hours were substituted for the number of hours worked by PTF, output levels would change because the PTF are 
less productive. Leaving productivity questions until later, * however, an estimate of the replacement cost is shown in Table XXII. This table is derived from information presented in earlier analysis, especially Table VI which presented data on the number of FTF required to substitute for PTF on the basis of actual hours worked by PTF.

Table XXII presents data on the current total compensation cost of FTF and PTF for an 11-week term (columns one and two). The current total cost of both faculty groups is shown in column three. In order to replace its PTF but maintain its current hours produced, the college would have to replace the PTF positions with the more costly FTF. The replacement cost (column four) is greater than the cost of PTF the college would eliminate, thus the total compensation cost of both faculty groups (column six) is greater than the total cost of using the mix of the two groups.

The last two calculations illustrate the savings to the college if it uses its current mix of FTF and PTF rather than using all FTF. The savings to the college is shown as an amount (column seven) and a percentage (column eight). The college saves from 18 percent to nearly 25 percent if they choose to employ the current mix of faculty rather than all FTF.

\section{Turnover Costs}

Another kind of cost which separates the two types of faculty is turnover costs. In this area the FTF can be expected to cost more for

*See productivity section, this chapter. 


\section{TABLE XXIT}

TOTAL COMPENSATION COST PER TERM OF FTF AND PTF WORKING CURRENT HOURS AND HYPOTHETICAL COMPENSATION COST IF FTF REPLACED PTF*

Current Total Compensation Costs

\begin{tabular}{crrrr}
\cline { 3 - 4 } College & & FTF & \multicolumn{1}{c}{ PTF } & Tota1 \\
\cline { 3 - 5 } A & & $\$ 978,146$ & $\$ 224,443$ & $\$ 1,202,589$ \\
B & & 564,610 & 69,096 & 633,706 \\
C & 382,674 & 52,330 & 435,004
\end{tabular}

Total Compensation Cost if Use FTF to Replace PTF**

\begin{tabular}{cr}
\hline Replacement & Tota1 \\
\hline$\$ 437,802$ & $\$ 1,415,948$ \\
157,601 & 722,211 \\
158,296 & 540,970
\end{tabular}

Total Compensation Savings if Use Current FTF/PTF Mix**

\begin{tabular}{rc}
\hline \multicolumn{1}{l}{ Amount } & Percent \\
\hline$\$ 213,359$ & $17.7 \%$ \\
88,505 & 14.0 \\
105,966 & 24.4
\end{tabular}

Source: Columns one and two derived from data gathered from college records and with the faculty questionnaire.

*A1l analysis is based on a standard 11-week term.

**The number of hours worked by PTF is replaced by FTF. Because FTF are more productive, total output Increases; however, these estimates disregard the increase from this source. 
each turnover than the PTF because the college is willing to invest in FTF which it expects and encourages to remain with the college for a considerable period of time. The college appears willing to pay additional dollars to its FTF to encourage low turnover: wages are high, tenure exists, and generous fringe benefits are contingent on the status of being full-time.

The college is not willing to provide incentives to the PTF to encourage employment stability. Wages earned by PTF are relatively low; they range from approximately 40 percent to 60 percent of the FTF wage, and fringe benefits are only those which must be provided by law. As could be expected, the fixed costs that the college makes in each of its faculty including hiring, termination, and training and orientation costs are lower for the PTF than for the FTF. The reason is the expected return; the college plans to employ the FTF for a longer length than the PTF, thus it is willing to bear additional costs because it can expect to yield a return in the form of a better qualified labor force in the long run. The PTF, in contrast, are employed by the college for a short period providing the college with the ability to adjust to fluctuating enrollments and changing student needs. Thus the college attempts to minimize the costs associated with hiring and termination of these faculty.*

As expected, the FTF have a consistently low turnover among the three colleges. Turnover is less than 7 percent for all the colleges.

\footnotetext{
*The reader is reminded that "training and orientation" costs are those costs associated with turnover; additional training costs may be associated with continued employment.
} 
The turnover rate of PTF is much greater but does not seem to have any pattern among the three colleges as does most of the other data. It varies from one-quarter to almost three quarters of the PTF each year. (See Table XXIII.)

TABLE XXIII

YEARLY TURNOVER OF FACULTY FOR 3-YEAR PERIOD

$\begin{array}{ccc}\text { College } & \text { Full-time Faculty } & \text { Part-time Faculty } \\ \text { A } & 6.5 \% & 73 \% \\ \text { B } & 5.2 & 26 \\ \text { C } & 5.8 & 45\end{array}$

Source: data derived from college records.

The costs associated with the turnovers are consistently lower for each individual PTF than for the individual FTF. Table XXIV shows that hiring and termination costs for the PTF are 16 percent of the cost of FTF at Coillege $A$ and 2 percent and 4 percent at Colleges $B$ and C. The training and orientation costs are also less for the PTF than for the FTF as the theory predicts: 21 percent, 15 percent and 7 percent at the respective colleges. The final columns in Table XXIV are the total cost of an individual turnover for the colleges. As expected, the cost of turnover of each FTF is greater than the cost of each PTF. The total cost of turnover for each faculty group is a function of the total number of faculty involved in the turnover each year. For the FTF, the total cost of turnover is the number of turnovers multiplied by the cost of the turnovers. Calculating the turnover cost for PTF is more complex because, in a sense, 100 percent of the PTF are re- 
TABLE XXIV

COST OF INDIVIDUAL TURNOVER*

\begin{tabular}{|c|c|c|c|c|c|c|c|c|c|}
\hline \multirow[b]{2}{*}{ College } & \multicolumn{3}{|c|}{$\begin{array}{l}\text { Hiring and Termination } \\
\text { Costs }\end{array}$} & \multicolumn{3}{|c|}{$\begin{array}{l}\text { Training and Orientation } \\
\text { Costs }\end{array}$} & \multicolumn{3}{|c|}{$\begin{array}{l}\text { Total Turnover } \\
\text { Costs }\end{array}$} \\
\hline & FTF & PTF & Percent & FTF & PTF & Percent & FTF & PTF & Percent \\
\hline $\mathbf{A}$ & $\$ 765$ & $\$ 121$ & $16 \%$ & $\$ 180$ & $\$ 38$ & $21 \%$ & $\$ 945$ & $\$ 159$ & $17 \%$ \\
\hline B & 1,735 & 40 & 2 & 234 & 35 & 15 & 1,969 & 75 & 4 \\
\hline C & 812 & 32 & 4 & 350 & 25 & 7 & 1,162 & 57 & 5 \\
\hline
\end{tabular}

Source: data derived from personnel office questionnatre.

*See Appendix D for cost of turnover of both types of PTF: those who have worked for the college previously and those who have not been employed by the college previously. 
employed every term. Because the PTF are not a permanent part of the college faculty, the college must re-employ PTF members who continue to work for the college from one term to the next. Data were gathered to recognize the differences between the two PTF groups. (See Appendix D.)

The cost of turnover of the PTF is actually two costs: one for the PTF member who has never worked for the college, and a separate cost for the PTF member who has worked for the college and is re-employed. Costs of PTF in Table XXIV are an average of the two costs, which can be found in Appendix $D$.

Because turnover rates were collected by the college on a yearly basis, in order to compute the total turnover costs, it is necessary to make the following assumption: each college re-hires 100 percent of its faculty each term for two terms; that is, all of the PTF who worked fall term returned to teach both winter and spring term. The cost of each individual turnover is listed in Appendix $D$ (column eight) and is multiplied by 100 percent to reflect the total cost of turnover. The turnover rate from spring to fall term (excluding summer term) is listed in Table XXIII and is applied to the cost of an individual turnover assuming the individual has worked previously for the college. (See column nine, Appendix D.) The effect of the above calculations for PTF probably slightly understates the turnover cost of the PTF to the college.

The total cost of turnover to the college is shown in Table XXV. While the cost of an individual FTF turnover is greater than a PTF turnover, the total cost of turnover of the PTF is greater because the 
quit rate is higher among the PTF. The total cost of turnover of FTF is low relative to the PTF, reflecting the lower rate of turnover of FTF even though the cost of turnover is considerably higher among the FTF.

TABLE XXV

TOTAL COST OF TURNOVER PER TERM*

College

A

B

C
Fu11-time Faculty

$\$ 2,835$

2,625

1,162
Part-time Faculty

$\$ 31,828$

5,808

2,360

Source: calculations made from data gathered with the personnel questionnaire, faculty questionnaire, and college records.

*The total turnover costs per term were calculated on a yearly basis assuming a standard 11-week term, and thus represent an "average" term. Summer term is excluded.

Following the analysis of earlier sections which estimated various costs of eliminating the PTF and replacing it with FTF, the same analysis can be applied to assess the impact on the colleges of all faculty costs: wages, fringe benefits, and turnover costs. This analysis, as did earlier ones, ignores the differences in productivity between the two groups and examines the cost impact of substituting FTF for the actual number of hours worked by PTF. Table XXVI includes compensation and turnover costs of both FTF (column one) and PTF (colunn two) as well as the total cost of both faculty groups (column three). The cost to the college of eliminating its PTF (but probably changing total output levels) by replacing the PTF with FTF shows that costs 
TABLE XXVI

TOTAL COMPENSATION AND TURNOVER COSTS PER TERM OF FTF AND PTF WORKING CURRENT HOURS AND HYPOTHETICAL COST IF FTF REPLACED PTF*

\begin{tabular}{|c|c|c|c|c|c|c|c|}
\hline \multirow[b]{2}{*}{ College } & \multicolumn{3}{|c|}{$\begin{array}{l}\text { Current Total Compensation } \\
\text { and Turnover Costs }\end{array}$} & \multicolumn{2}{|c|}{$\begin{array}{l}\text { Tota1 Compensation and Turnover } \\
\text { Cost if Use FTF to Replace PTF** }\end{array}$} & \multicolumn{2}{|c|}{$\begin{array}{l}\text { Total Compensation and } \\
\text { Turnover Savings if } \\
\text { Use Current FTF/PTF Mix** }\end{array}$} \\
\hline & FTF & PTF & Total & Replacement & Total & Amount & Percent \\
\hline A & $\$ 980,981$ & $\$ 256,271$ & $\$ 1,237,252$ & $\$ 449,718$ & $\$ 1,430,699$ & $\$ 193,447$ & $15.6 \%$ \\
\hline B & 567,235 & 74,904 & 642,139 & 167,737 & 734,972 & 92,833 & 14.5 \\
\hline C & 383,836 & 54,960 & 438,526 & 163,081 & 546,917 & 108,391 & 24.7 \\
\hline
\end{tabular}

Source: columns one and two derived from data gathered from college records and with the faculty questionnaire.

*All analysis is based on a standard 11-week term.

**The number of hours worked by PTF is replaced by FTF. Because FTF are more productive, total output increases; however, these estimates disregard the increase from this source. 
increase (column four), as was the case in earlier analysis. The alternate total cost (column five) if the college uses an all FTF shows an increase over the total cost of using the current mix of FTF and PTF.

The savings by using the current mix of faculty rather than an al1 FTF is shown as an amount (column six) and a percentage (column seven) and is only slightly less than was the case of total compensation costs shown in Table XXII.

\section{PRODUCTIVITY}

The previous section indicated that PTF are cheaper to employ than FTF. However, the college or any other institution does not hire with respect to costs only; productivity is also considered.

The problems of definition and measurement of productivity of teachers were discussed earlier (in Chapter III). Given these problems, the approach taken here does not attempt to measure output; rather the inputs are used to estimate productivity according to the literature on human resources. Following the human resources approach, investment in workers by the workers themselves or firms which employ them is the basic source of differentiation of productivity and thus labor incomes. The approach is consistent with how the colleges appear to value the productivity of faculty; that is, the college is willing to pay a faculty member a greater amount of income for each additional level of teaching or professional experience, or a higher educational degree. In other words, the colleges apparently view added education and training as the major contributions to greater productivity of faculty. 
While the FTF are paid income according to their respective background characteristics, PTF are paid a flat fee for teaching at the respective college. The college apparently believes that PTF have a relatively homogeneous background and thus pay differences are not necessary. The college hires PTF with reference to the same kinds of characteristics that it hires FTF, for example, preferring that the faculty member hold a master's degree in the subject area in which he or she teaches. The college apparently values the same characteristics which contribute to greater productivity of its FTF and believes these contribute to greater productivity among its PTF. Valuing productivity by use of salary is not only consistent with the view the college apparently holds, but it is also consistent with the literature of human capital. The approach is to value the background characteristics of the. FTF by use of salary, then to apply the values to the PTF. While salary of FTF is used to measure the value of background characteristics and estimate productivity, the results are independent of PTF salary because the PTF background characteristics are measured in terms of the values established by FTF characteristics. The values are used to estimate the relative differences between the two groups. The characteristics the colleges use to value productivity are the same at the three colleges. Each uses the following three: education, professional experience, and teaching experience. Using these characteristics, two approaches are used in this dissertation to measure productivity. The first approach is a regression analysis of the FTF salary to measure the impact of various characteristics on productivity. The second approach uses the salary schedule to measure 
the impact of various characteristics.

\section{Regression Analysis Approach}

The regression analysis is an attempt to determine the actual contribution of a number of variables which the college indicates are important to the level of salary paid to FTF. Once the value of each characteristic is determined, these measurements can then be applied to each PTF to determine the average level of productivity as measured by the hypothetical wage of this group as a whole.

Salary was chosen as the dependent variable. The independent variables were chosen from those characteristics the college appears to view as important: grade school, high school, private, and other school teaching experience; university, four-year college, and community college experience; professional experience; and internal experience at the community college itself. All of the above variables were coded according to length and full-time or part-time experience. Education level and sex were also included as independent variables. (See Appendix E.)

The stepwise model SPSS subprogram Regression was used to test the independent variables and to place those with the largest $R$ at the first of the list. Thus change in $\mathrm{R}^{2}$ grew smaller but the amount of variance explained grew larger at each step.

An analysis of the regression results indicated that the only significant predictor was length of full-time internal experience. This was true at all three community colleges; no other variable was included in the regression equation with the exception of College $B$ at which sex was also significant. (See Appendix E.) 
The purpose of the regression is to generate parameters which indicate what determines the salary of FTF. The characteristics of PTF would then be filled into the equation to determine what value the PTF is in relation to the FTF. On this basis, the results of the regression are disappointing because the only statistically significant variable is length of full-time experience. Only a few PTF have fulltime experience. At College A one person has full-time experience, at College B no PTF have full-time experience, and at College $\mathrm{C}$ two persons have limited full-time experience. In no case is the experience more than one year.

The parameter of one important variable, degree, could not be determined. All FTF have earned a master's degree or higher, thus this variable acted as a constant in the regression analysis. In other words, there is no linear relationship between higher degree and higher salary because degree does not vary.

While applying the results of the regression to PTF is inappropriate, the results appear to lend empirical support to those values the colleges appear to believe are important. The colleges view many types of experience as important. For example, faculty may have various background experiences but all include teaching or professional job experience. Faculty backgrounds may differ within these categories regarding length but background characteristics do not differ substantially; all are either teaching or another professional category of work experlence. Other types of experience such as clerical, sales, service or craft experience are not considered relevant or important by either the college or the faculty. No FTF member in the sample had 
these other types of experience, or, if they did, did not believe them important enough to report them on the questionnaire. Therefore, not only do faculty believe these characteristics to be unimportant, but the college does not hire persons with these characteristics as a major part of their background.

Faculty backgrounds, if viewed separately, are dissimilar with respect to length of experience within each category and type of experience, although if length of all experience is included into one category, there is a high degree of similarity. The coefficient of variation is approximately 40 percent to 50 percent for all FTF at all colleges compared to well over 100 percent for the various categories when viewed separately. When viewed as categoric variables, all FTF have teaching experience.

The results of the regression indicated that internal experience is an important contributor to the salary of the FTF. This result is not unexpected because of the relationship betweenexperience and on-thejob training (OJT). Experience is an attempt to measure the effect of OJT which has a number of characteristics. First, the amount of OJT on productivity appears to increase as education levels increase (Mincer 1962). Thus, college faculty may possess a considerable amount of OJT as the result of both formal instruction by the college and increased experience. The initial cost of training and orientation of new faculty was discussed earlier; however, these costs are associated with turnover and do not reflect all training costs.

*See section on turnover costs in this chapter. 
While the productivity of faculty is increased during the training period, it does not continue to increase at the same rate; rather the rate of increase slows and at some point the productivity reaches a higher level where the rate of increase approaches zero (Becker 1962). If a large part of the total faculty has finished the training, then the regression results would fail to show differences among the faculty because, in fact, there are few differences. All faculty responding to the dissertation questionnaire hold a master's degree and most (70 percent to 80 percent) have been employed by the college long enough to have been awarded tenure.*

Second, if some OJT does occur at the college, it is more likely to occur at an earlier rather than at a later time period because the return to the college and to the instructor, in terms of higher productivity and higher wages, can accrue over a longer time period. (This assumes that the benefits of OJT accrue over a relatively long period of time, and furthermore, that training is not completely genera1.)

The above characteristics argue that the effect of OJT as measured by experience is substantial, but in addition, an attempt to measure the effect of earlier experience or OJT results in a measurement of the "flat" portion of the productivity curve because most FTF have been employed by the college for a long period and do not provide enough variation for measurement with regression analysis.

If faculty are distributed along the curve, regression analysis can determine the effect of various factors on productivity; however, faculty.

*See Chapter IV for discussion on length of employment by the 
the coefficient of variation (V) of actual salary of FTF shows that the faculty tend to be clustered. For the three colleges, $V$ is 12 percent, 20 percent, and 25 percent, while $V$ for potential salary of FTF is much greater.

The empirical results tend to substantiate the theoretical predictions that the college considers wage an estimate for productivity of FTF. But because all FTF hold master's degrees, have similar experience beckgrounds, and have a long length of employment at the college, the results are not applicable to the PTF.

\section{The Salary Schedule Approach}

An alternative to the regression analysis is the salary schedule approach. The regression analysis approach, while providing support for the hypothesis that the college uses education and training as an estimate for expected productivity, does not provide measurements to apply to the PTF. The measurements necessary are the values of those characteristics which allow for initial placement on the FTF salary scale. These values could then be applied to the education and experience levels of the PTF to obtain values for expected productivity of the individuals of this group.

In this second approach, the college salary schedule* is used to determine what PTF would earn if they were employed full-tlme at the respective colleges. The assumption behind this approach is that the salary schedule accurately reflects the valuation of each background

\footnotetext{
*See Appendix F for salary schedule of the colleges.
} 
characteristic of faculty. The schedule is used to value a number of different characteristics such as the level of education attained, the amount of previous teaching experience, as well as the level of that experience, whether grade school, high school, or college, and the amount of previous professional job experience in business, industry, or government. In nearly every case the college salary guide specifies full-time experience that eliminated the valuation of the considerable amount of part-time experience by PTF. Almost none of the PTF has been employed full-time at the college; therefore, this group is placed at the appropriate beginning spot on the schedule. In order to advance on the schedule, faculty must be employed full-time; consequently the internal part-time experience of the PTF of approximately two years at the respective colleges does not enter into the estimates of salary placement.

The salary schedules are used in a specific manner; they are interpreted in a way which places PTF in the proper salary position relative to how the college would place them if it employed them fulltime. The attempt was made to translate the schedule in a logical, consistent, and appropriate manner. Therefore, the faculty member with a master's degree, three years of full-time professional experience, and two years of full-time teaching experience will, for example, be placed at the appropriate level and step of the 1977-78 salary schedule of the respective college. If an individual falls between steps in terms of previous experience, the individual is placed on the upper step if the experience level totals over one-half of that required to gain the next step, or the lower step if the experience is less than 
one half.

Once faculty are employed full-time, all are required to engage in professional development. Because this does not enter the step determination until after an instructor becomes full-time, it does not influence the salary schedule formula for PTF.

The hypothetical wage for PTF based on the salary schedule represents the college's value for the PTF, in other words, the expected productivity of the PTF. These figures can be interpreted as a percentage of the FTF salary because the FTF are also valued on the same scale. Thus the relative value of the PTF to the FTF is $.7, .69$, and .78 as can be seen from Table XXVII.

Table XXVII also lists what the actual salary of PTF would be if they were employed full-time. These figures (column three) represent the actual average wage for a nine-month year, based on the actual wage per hour for the PTF at each college, the actual hours per week of FTF, and an 11-week term.

TABLE XXVII

PRODUCTIVITY MEASURE BASED ON SALARY SCHEDULE

\begin{tabular}{|c|c|c|c|c|}
\hline College & $\begin{array}{c}\text { Average Wage } \\
\text { of FTF } \\
\end{array}$ & $\begin{array}{l}\text { Hypothetical } \\
\text { wage of PTF if } \\
\text { employed full-time* }\end{array}$ & $\begin{array}{l}\text { Actual Wage } \\
\text { of PTF if } \\
\text { employed ful1-time }\end{array}$ & $\begin{array}{l}\text { Product- } \\
\text { ivity } \\
\text { Ratio } \\
(2 \div 1) \\
\end{array}$ \\
\hline A & $\$ 17,979.13$ & $\$ 12,606.21$ & $\$ 10,200.96$ & .70 \\
\hline B & $18,152.40$ & $12,572.20$ & $8,886.24$ & .69 \\
\hline C & $18,241.67$ & $14,268.86$ & $6,805.59$ & .78 \\
\hline
\end{tabular}


It is clear from Table XXVII that if the college's salary schedule is an accurate reflection of the expected productivity of faculty, the college is paying the PTF less than their marginal revenue product (MRP) as represented by the hypothetical wage (column two). The most common explanation of this difference is found in the literature of discrimination.* However, a better explanation of the difference in the unwillingness of the colleges to pay the PTF their MRP can be found in the literature of investment in human capital (Becker 1962). If the college is knowledgeable of its costs, then it is rational for the college to pay the FTF an amount equal to their MRP while it will pay the PTF less than its MRP. The training costs of the two groups of faculty were discussed earlier and data were collected on those aspects of training which were related to costs to the college of hiring and orientation.**

*Becker (1959) suggested that discrimination is similar to a restriction of international trade. If two societies exist between which trade takes place and one society has a "taste" for discrimination, it imposes a "tariff" in the form of a preference which restricts trade. In an alternative model Thurow (1969) suggested that those who discriminate act as discriminating monopolists and thus establish relationships in which a portion of the socfety (those discriminated against) occupy the inferior positions.

Becker's model relies on a physical distance preference and Thurow's on a social distance preference by the discriminators. Those who belong to the PTF are not radically different on the basis of sex, race, ethnic background, or education from those who teach full-time. Two additional authors (Phelps 1972 and Arrow 1973) have suggested that discrimination takes place when the firm has imperfect knowledge. In this case, the college would view the PTF as being less productive than they actually are and therefore would not be willing to pay them their MRP. Information is costly, but the colleges have employed PTF for a considerable length of time and in all probability they are as aware of the productivity of this group of faculty as they are of the FTF.

**See section on turnover costs in this chapter. 
In addition workers increase their productivity while on the job and incur costs to the firm which are unrelated to these initial training costs.

If training takes place (it can be specific or some combination of general and specific), the willingness of the college to pay for the training is related to turnover of its faculty. If the college pays the total training costs and the faculty member quits, it cannot hire a new employee who is equally productive, thus it must incur additional costs to train another employee.

The likelihood of an employee terminating his or her employment is related to a number of factors; the college can discourage quits by allowing the individual to share in the return from training by offering a higher wage. The college appears willing to pay the FTF their MRP, and thus willing to share with this group the increased productivity from training.

The PTF, in contrast, have a high turnover rate (see Table XXIII) which the colleges as well as the faculty appear to prefer. The college does not appear willing to discourage turnover, and because turnover is high the college appears to have shifted a large part of the cost of training to the PTF in the form of lower wages. Thus, the PTF must bear a large part of the cost of training which results in a wage rate below the MRP for this group.*

*In a study by Tuckman and Caldwell (1979), data are presented which lend indirect support to the above argument. PTF in this study were paid less than their FTF counterpart, and were rewarded less on the basis of human capital investment than the FTF. 
THE PRODUCTIVITY MEASUREMENT

Using the productivity measurement developed from the earlier analysis (Table XXVII), the problem is to convert these figures into empirically useful measurement. For this purpose, the concept of a "productive hour" (p) is developed.

The actual average of hours worked by both faculty groups is shown in Table XXVIII, columns one and two. These are the hours of work actually performed by the FTF and the PTF according to the survey results. When the productivity measurements (columns three and four) are applied to these actual hours of work, the result is called productive hours. These are not actual hours of work done but the value or productivity of those hours. As can be seen in column three, the FTF have output equivalent to 42 productive hours which is the same as the number of hours actually worked; however, the PTF are less productive than the number of hours of actual work indicate, reflecting the productivity measurements of the PTF which are less than 1.0. For example, the PTF at College A work 11 hours a week, but they actually produce 30 percent less or 7.7 productive hours of output.

This section has examined productivity. While the earlier sections have indicated that the FTF cost more, this section developed a measurement which suggests why the college expects the PTF to be less productive than the FTF. In other words, the PTF not only work fewer hours than the FTF but are also less productive in each hour. 
TABLE XXVIII

HOURS ACTUALLY WORKED AND PRODUCTIVE

HOURS OF OUTPUT

\begin{tabular}{|c|c|c|c|c|c|c|}
\hline \multirow[b]{2}{*}{ College } & \multicolumn{2}{|c|}{$\begin{array}{l}\text { Hours Worked } \\
\text { per Week }\end{array}$} & \multicolumn{2}{|c|}{$\begin{array}{l}\text { Productivity } \\
\text { Measurement }\end{array}$} & \multicolumn{2}{|c|}{$\begin{array}{l}\text { Productive Hours } \\
\text { of Output }(2 \div 1)\end{array}$} \\
\hline & FTF & PTF & FTF & PTE & FTF & PTF \\
\hline A & 42 & 11 & 1 & .70 & 42 & 7.7 \\
\hline B & 44 & 11 & 1 & .69 & 44 & 7.6 \\
\hline C & 41 & 16 & 1 & .78 & 41 & 12.5 \\
\hline
\end{tabular}

Source: columns one and two derived from data gathered from faculty questionnaire.

Earlier tables (see Tables XIX, XXII, and XXVI) have indicated that costs increase if FTF replace the hours worked by PTF, but none of the earlier analysis of this chapter had developed the tools to provide an analysis of the impact of productivity differences between the faculty groups. Table XXVIII provides the productivity measures and also the basis for such an analysis. As shown in Table XXIX, the total output is less if the college uses its current mix of FTF and PTF rather than using an all full-time faculty.

The amount of loss of productive hours by employing the current mix of faculty groups is dependent on several factors: the productive hours measurement, as defined earlier, the mix of faculty because more PTF employed causes the total productive loss to increase, and the number of hours each faculty works per term. For example, College A loses over 9 percent of its productive hours by hiring the current mix of faculty. Table XXIX disregards cost differences between the two 
TABLE XXIX

PRODUCTIVITY PER TERM OF FTF AND PTF WORKING CURRENT HOURS AND HYPOTHETICAL PRODUCTIVITY IF FTF REPLACED PTF*

\begin{tabular}{ccccc} 
& & \multicolumn{3}{l}{ Current Total Productive } \\
Hours of & Output & \\
\cline { 5 - 6 } College & & FTF & PTF & Total \\
\cline { 1 - 1 } A & & 61,908 & 19,396 & 81,304 \\
B & & 37,298 & 7,180 & 44,478 \\
C & & 22,550 & 7,276 & 29,826
\end{tabular}

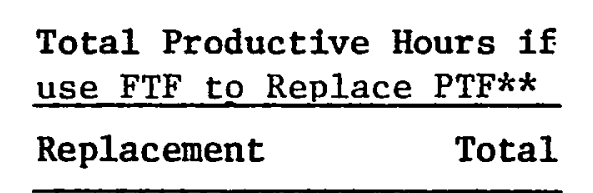

$\longrightarrow$

Total Productive Hours Loss if Use Current FTF/PTF Mix**

Amount Percent

$\begin{array}{cc}8,313 & 10.2 \% \\ 3,226 & 7.3 \\ 2,052 & 6.9\end{array}$

Source: columns one and two derived from data gathered from college records and with the faculty questionnaire.

*All analysis is based on a standard 11-week term.

**The number of hours worked by PTF is replaced by FTF. Because FTF are more costly, total cost increases; however, these estimates disregard the increase from this source. 
faculty groups.

This chapter has examined the costs and productivity of both types of faculty. Earlier tables illustrated the cost increase (see Tables $X I X, X X I I$, and XXVI) and the productivity loss (see Table XXIX) of replacing the entire PTF with FTF. None of the estimates in the above tables allowed for shifts in total output or cost as the employment ratios between the two groups changed; however, this chapter has developed the tools which can be used to examine the optimum use of the respective faculty groups by the colleges. 
CHAPTER VI

THE LINEAR PROGRAMMING PROBLEM AND CONSTRAINT ADJUSTMENT

The final step in the process of examining the use of full-time faculty (FTF) and part-time faculty (PTF) at community colleges is determining the optimum use of faculty by the college, not only given current costs and output status but also given simulated situations and constraints.

The method used in this dissertation to determine the optimum use of resources is linear programing, a procedure which allows the researcher to specify the most desirable action for a situation in which a number of alternate actions is possible. Linear programming defines a feasible region for a set of equations and determines the optimum feasible solution if one exists.

Here the college is assumed to have the ability to produce output with a combination of two types of faculty which have different costs associated with their respective use. Each faculty group can be substituted for the other to provide a given output. There are a number of possible courses of action. The purpose of linear programing is to determine the "best" course of action: that is, within the constraints of the model, the least cost of maximum output method is provided by the model.

A crucial assumption is linearity. It is assumed that either faculty group can be increased or decreased and that the costs and productivity assoclated with either group increases or decreases in direct proportion with its use. This is a realistic assumption given the costs 
associated with the employment of faculty-wage, turnover, and interest costs-which increase in proportion to the use of additional faculty.

Wage costs can be expected to increase with the use of more faculty from either group. The colleges have been shown to face a perfectly elastic supply of FTF and PTF, thus if any one college chose to increase its use of FTF and decrease employment of PTF, wage costs would not be affected. They would increase or decrease in direct proportion to the use of the faculty group.

Because the duties performed by the two faculty groups do not differ substantially, it has been argued that the PTF and FTF can be considered perfect substitutes.* There are two reasons why substitution does not take place on a one-to-one ratio. First, the FTF work more hours per week than the PTF, so several PTF are required to perform the same number of work hours each week that one FTF performs. Second, the FTF are more productive in each hour of work than the PTF. An hour of work by a FTF member produces more output than an hour of work by a PTF member. FTF are more productive for the above two reasons, so the concept of a "productive hour" was developed earlier (in Chapter V) and expresses the value of work by each faculty group.

Since the FTF and PTF can be considered perfect substitutes, substitution takes place between the two faculty groups at a specified ratio without affecting output. Such a relationship is linear, and examination of marginal changes using a linear model can closely approximate the situation of faculty at an urban community college. Assuming

*If not perfect substitutes, FTF and PTF are very close to being perfect substitutes. See Chapter IV, Table VIII. 
linearity for changes other than those which are marginal may be less than satisfactory because of the possibility of diminishing returns. Larger changes are discussed, however, and can be considered estimates.

This model is a simplification of the real situation but contains all the important features of the labor costs and productivity differences between FTF and PTF. The following terms are included in the linear programming model and were explained more fully in earlier chapters:

(A) The average cost of the weekly total cost of each faculty member, which is the total of the average weekly compensation costs, turnover costs, and interest costs of each faculty member. (See Table $\mathrm{XXX}$.

(B) The total weekly productive hours of each faculty group as determined by the average total hours worked each week and adjusted by the productivity measure. (See Table XXXI.)

TABLE XXXI

ACTUAL HOURS AND PRODUCTIVE HOURS OF OUTPUT EACH WEEK

\begin{tabular}{|c|c|c|c|c|c|c|}
\hline \multirow[b]{2}{*}{ College } & \multicolumn{2}{|c|}{$\begin{array}{l}\text { Actual Average } \\
\text { Weekly Total } \\
\text { Hours Worked }\end{array}$} & \multicolumn{2}{|c|}{$\begin{array}{l}\text { Productivity } \\
\text { Measure }\end{array}$} & \multicolumn{2}{|c|}{$\begin{array}{l}\text { Average Total } \\
\text { Weekly Productive } \\
\text { Hours Worked }\end{array}$} \\
\hline & FTF & PTF & $\underline{\text { FTF }}$ & PTF & FTF & PTF \\
\hline A & 42 & 11 & 1.0 & .70 & 42 & 7.7 \\
\hline B & 44 & 11 & 1.0 & .69 & 44 & 7.6 \\
\hline C & 41 & 16 & 1.0 & .77 & 41 & 12.5 \\
\hline
\end{tabular}


TABLE XXX

COMPENSATION, TURNOVER, INTEREST, AND TOTAL COSTS OF FACULTY PER WEEK

\begin{tabular}{|c|c|c|c|c|c|c|c|c|}
\hline College & \multicolumn{2}{|c|}{ Weekly } & $\begin{array}{l}\text { Weekly } \\
\text { Turnover } \\
\text { FTF }\end{array}$ & $\begin{array}{l}\text { Costs } \\
\text { PTF }\end{array}$ & $\begin{array}{l}\text { Weekly } \\
\text { Interest } \\
\text { FTF } \\
\end{array}$ & $\begin{array}{l}\text { Costs } \\
\text { PTF }\end{array}$ & \multicolumn{2}{|c|}{$\begin{array}{l}\text { Total Weekly } \\
\text { Faculty Costs }\end{array}$} \\
\hline A & $\$ 663.60$ & $\$ 89.10$ & $\$ 1.86$ & $\$ 13.30$ & $\$ .07$ & $\$ .46$ & $\$ 665.53$ & $\$ 102.86$ \\
\hline B & 666.60 & 73.04 & 3.10 & 6.55 & .11 & .22 & 669.81 & 79.81 \\
\hline C & 693.72 & 89.76 & 2.04 & 4.91 & .07 & .17 & 695.83 & 94.84 \\
\hline
\end{tabular}

Source: derived from faculty and personnel office questionnaires and from college records. 
(C) The number of faculty of each group and the number of tenured faculty. (See Table XXXII.)

A weekly rather than a quarterly time period is used to keep the size of the figures manageable.

TABLE XXXII

NUMBER OF FACULTY EMPLOYED AND TENURED

\begin{tabular}{|c|c|c|c|c|}
\hline \multirow[b]{2}{*}{ College } & \multicolumn{2}{|c|}{ Number Employed } & \multicolumn{2}{|c|}{ Number Tenured } \\
\hline & FTE & PTE & FTF & PTF \\
\hline A & 134 & 229 & 107 & 0 \\
\hline B & 77 & 86 & 53 & 0 \\
\hline C & 50 & 53 & 41 & 0 \\
\hline
\end{tabular}

Source: derived from college records.

The linear programing problem is viewed in two ways: first as a cost minimization problem (MIN COST) and second as an output maximization problem (MAX OUT). The conceptualization of the two problems is similar and the solutions are in some cases identical; however, the two methods of analyzing the problem have separate goals. The cost minimization problem views the college as setting a goal of a specific number of productive hours. The purpose of the solution is to minimize the cost of providing this output. In contrast to this, the output maximization problem views the college as determining a specific number of dollars it is willing to spend, then attempting to maximize the output produced for dollars spent.

The linear programing problems for the three colleges are set up In the following manner: first, if the problem is viewed as a cost 
minimization problem, a minimum amount of output to be produced is determined, then the computer is directed to find that combination of FTF and PTF which can produce the output at the least cost. The objective function follows the model which was developed earlier* and is of the form:

$$
\begin{aligned}
\text { MIN COST: } & N_{a}\left(H_{a}\left[w_{a}+F_{a}\right]+T_{a} q_{a}[1+.5 r]\right)+ \\
& N_{b}\left(H_{b}\left[w_{b}+F_{b}\right]+T_{b} q_{b}[1+.5 r]\right)
\end{aligned}
$$

The computer is directed to minimize this equation subject to the following constraints:

$$
\begin{aligned}
\mathrm{P}_{a} \mathrm{~N}_{\mathrm{a}}+\mathrm{P}_{\mathrm{b}} \mathrm{N}_{\mathrm{b}} & \geqq \mathrm{Q} \\
\mathrm{N}_{\mathrm{a}} & \geqq \mathrm{N}_{\mathrm{o}}
\end{aligned}
$$

The above terms were defined earlier (see p. 26) and differ here in that they are expressed for the period of a week rather than a term to keep the numbers from becoming cumbersome. In addition the term productive hours ( $P$ ) is substituted for productivity (P). For linear programming purposes, this equation differs slightly from the earlier expression (see expression 2.6 in Chapter II); $\mathrm{N}_{a}$ and $\mathrm{N}_{b}$ are variables, and the rest of the terms are entered as specific values depending on the college. In addition, the term $\left(w_{a}+F_{a}\right) H_{a}$ expresses wages plus fringe benefits per hour rather than the benefits expressed as a separate non-wage cost.

The cost equation states the important parts of the cost of each faculty member to the college. Constraint 6.2 states the productivity of the FTF and PTF and the relationship between the two groups. Further- 
more, it states that at least a certain number of productive hours (Q) must be produced. That number is the number currently produced by the faculty. Constraint 6.3 states that there must be at least a certain number $\left(\mathrm{N}_{0}\right)$ of the FTF in order to fulfill the needs of the college for stability. The minimum number of FTF chosen as an initial constraint is the number currently employed by each respective college. Later analysis relaxes this assumption.

The problem faced by the college can also be analyzed as an output maximization model. Viewed this way, the computer is asked to determine the optimum combination of FTF and PTF given a total cost that cannot be exceeded. The objective function is of the form:

$$
\text { MAX OUT: } \mathrm{p}_{a} \mathrm{~N}_{a}+\mathrm{p}_{b} \mathrm{~N}_{b}
$$

where the productivity (p) of the FTF and PTF is as defined earlier.* The constraints of the model are as follows:

$$
\begin{aligned}
& N_{a}\left(H_{a}\left[w_{a}+F_{a}\right]+T_{a} q_{a}[1+.5 r]\right)+ \\
& N_{b}\left(H_{b}\left[w_{b}+F_{b}\right]+T_{b} q_{b}[1+.5 r]\right) \leqq T C \\
& N_{a} \quad \cong \quad N_{0}
\end{aligned}
$$

The cost constraint is the objective function in the previous cost minimization problem, although now it is stated that the cost combination of FTF and PTF must be less than or equal to a specific budget amount (TC). This amount is the current weekly budget for both faculty groups at each respective college.

Non-negativity restraints are unnecessary because the computer program is written to allow only non-negative values.

\footnotetext{
* See productivity section of Chapter $V$.
} 
All problems are solved by use of a computer program although the solutions were obvious in some cases. The computer provided the major advantage of speed of completion which allowed a large number of simulations to be processed. There was, however, round-off error.

The analysis provides solutions to both the cost minimization and the output maximization problems. Simulations attempt to analyze the effect of various changes in costs and constraints on the rational employment of both the FTF and the PTF at the urban community college. The following situations and simulations are analyzed: first, optimization of the employment of FTF and PTF given the current constraints and costs, or output limitations. Second, the effect of various constraints of a specified number of faculty members in one group on the number employed in the other group is analyzed. Third, the effect of various budget constraints, and fourth, the effect of various total productive hours constraints are examined. Chapter VII deals with two additional simulations: the effect of various changes in the cost ratios between the two faculty groups and the effect of various changes in the productivity ratios between the two faculty groups.

\section{OPTIMIZATION: THE CURRENT STATUS}

In the case of output maximization, variables are cost and productivity of faculty and constraints are total cost and a minimum number of FTF. The results for each college are the optimum number of each type of faculty and the amount of output. For cost minimization, the same variables of cost and productivity of each faculty group and a minimum number of FTF are entered; however, total productive hours is the con- 
straint. Solution to the cost problem is the optimum number of faculty of each group and the total cost.

The solutions to the cost minimization and output maximization problems show that the colleges are optimizing at current employment levels. Whether the problem is viewed as a cost minimization or output maximization model, the results are the same: Tables XXXIII and XXXIV show the optimum solutions.

In all cases, whether viewed as maximization of output or minimization of total cost, the optimum solution at each college is the current status. (This solution will henceforth be called the "current status.") The crucial assumption in the determination of the result is the minimum number of FTF considered necessary. The importance of this number of faculty results from the cost and productivity relationship of the two groups of faculty at each college: the PTF can produce more output at less unit cost than the FTF. The solutions can be considered "optimum" in the sense that these are the best possible solutions to the problems given the constraint of a specified number of FTF.

The assumption is that while the goal of a "stable" faculty (which the FTF provide) is difficult to quantify, there is a minimum number that provides this goal. Given that a specified number of FTF are required to provide stability, it is assumed that the number currently employed at each respective college is the minimum FTF required.

The current status solutions provide important information which allows for marginal analysis. The college has a number of options by which it can increase output or decrease total cost. If the problem is viewed as output maximization, as shown in Table XXXV, the first option 
TABLE XXXIII

OPTIMIZATION: THE PROBLEM VIEWED AS OUTPUT MAXIMIZATION

\begin{tabular}{|c|c|c|c|c|c|c|c|c|c|}
\hline \multicolumn{7}{|c|}{ Variables Given } & \multicolumn{3}{|c|}{ Solutions } \\
\hline College & $\begin{array}{l}\text { Cost of } \\
\text { FTF }\end{array}$ & $\begin{array}{c}\text { Faculty } \\
\text { PTF }\end{array}$ & $\begin{array}{l}\text { Productive } \\
\text { of Faculty } \\
\text { FTF }\end{array}$ & $\begin{array}{l}\text { Hours } \\
\text { PTF }\end{array}$ & Total Cost & $\begin{array}{l}\text { Minimum } \\
\text { Number } \\
\text { of FTF }\end{array}$ & $\begin{array}{l}\text { Number } \\
\text { FTF }\end{array}$ & $\begin{array}{c}\text { of Faculty } \\
\text { PTF }\end{array}$ & $\begin{array}{l}\text { Number of } \\
\text { Productive } \\
\text { Hours }\end{array}$ \\
\hline $\mathbf{A}$ & $\$ 665.53$ & $\$ 102.86$ & 42.0 & 7.7 & $\$ 112,736$ & 134 & 134 & 229 & 7391 \\
\hline B & 669.81 & 79.81 & 44.0 & 7.6 & 58,439 & 77 & 77 & 86 & 4041 \\
\hline C & 695.83 & 94.84 & 41.0 & 12.5 & 39,818 & 50 & 50 & 53 & 2712 \\
\hline
\end{tabular}

Source: calculated using linear programing with data gathered with faculty and personnel office questionnaires and from college records. Round-off error is present. 
TABLE XXXIV

OPTIMIZATION: THE PROBLEM VIEWED AS COST MINIMIZATION

\begin{tabular}{|c|c|c|c|c|c|c|c|c|c|}
\hline \multicolumn{7}{|c|}{ Variables Given } & \multicolumn{3}{|c|}{ Solutions } \\
\hline College & $\begin{array}{l}\text { Cost of } \\
\text { FTF }\end{array}$ & $\begin{array}{c}\text { Faculty } \\
\text { PTF }\end{array}$ & $\begin{array}{l}\text { Productive } \\
\text { of Faculty } \\
\text { FTF }\end{array}$ & $\begin{array}{l}\text { Hours } \\
\text { PTF }\end{array}$ & $\begin{array}{l}\text { Total } \\
\text { Productive } \\
\text { Hours }\end{array}$ & $\begin{array}{l}\text { Minimum } \\
\text { Number of } \\
\text { FTF }\end{array}$ & $\begin{array}{l}\text { Number of } \\
\text { Faculty } \\
\text { FTF }\end{array}$ & PTF & $\begin{array}{l}\text { Total } \\
\text { Cost }\end{array}$ \\
\hline A & $\$ 665.53$ & $\$ 102.85$ & 42.0 & 7.7 & 7391 & 134 & 134 & 229 & $\$ 112,745$ \\
\hline B & 669.81 & 79.81 & 44.0 & 7.6 & 4041 & 77 & 77 & 86 & 58,442 \\
\hline C & 695.83 & 94.84 & 41.0 & 12.5 & 2712 & 50 & 50 & 53 & 39,807 \\
\hline
\end{tabular}

Source: calculated using linear programming with data gathered with faculty and personnel office questionnaires and from college records. Round-off error is present. 
is the least cost method to increase output. Estimates are given for the number of PTF that is necessary to replace the FTF. Using College $A$ as an example, increasing productive hours but remaining at the same total cost can be achieved by decreasing the FTF from 134 to 133 and

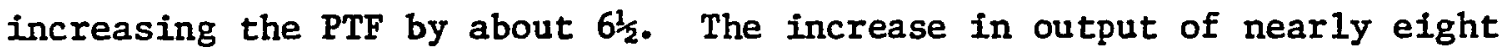
productive hours is the result of an output decline of 42 productive hours by decreasing the FTF by one member, and an increase of 49.8 productive hours by the PTF. The net gain of 7.82 productive hours results.

TABLE XXXV

OPTIONS TO INCREASE OUTPUT: PROBLEM VIEWED AS OUTPUT MAXTMIZATION

If Decrease FTF by One Member If Increase Budget by $\$ 100$

\begin{tabular}{|c|c|c|c|c|}
\hline College & $\begin{array}{l}\text { Additional } \\
\text { PTF to } \\
\text { Replace } \\
\text { FTF }\end{array}$ & $\begin{array}{l}\text { Resulting } \\
\text { Increase in } \\
\text { Productive } \\
\text { Hours* }\end{array}$ & $\begin{array}{l}\text { Number of } \\
\text { Additiona1 } \\
\text { PTF }\end{array}$ & $\begin{array}{l}\text { Increase in } \\
\text { Productive } \\
\text { Hours }\end{array}$ \\
\hline A & 6.5 & 7.8 & 1.0 & 7.7 \\
\hline B & 8.4 & 19.7 & 1.3 & 9.5 \\
\hline C & 7.3 & 50.7 & 1.1 & 13.2 \\
\hline
\end{tabular}

Source: calculated using linear programming with data gathered with faculty and personnel office questionnaires and from college records.

*The increase in productive hours results with no increase in total cost.

A second marginal decision-making tool that is provided by the model furnishes information on the maximum output option if the college wishes to increase its budget. In all cases, the maximum output is 
achieved by increasing the PTF. A $\$ 100$ increase in the budget allows College C, for example, to hire slightly over one more PTF who will supply 13.2 more productive hours. For the same $\$ 100$, the college could afford to hire approximately 14 percent of one FTF who will produce approximately eight more productive hours. Clearly the PTF provide more output for each dollar spent.

If the model is viewed as minimization of total cost as shown in Table XXXVI, the problem provides information on net cost savings if the college decreases its FTF and increases its PTF. At College B, a savings of $\$ 207.14$ per week results if the college decreases its FTF by one member and increases its PTF by approximately six members. A decrease in the FTF from 77 to 76 saves the college $\$ 669.81$ and an increase of its PTF from 86 to almost 92 costs $\$ 462.90$. This saving results from a shift in the number of faculty in each group; output remains at 4041 productive hours.

TABLE XXXVI

OPTIONS TO SAVE COSTS: PROBLEM VIEWED

AS COST MINIMIZATION

If Decrease. FTF by One Member If Add 100 Productive Hours

Additiona1 PTF Resulting Number of Add- Resulting

College to Replace FTF Cost Savings*
tional PTF Cost Increase

$\begin{array}{rrrrr}\text { A } & 5.5 & \$ 104.48 & 13 & \$ 1336 \\ \text { B } & 5.8 & 207.14 & 13 & 1052 \\ \text { C } & 3.3 & 384.75 & 8 & 759\end{array}$

Source: calculated using linear programming with data gathered with faculty and personnel office questionnaires and from college records. hours.

*The cost savings results with no decrease in total productive 
Viewing the problem as minimization of total cost, the model provides a second option to save costs if the colleges wish to increase output by, say, 100 productive hours. The model states that for the same cost, the PTF provide the college a greater amount of output than would the FTF. At College B, 13 more PTF must be hired to produce an additional 100 more productive hours, at a cost of $\$ 1052$. If the FTF were hired to produce 100 more productive hours, it would take slightly more than two at a cost of $\$ 1522$; therefore, the college is clearly better off hiring PTF to produce the additional 100 productive hours. These numbers provide additional knowledge of the cost of the FTF in terms of the PTF and a knowledge of the more efficient method to increase output or spend additional dollars. The additional knowledge of the cost of these decisions does not necessarily mean that the college will always choose PTF over FTF. Marginal analysis provides information on the cost of the decisions, but the final decision-making process in the college may involve additional non-economic goals. (See Chapter VIII.)

\section{CONSTRAINT ADJUSTMENT BETWEEN FACULTY GROUPS}

An important objective of the model is to analyze the changes in output or cost if the college adjusts the inputs. In other words, the model allows observation of the cost of making adjustments in its input mixture from the current status to one in which the mixture of FTF and PTF is different.

The college may choose to adjust the input mixture to conform to changes in its twin goals of providing stability by employing FTF and providing flexibility with its use of PTF. For this as well as other reasons, including budget and output requirements, the college may wish 
to employ a different mix of its inputs.

The cost can be viewed as an increase or decrease in either the budget or the productive hours, depending on how the model is instructed to make decisions. If the model is instructed to maximize output subject to a budget constraint, then the dollars spent act as a constraint while output changes in response to changes in the input constraints. Alternatively, if the situation is viewed as a cost minimization problem, then the output remains constant while costs change in response to input constraint adjustment.

Five adjustments are considered: first, removal of the FTF constraint; second, adjustment of the constraint to tenured FTF; third and fourth, adjustment of the PTF members to 50 percent and 25 percent of those currently employed; and fifth, elimination of the PTF. The results are shown in Tables XIIX through LIV of Appendix H.

In the first case, elimination of the FTF constraint results in the college hiring all PTF because more output is provided for the same cost, or the same output can be maintained for a smaller cost than if the colleges hired FTF. The savings to the college may be dramatic as in the case of College $\mathrm{C}$ which, at the same output, can reduce costs nearly 50 percent (see Table LI), or for the same cost and the same action, can increase output nearly 93 percent (Table LIV). The savings can be less dramatic as in the case of College $A$; an all PTF results in a cost savings of 12.4 percent (Table LXLX), or a 3.5 percent increase in output for the same budget (Table LII).

The second adjustment, a less dramatic action by the calleges, is adjusting the model constraint to tenured FTF. This action results in 
the elimination of all FTF who are non-tenured and reduces the FTF approximately three to nearly eight and one-half members, depending on the college. This action decreases costs at each of the colleges by from 2.5 percent to 8.6 percent if the problem is viewed as cost minimization, or increases output by from 7.7 percent to almost 17 percent if viewed as output maximization. (See Tables XLIX through LIV.)

The above two possible actions by the college reduce costs because of the relationship between the FTF and PTF: in all cases the PTF cost less to employ for the same production of output. For example, if College $A$ is examined, it is not clear that the PTF are more productive and cheaper than the FTF, because the FTF cost the college $\$ 665.53$ for 42 productive hours while the PTF cost $\$ 102.86$ for 7.7 productive hours. The cost of faculty for one productive hour of work is shown in Table XXXVII. At College A the FTF cost $\$ 15.85$ for one productive hour while the PTF cost $\$ 13.36$ for each productive hour. While one FTF is more productive than one PTF, the FTF are shown to be relatively more expensive based on the value of the productive hours. For Colleges B and C the same relationship is true; one. FTF is more productive than one PTF but the PTF are relatively less expensive than the FTF when the cost per productive hour is examined. At College B the FTF cost $\$ 15.22$ and the PTF cost $\$ 10.50$ for each productive hour, while at College $C$ the FTF cost $\$ 16.97$ and the PTF cost $\$ 7.59$ for each productive hour. 
TABLE XXXVII

COST FOR EACH PRODUCTIVE HOUR BY FACULTY

College

A

B

C
Fu11-time Faculty

$$
\$ 15.85
$$

15.22

16.97
Part-time Faculty

$\$ 13.36$

10.50

7.59

Source: derived from data gathered using faculty questionnaire.

Because the model is linear, if the constraint which requires a minimum number of FTF is moved or totally removed, the results of the model show that the most output which can be produced at the specified cost is where the fewest FTF are employed and the PTF produced the rest of the output.

The following two alternatives show cost or output changes when the PTF is decreased to 50 percent and to 25 percent of its current size. The result in each case is an increase in the total cost or a decrease in the total output produced by the college. This is the obvious result of the linear programming model in which all solutions are corner solutions; as the constraint is moved, the solution also moves to the least expensive combination of inputs.

The results for the cost minimization problems are shown in Tables XLIX, L, and LI of Appendix H. At College A, the cost of changing to 50 percent of its current PTF has the effect of decreasing the PTF from 229 to 155 and increasing costs by over $\$ 2000$, a nearly 2 percent increase in total cost. If the PTF are reduced to 25 percent of its current size, this action increases costs by nearly 3 percent. These cost in- 
creases represent a movement away from the PTF to the relatively more expensive FTP.

The last alternative is a shift to all FTF, completely eliminating the PTF employed by the college. If the problem is viewed as minimization of total cost, the cost increase varies from 3.9 percent to 5.3 percent at College $A$ and $B$ respectively to 15.5 percent at College C. (See Tables XLIX, L, and LI.) If the problem is viewed as output minimization, the output produced decreases if the college uses only FTF. At College $B$, the output produced decreases by 5 percent while output produced decreases by approximately 13.5 percent at both Colleges $\mathrm{A}$ and $\mathrm{C}$. (See Tables LII, LIII, LIV.)

The impact at the college is the result of the tradeoff at the resspective college between FTF and PTF and the relative number of each group employed currently at the college. Because the model is linear, the tradeoffs remain the same between the two faculty groups. These tradeoffs, shown in Tables $X X X V$ and $X X X V I$, list the marginal cost savings, if the problem is viewed as cost minimization, or the marginal production increase, if the problem is viewed as output maximization, of options the college may consider.

\section{ADJUSTMENT OF BUDGET CONSTRAINTS}

The community college faces the possibility of a budget increase or decrease from a number of different sources: legislative mandate, shifts or changes in enrollments, the potential increase or decrease in local, state, or federal tax revenues, or loss or recefpt of private or governmental grants. Changes in the amount of funding cause the bud- 
get to increase or decrease, thus resulting in actions by the college to compensate for these changes.

The purpose of this section is to examine the impact on the employment of full and part-time instructors if the budget constraint is increased or decreased by whatever cause. This problem can only be examined by use of the output maximization model because only this model is set up to allow adjustment of budget amounts.

Changes in the budget allow the colleges to produce more or less output. It was theorized earlier (in Chapter II) that the college would treat the PTF as a variable input and the FTF as a fixed input. Each college acts according to the theory: as the budget is increased, the college produces more output; however, it uses PTF to produce that addtional output. Alternatively, if the budget is decreased, the college produces less output, hiring fewer PTF and the same number of FTF.

Results are shown in Appendix I, Tables LV, LVI, and LVII. Using College $A$ as an example, a budget increase of 10 percent allows the college to increase its total productive hours from 7391 (at current status) to 8235 , or by over 11 percent. To increase productive hours, the college employs more. PTF, 448 rather than 229, and the same number of FTF; thus the increase in productive hours is the result of an increase in employment of PTF. A decreased budget results in PTF employed and less output produced. (See Table LV for College A.)

The increase of decrease in budget results in a larger percentage change in output than in cost. For example, a 10 percent change in the budget results in a 11.4 percent change in output at College A. This greater change in output occurs whether the budget increases or decreases 
and is the result of the earlier discussed relationship between the cost and productivity of the FTF and PTF. Because the PTF produce more output for the dollars spent, a 10 percent change in the budget can be expected to yield a greater than 10 percent change in output if the college either hires or eliminates PTF rather than FTF.

An interesting application of a budget change is the examination of how far a budget can be decreased before the college must completely eliminate its PTF. This figure is important from the standpoint of the college because it gives an idea of the amount of flexibility at each college. That is, it tells how far a budget decrease can go before the college must begin to adjust its fixed factor of production. At College A, the PTF are eliminated with a budget decrease of over 20 percent. At Colleges $B$ and $C$ the variable factor is eliminated with approximately 12 percent decrease in the budget. (See Table XXXVIII.)

TABLE XXXVIII

BUDGET DECREASE LTMITS

\begin{tabular}{|c|c|c|c|c|}
\hline \multirow[b]{2}{*}{ College } & \multicolumn{2}{|c|}{$\begin{array}{l}\text { Necessary to Eliminate } \\
\text { all PTF }\end{array}$} & \multicolumn{2}{|c|}{$\begin{array}{l}\text { Necessary to Eliminate } \\
\text { Al1 PTF and Non-tenured FTF }\end{array}$} \\
\hline & $\begin{array}{l}\text { Amount of } \\
\text { Budget }\end{array}$ & $\begin{array}{l}\text { Percent } \\
\text { Decrease }\end{array}$ & $\begin{array}{l}\text { Amount of } \\
\text { Budget }\end{array}$ & $\begin{array}{l}\text { Percent } \\
\text { Decrease }\end{array}$ \\
\hline A & $\$ 89,181$ & $20.9 \%$ & $\$ 71,212$ & $31.7 \%$ \\
\hline B & 51,575 & 11.7 & 35,500 & 60.7 \\
\hline C & 34,793 & 12.6 & 28,530 & 28.3 \\
\hline
\end{tabular}

Source: calculated using linear programming with data gathered with faculty and personnel office questionnaires and from college records. Refer to Tables XXX, XXXI, and XXXII for data upon which results were derived. Round-off error is present 
If the budget decrease is greater than the above figures then the college must begin to eliminate the FTF. At College A, a 32 percent decrease in the budget will eliminate not only the PTF but also all the non-tenured FTF. At College C, a 28 percent decrease will eliminate the non-tenured FTF as well as the PTF while at College $B$ an over 60 percent budget decrease is necessary to eliminate these faculty.

If budgets decrease, the colleges could choose to eliminate some PTF and some FTF rather than all PTF. This alternative would allow the colleges to employ the balance of faculty they feel necessary to fulfill their twin goals of flexibility and stability. Thus, if the budget decreased by 20 percent, College A could eliminate some of the nontenured FTF positions while retaining part of its PTF staff, rather than eliminating all its PTF. These are policy decisions which are made only by college administrators; however, cost considerations may be important in the decision process.*

ADJUSTMENT OF TOTAL PRODUCTTVE HOURS

The comminity college may find it necessary to adjust the total hours produced in order to accommodate shifts in enrollments, changes in staff requirements, or other internal or external changes. The colleges may wish to accommodate these changes by adjusting the total hours produced, then observing the increase or decrease in total cost and in employment of faculty.

The adjustment process as described in this section is similar to the previous section which described budget adjustments, except that in

* See expanded discussion on non-economic goals in Chapter VIII. 
this case the total productive hours are being adjusted and the budget is allowed to respond. In the previous section total productive hours changed as a result of budget adjustments. Examining the adjustment of total productive hours can be viewed only in the model of minimization of total cost.

In order to produce more hours in the short run, the college must hire more faculty, thus the cost to produce the output increases. The college adjusts to changes with adjustments in the variable factor of production, the PTF. These PTF produce more output for less cost than the FTF, thus the hours produced increase (or decrease) faster than the cost.

Appendix J, Tables LVIII, LIX, and LX show that the colleges adjust output by using the PTF. If the college wishes to produce more output, it employs the same number of its fixed factor, the FTF, and more of its variable factor, the PTF. At College A, for example, approximately 96 more PTF are required to produce 10 percent more output and 192 PTF are required to produce 20 percent more output. (See Table LVIII.) As can be seen from the tables, the increase in employment of PTF is greater than the increase of budget. Each PTF is less productive than each FTF; however, the cost of each productive hour is less for the PTF than for the FTF. Thus the total cost of producing the 10 percent more output increases by less than 10 percent. In the case of College $B$, the cost increases by 7.3 percent while the cost of 20 percent more output costs College B 14.5 percent more. (See Table LIX.)

A decrease in productive hours acts in a similar way: the cost of producing less output changes by a smaller percentage than the percentage 
change in output. Thus, a 10 percent decrease in productive hours does not cost the college 10 percent less but 5.3 percent less, in the case of College C. A 20 percent decrease in productive hours costs the same college approximately 11 percent less. (See Table LX.)

As was pointed out earlier, the college adjusts productive output by adjusting employment of PTF. As the productive hours increase or decrease, the employment of PTF increases or decreases. If the college decides to decrease productive hours, it decreases its variable factor of production, the PTF. There is a point when the variable factor is completely eliminated; for Colleges $A$ and $C$, the PTF are eliminated with a 24 percent decrease in output; for College B, a 16 percent decrease in output eliminates the PTF. (See Table XXXIX.) If the college chooses to produce even less output than can be produced by its current FTF, the college must begin to eliminate its fixed factor of production, its FTF. Table XXXIX also shows the percentage decrease in productive hours necessary to eliminate the non-tenured FTF, as shown in columns three and four. These adjustments allow for a much larger decrease in productive hours: approximately 40 percent for all colleges. 
TABLE XXXIX

PRODUCTIVE HOURS DECREASE LIMITS

\begin{tabular}{cccccc} 
& $\begin{array}{l}\text { Necessary to Eliminate } \\
\text { All PTF }\end{array}$ & & \multicolumn{2}{l}{$\begin{array}{l}\text { Necessary to Eliminate } \\
\text { All PTF and Non-tenured FTF }\end{array}$} \\
\cline { 5 - 6 } $\begin{array}{l}\text { Number of Pro- } \\
\text { ductive Hours }\end{array}$ & $\begin{array}{l}\text { Percent } \\
\text { Decrease }\end{array}$ & & $\begin{array}{l}\text { Number of Pro- } \\
\text { ductive Hours }\end{array}$ & $\begin{array}{l}\text { Percent } \\
\text { Decrease }\end{array}$ \\
\cline { 5 - 6 } A & 5628 & $23.8 \%$ & 4494 & $39.2 \%$ \\
B & 3388 & 16.2 & 2332 & 42.3 \\
C & 2050 & 24.4 & 1681 & 38.0
\end{tabular}

Source: calculated using linear programming with data gathered with faculty and personnel office questionnaires and from college records. Refer to Tables XXX, XXXI, and XXXII for data upon which results were derived. Round-off error is present.

It should be noted that the point where the PTF are eliminated and the point where the PTF and the non-tenured FTF are eliminated are the same whether the college is adjusting total productive hours or adjusting its budget constraint. That is, if College A views the problem as an output maximization problem and wishes to produce only the output which the FTF can produce, the output produced is reduced to 5628 productive hours at a cost of $\$ 89,181$. (See Table XXXVIII.) This point corresponds exactly to the problem as viewed as cost minimization in which the college reduces costs to the minimum which the current FTF produce. The budget is $\$ 89.181$ at which the college produced 5628 hours. (See Table XXXVIII.) This result is a natural consequence of the two models' correspondence with one another; each FTF at College A costs $\$ 665.53$ and produces 42 productive hours, so that point where only the current FTF are employed is the same whether the college views the model as an output maximization or a cost minimization problem. 
CHAPTER VII

\section{RATIO ADJUSTMENTS WITH LINEAR PROGRAMMING}

This chapter examines the effects of two additional changes: a change in the ratio of costs and a change in the ratio of productivity. The cost and productivity ratio adjustments are made by use of the same models discussed earlier: cost minimization and output maximization. The results of the analysis are various employment patterns, output, and costs, as is the case of the analysis of the previous chapter.

In contrast to the simulations of Chapter VI which examined the impact of increases or decreases the total budget, total productive hours, and changes of the constraints of the total number of faculty in each group, all adjustments in this chapter are ratios between the two groups. In other words, the cost or productivity of one group is changed while that of the other group remains constant.

Because ratios between the groups are allowed to change, marginal analysis plays an even more important role than it did in the previous chapter. Tables XXXV and XXXVI illustrated the cost of various options the college faces: options to increase output if the problem is viewed as maximizing output (see Table $\mathrm{xXXV}$ ), and options to save costs if the problem is viewed as minimizing cost (see Table XXXVI). In the previous chapter, the cost of these options remained constant throughout the analysis because the cost and productivity ratios between the two faculty groups remained constant. 
In this chapter, these options change as the ratios between the two groups change. The questions asked are whether changes in the ratio of cost or productivity influence the behavior of the college. This section presents a discussion of the effects of changes of the relative cost of the two factors of production. In other words, examination is made of the impact of the change in the cost of one factor while cost of the other factor remains constant.

COST RATIO ADJUSTMENTS

There are a number of reasons why the cost of one factor might increase while the cost of the other does not. For example, increases in human resource investment may result in greater productivity and thus higher wages among the FTF but not the PTF. Thus, the FTF may have an incentive to increase their educational attainment because they receive a monetary reward for increased investment. Earlier analysis showed that PTF are less likely to receive a monetary reward from the college for increased investment. (See productivity section in Chapter v.) Thus, wages of the FTF may increase relative to the PTF.

In addition, the FTF are unionized and form an internal labor market, thus the cost of these faculty may increase as a result of interaction between the FTF and the administration. Even though there may be a surplus quantity supplied of FTF which might otherwise depress the FTF wages, the union or the internal labor structures may be able to maintain or even increase the wages of the FTF.

The policy which regulates the salary offered to the PTF is more subject to the external influences of supply and demand. Although the 
wage offered appears to be somewhat rigid in a downward direction, downward wage adjustments occur if the PTF wages remain unchanged while other wages increase. The wages of PTF may increase relative to the wages of the FIF if the college finds the quantity supplied of the PTF is inadequate compared to the quantity demanded. Other supply and demand shifts can result in shifts in the wage rate.

As an Output Maximization Problem

If the college's goal is to maximize output, it establishes a total budget as a constraint, then determines the maximum output it can produce with this cost. This involves adjusting the number of employees. Because the FTF is the fixed input when costs increase, the college has less to spend, and the employment of the variable factor, the PTF, decreases. Employment of the PTF also decreases if the cost of the PTF increases; however, if the cost of the PTF or the FTF decreases, the college hires more PTF because these cost changes have effectively released more dollars which allow the college to increase the number of its variable factor.

Appendix $K$, Tables LXI, LXII, and LXIII show the cost ratio adjustments viewed as output maximization problems. The current status is listed in the first row and shows the current cost and number of each faculty group and total productive hours. A number of alternate actions may occur: FTF or PTF costs may increase, or the FTF or PTF costs may decrease. If the college wishes to maximize output, it adjusts its employment of faculty (columns three and four) and the total productive hours (column five). The resulting change in total productive hours is shown in columns six and seven. 
Using College B as an example, the current number of productive hours is 4041 , but as the cost of either FTF or PTF is increased, employment of the PTF decreases. Because less input is hired, the number of productive hours also decreases. If, for example, the cost of the FTF increases to 10 percent, from $\$ 669.81$ to $\$ 736.79$, the PTF employment falls from 86 to 21 and the number of productive hours falls from 4041 to 3550 . Employment of PTF and productive hours also fall when the cost of the PTF Increases. The opposite happens when the cost of either factor decreases: the employment of the PTF and the total productive hours increase. (See Table LXII.)

As can be seen from Tables LXI, LXII, and LXIII, an increase in the cost of FTF has a greater impact on output and employment of PTF than an increase in the cost of PTF. This differential impact is due to two factors: first, the college finds it necessary to hire fewer PTF if the cost of either FTF or PTF increases. The relative size of the FTF in terms of contribution to productive hours and total cost is much larger than the PTF. The same percentage change of FTF cost causes a much larger impact on employment and output than the same percentage cost change by the PTF. At College $\mathrm{B}$, for example, the total cost to the college of the FTF is over $\$ 50,000$, while the total cost of the PTF is less than $\$ 7,000$. Thus, a 10 percent increase in the cost of the FTF totals over $\$ 5,000$ and is much greater than a 10 percent increase in the PTF of $\$ 700$.

The second reason is due to the shift in relative input employment. If the cost of the FTF increases, the college responds by hiring fewer PTF members who are relatively more productive than the FTF. In 
other words, a shift to more FTF and fewer PTF causes total productive hours per dollars worth to decrease; the college finds that as the number of PTF falls relative to FTF, total productive hours fall. At College B, if the cost of FTF increases by 10 percent, the employment of PTF falls from 86 to 21 and productive hours fall by 12.2 percent which is entirely due to a decrease in contribution by PTF.

For the same two reasons, a decrease in the cost of the FTF increases productive hours by a greater percentage change than a decrease in the cost of PTF. A decrease in the cost of either factor of production allows the college to hire a greater number of the relative1y more productive factor; however, the reduction in the cost of FTF has a greater impact than the same percentage reduction among the PTF. As discussed in Chapter VI, there are a number of options by which the college can increase output. These options remained constant in the linear models of the last chapter, but would vary if the cost of one faculty group changed while the cost of the other faculty group remained constant. These alternatives are shown in Appendix $\mathrm{K}$, Tables LXIV, LXV, and LXVI and illustrate two options: first, if the college wishes to increase productive hours but maintain the current budget, it can decrease the FTF by one member (column one) and increase the PTF by a specified number (column two). However, the number of PTF that the college can hire to replace its FTF member will vary, thus the resulting increase in productive hours will vary.

For example, if College $A$ wishes to Increase output, it can decrease 1ts FTF by one and increase its PTF by six and one-half. Output increases by 7.8 productive hours. If the cost of the FTF increases 
by 10 percent, the college responds by hiring fewer PTF. In addition, the model indicates that since the PTF cost has remained constant, more PTF can be hired for one FTF (7.1 members instead of 6.5$)$ and the number of additional productive hours wiich the PTF contribute increase to 12.8. (See Table LXIV.) When the PTF cost decreases relative to the FTF, the tradeoffs change in the same direction as the above analysis of a FTF cost increase.

If the cost of FTF decreases or the cost of PTF increases and the college wishes to increase output, the cost of the option to increase productive hours changes. The increase in the amount of output, resulting from a decrease by one FTF and increase in the PTF, diminishes if the cost of the PTF Increases or the FTF decreases because the PTF are relatively more expensive. The cost of shifting away from FTF thus becomes greater.

The next two columns (three and four) of Tables LXIV, LXV, and LXVI illustrate what action is the most efficient if the college increases its budget by $\$ 100$. The number of productive hours which the college can expect from a budget increase of $\$ 100$ changes as the PTF costs change; however, it will not respond to changes in the FTF cost adjustments as long as the PTF produce the most output for the least cost.* If the cost of PTF changes in the output maximization problem, and the cost of PTF increases, the college hires fewer PTF. In the case of College A, if PTF cost increases 10 percent, the college hires 88 rather than 97 PTF. The number of productive hours which the college

*FTF costs are not shown in these tables in order to simplify presentation of the tables. 
obtains from a $\$ 100$ budget increase falls from 7.5 to 6.8 . If PTF

costs decrease, the college can afford to hire more PTF, and there will be an increase in productive hours.

An interesting extension of the cost ratio adjustments is examination of the changes in the ratios which result in the model's selection of an all FTF and no PTF. There are three circumstances where this might occur: first, the cost of the FTF increases; second, the cost of FTF decreases; and third, the cost of PTF increases.

In the first circumstance, if the cost of the FTF increases substantially, there is a point at which the college could afford to hire only FTF and no PTF. The PTF would be completely eliminated if extreme circumstances dictated, because (using the assumptions of this model) the college allocates only specific funds to the faculty costs and the cost increases would eliminate additional dollars for PTF. The college may choose to continue to hire some PTF under the circumstances described above, by eliminating all or some non-tenured FTF. At College C, for example, instead of employing $50 \mathrm{FTF}$ at a cost of $\$ 796.13$ each and no PTF for a total cost of $\$ 39,806.50$, the college could hire only tenured FTF for a cost of $\$ 32,641.33$. With the $\$ 7,000$ difference, the college could hire 76 PTF at the cost of $\$ 94.84$ each. This action results in more output if the college hires a combination of $41 \mathrm{FTF}$ and $76 \mathrm{PTF}(2,625$ productive hours $)$ than if it hires the original 50 FTF and no PTF (2,050 productive hours).

There are two additional cases in which the college hires only FTF. Both occur because the relative cost of the FTF is less than that of the PTF. These occur if, first, the cost of FTF decreases such that 
the output produced by the FTF is cheaper than that produced by the PTF, and second, the cost of the PTF increases such that output produced by the PTF is relatively more expensive than the FTF. These two points have been identified as "breakpoints" as shown on Table XL and can be Identified further as those points at which the productivity-cost advantage of hiring PTF over FTF becomes negative.

TABLE XL

\section{BREAKPOINTS OF COST RATIO ADJUSTMENTS: PROBLEM} VIEWED AS MINIMIZATION OF TOTAL COST*

College

A

B

C

FTF Cost Decrease

$15.7 \%$

36.6

55.3
PTF Cost Increase

$18.7 \%$

45.0

122.9

Source: calculated using linear programming with data gathered with faculty and personnel office questionnaires and from college records. Refer to Tables XXX, XXXI, and XXXII for data upon which results were derived. Round-off error is present.

*A "breakpoint" is defined as that point where the cost of the FTF productive hours becomes less than the cost of the PTF productive hours.

\section{As a Cost Minimization Problem}

Cost ratio adjustments can also take place in the model when viewed as a cost minimization problem as presented in this section. While the basic concepts of the two problems are the same, the outcome differs somewhat bacause the output maximization model views the problem as maximizing output with a given total cost, while the cost minimization model (of the previous section) views output as given and allows cost to vary.

A result of this model is that the college continues to hire the 
same ratio of FTF to PTF within a relatively wide range. For example, if the cost of either the FTF or the PTF increases by 10 percent, the costs to the college increase but the institution continues to hire the same number of each type of faculty. This result is not surprising because the goal of this model is to produce a specific amount of output, 7,391 productive hours in the case of College $\mathrm{A}$, and as long as cost ratios between the two groups are not extreme, and if the college chooses to employ a minimum of $134 \mathrm{FTF}$, then it finds it can minimize the cost of producing those 7,391 productive hours by employing exactly 134 FTF and 229 PTF. (See Table LXVIII in Appendix L.)

Appendix L, Tables LXVII, LXVIII, and LXIX show the results of the linear programing models for the problems as viewed as minimization of total cost. With changes in the cost ratios between the two faculty groups (columns one and two), employment remains constant (columns three and four) as long as the cost of one group does not change such that the FTF productive hours are cheaper than the PTF productive hours. In those changes, the model selects all FTF and no PTF. (See Table LXVII, actions 3 and 8.)

The total cost of producing output is listed in column five, and shows that as the cost of the faculty groups change, total cost changes. If the cost of the FTF increases by 10 percent, the total cost to College A increases by 7.9 percent, from $\$ 112,745$ to $\$ 121,663$. Employment of the FTF and PTF does not change because the college goal is to continue to produce 7,391 productive hours. The same result occurs if PTF cost increases: a 10 percent wage increase from $\$ 102.86$ to $\$ 113.15$ causes total cost to the college to increase by 2.1 percent from 
$\$ 112,745$ to $\$ 115,103$. Employment does not change and the college continues to produce the same number of hours.

The results of a decrease in the cost of either factor of production are the same as described above; however, in this case total costs decrease.

The effect of a cost increase or decrease of FTF has a greater impact on total cost than a similar cost change for PTF. The FTF contribute relatively more productive hours and cost more total dollars than the PTF. This reason is the same as cited earlier in the output maximization model: a 10 percent increase in the cost of the FTF $(\$ 89,181.02 \times 10$ percent $=\$ 8.918 .10)$ has a greater impact on the total cost than a 10 percent increase in the cost of PTF $(\$ 23,554.94 \times 10$ percent $=\$ 2,355.49)$.

The college faces a number of options to save costs or increase output similar to those described in the previous section. The options are shown in Tables LXX, LXXI, LXXII. If the college wishes to maintain current output levels but save costs, it could decrease its FTF by one and increase its PTF (column one). The resulting cost savings are listed in column two and decrease as the FTF or PTF becomes more expensive and increase as either faculty group becomes less expensive.

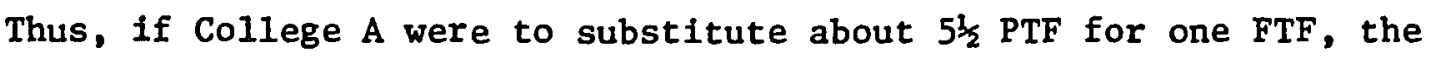
cost savings is slightly over $\$ 100(\$ 104.48)$; however, if the cost of the FTF were to increase by 10 percent, then the same number of PTF could be substituted by FTF at a savings of $\$ 171.03$. The savings decrease if the cost of the FTF decreases or the PTF cost increases. 
Although the model indicates that the college will continue to hire a minimum number of FTF and the rest of its faculty as PTF, the college might consider hiring more FTF if the savings of substituting PTF for FTF increases as the result of a FTF cost decrease or PTF cost increase. Alternatively, the college might consider reducing the minimum number of FTF it is willing to hire if the cost savings increase as the result of a FTF cost increase or PTF cost decrease. Tables LXX, LXXI, LXXII also show the cost of increasing output by 100 productive hours. The number of additional faculty necessary are shown in column three and the resulting savings is shown in column four. The cost shifts only if PTF costs increase or decrease and change directly with the PTF cost shifts; if the PTF cost increases by 10 percent, the cost of producing 100 more hours with the PTF increases by 10 percent.

As with the output maximization model, the cost minimization problem also has breakpoints. In this model, however, the gradual decrease in employment of the PTF as cost increases is replaced by a sudden shift from the employment of some FTF and some PTF to all FTF. In other words, the ratio employed of FTF to PTF remains the same at a11 cost changes until the breakpoints are reached, then the college completely eliminates its PTF in favor of its FTF. The breakpoints are listed in Table XLI.

These breakpoints are the same as described earlier in this section; however, they occur as the result of two rather than the aforementioned three causes: first, the FTF cost decreases, and second, the PTF cost increases. In either case, the breakpoints occur when output 
produced per dollar spent on PTF is greater than that spent on FTF, so the college would choose to hire all FTF rather than a combination of FTF and PTF.

\section{TABLE XLI}

BREAKPOINTS OF COST RATIO ADJUSTMENTS: PROBLEM VIEWED AS MAXIMIZATION OF OUTPUT*

College

A

B

C
FTF Cost Decrease

$15.7 \%$

36.8

55.3
PTF Cost Increase

$18.7 \%$

44.8

123.8

Source: calculated using linear programming with data gathered with faculty and personnel office questionnaires and from college records. Refer to Tables XXX, XXXI, and XXXII for data upon which results were derived. Round-off error is present.

*A "breakpoint" is defined as that point where the cost of the FTF productive hours becomes less than the cost of the PTF productive hours.

The breakpoints are more a function of a linear model than an indication of the actions of a college. The reaction to changes in the cost ratios would be more gradual as the college calculated the differential rather than a sudden shift as the model results indicate.

\section{PRODUCTIVE HOUR RATIO CHANGES}

This section deals with changes in productive hours between FTF and PTF. The importance of this section is twofold. First, there is a possibility that productivity may change; for example, the FTF or the PTF may become either more or less productive due to a number of factors: increased or decreased education levels among the faculty, higher or lower quality experience backgrounds, or the respective groups may work 
more or fewer hours than they are currently employed.

Second, there may be a tendency for the FTF to become better educated relative to the PTF. Part of the service faculty members provide is keeping abreast of one's discipline. FTF may have more time to engage in such activities than PTF because FTF specifically allocate working time to such activities, more so than the PTF. (See Appendix B.) Thus, the FTF may have a tendency to increase their human resource investment relative to the PTF.

This section is similar to the previous section which dealt with changes in the cost ratios between the two faculty groups; however, the productivity changes introduce modifications in the assumptions of hours worked and productivity of those hours, rather than the cost of the faculty. The cost ratio section examined responses by the college to changes in the cost of one group while the cost of the other group remained constant. The productivity section parallels the cost section in that it examines changes in the productive hours of one group while those of the other group remain constant. Both sections use the two models of output maximization and cost minimization to analyze behavior response by the college.

\section{As a Cost Minimization Problem}

The productive hours adjustments in the model can be viewed as a cost minimization problem in which the college is viewed as determining a total output goal, then minimizing the total cost of achieving this goal. The college adjusts the number of faculty hired as the productivity of the two groups changes because the college needs a greater or 
lesser number of faculty to attain the goal of a specific amount of output.

Tables IXXIII, IXXIV, and IXXV in Appendix $M$ are similar to the earlier tables of Appendices $K$ and $L$, in the previous sections presenting cost ratio adjustments. The productive hours ratio adjustments are presented as a problem of minimization of total cost, thus columns one through four show the productive hours of FTF and PTF and the number employed of each group. The results of the linear programing show that adjustments of the number of PTF (column three) result as productive hours of one group change. The cost of providing the total output changes.

Given the FTF constraints, productive hour increases of FTF or PTF result in fewer of the variable factor hired. If the productive hours of the FTF or PTF decrease, the college hires fewer PTF. If College $A$ is used as an example, the current status shows 42 FTF productive hours and 7.7 PTF productive hours. The employment of FTF is 134 and that of PTF is 229. If the productivity of the FTF increases by 10 percent to 46.2 , the college hires 156 PTF instead of 229 and total cost decreases by $\$ 7,518$ or 6.7 percent. At this decreased total cost and fewer total faculty, the college is able to maintain 7,391 productive hours because the FTF are now more productive. The same response occurs if FTF productive hours increase. (See Table IXXIII.)

If the productivity of either the FTF or PTF at College A decreases, the college finds it necessary to hire more PTF, because in order to produce 7,391 productive hours, College A must employ more of Its variable factor, the PTF, to compensate for the decrease. 
There is a differential impact of a 10 percent decrease in productivity of FTF when compared to a 10 percent decrease in the productivity of the PTF. The reason for this is similar to the reason why the cost ratio changes have differential impact on total cost; the PTF are a relatively smaller group in terms of total amount produced than the FTF. At College B, for example, a 10 percent decrease in the productive hours of PTF causes a 1.4 percent increase in costs while the same decrease in FTF productive hours causes a 6.1 percent increase in total costs. The FTF contribute 3,388 productive hours while the PTF contribute 654 productive hours; therefore, a 10 percent reduction in the FTF productivity $(3,388 \times 10$ percent $=339)$ has a much greater impact on total hours produced and hours to be replaced than a 10 percent reduction among PTF $(654 \times 10$ percent $=65)$.

Tables LXXVI, LXXVII, and LXXVIII of Appendix M show options the college can consider if it wishes to save cost or increase output. These alternate actions are: first, maintaining current output levels but saving cost by decreasing the FTF and increasing the PTF (columns one and two), and second, the more efficient method of increasing output (columns three and four).

The cost savings of substituting PTF for FTF shifts as productivity ratios change. At College $B$, for example, if nearly six PTF are substituted for one FTF, the cost savings is slightly over $\$ 200$ $(\$ 207.14)$. If the PTF productivity increases or FTF productivity decreases, the number of PTF needed to replace one FTF also decreases and the cost savings of substituting PTF for FTF increases. For example,

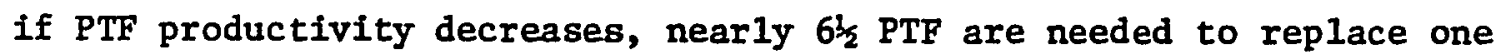


FTF, and cost savings decrease to $\$ 152.63$. (See Table LXXVII.)

The cost of producing 100 more productive hours also shifts with changes in productivity ratios.* As the productivity of the PTF increases (decreases) the cost of producing 100 more productivity hours also decreases (increases). If, for example, the productivity of the PTF increases by 10 percent, it takes seven faculty, rather than eight, to produce 100 additional hours, and the cost decreases from $\$ 759$ to $\$ 687$.

As was the case with the cost ratio changes in the previous section, the productivity changes in the cost minimization model also have breakpoints. (See Table XLII.) In this case, the college can minimize total costs by hiring FTF only when the FTF are relatively more productive than the PTF. For this model the breakpoints occur at the following places: first, the productivity of the FTF may increase, or second, the productivity of the PTF may fall relative to the FTF. In both cases custs remain the same, but the college can minimize total cost by hiring only FTF.

As was pointed out in the previous section, these breakpoints are more a function of a linear model than indicative of the reactions of a college. The college would react to the above described changes in the predicted manner, although more gradually than the model indicates.

*For simplication, the tables show the cost of increasing output with PTF only because they are usually the least expensive option. 
TABLE XLII

BREAKPOINTS OF PRODUCTIVITY RATIO ADJUSTMENTS: PROBLEM VIEWED AS MINIMIZATION OF TOTAL COST *

\begin{tabular}{ccc} 
College & $\begin{array}{c}\text { FTF Productive } \\
\text { Hours Increase }\end{array}$ & $\begin{array}{c}\text { PTF Productive } \\
\text { Hours Decrease }\end{array}$ \\
\cline { 2 - 2 } & $18.6 \%$ & $15.7 \%$ \\
B & 19.3 & 30.7 \\
C & 32.3 & 55.1
\end{tabular}

Source: calculated using linear programming with data gathered with faculty and personnel office questionnaires and from college records. Refer to Tables XXX, XXXI, and XXXII for data upon which results were derived. Round-off error is present.

*A "breakpoint" is defined as that point where the cost of the FTF productive hours becomes less than the cost of the PTF productive hours.

As an Output Maximization Problem

If the productivity changes are viewed within an output maximization model, the model is instructed to maximize the output for a given cost. As long as the productivity of the two groups remains within limits (within the breakpoints), the college employs neither more nor fewer PTF but finds that maximum output can be produced by the same ratio of FTF and PTF.

Tables LXXXIX, LXXX, and LXXXI in Appendix $N$ show the total productive hours in columns one and two and the number of faculty in columns three and four. If productive hours of either faculty group change, the total productive hours change (column five). The amount and percentage of each change from the current status are shown in columns six and seven. 
At College C, for example, if the productive hours of either FTF or PTF increase, total productive hours also increase. If there is a 10 percent increase or decrease in the productivity of the FTF, productive hours respond by increasing or decreasing by over 7.5 percent. For PTF, the response to a 10 percent change in productive hours is 2.5 percent change in total productive hours. (See Table IXXXI.)

The impact on total productive hours of a 10 percent change in the FTF (or a 10 percent change in the PTF) is due entirely to a change in the productivity of the FTF (PTF). Thus, at College C, the FTF productive hours increase of 10 percent causes total productive hours of FTF to increase by 205 which is exactly the total productive hours increase of the FTF. The total productive hours increases by less than 10 percent ( 7.5 percent) because only the FTF have contributed to increased hours, rather than both groups.

The PTF increase in productivity of 10 percent causes a smaller change in productivity than a 10 percent change among the FTF. The reasons discussed earlier in this section are applicable here; the FTF contribute a larger amount to total output than the PTF and therefore the impact of changes is greater.

If the college wishes to increase output, options available to the college are shown in Tables LXXXII, LXXIII, and LXXIV of Appendix N. While the tables show the employment of the two groups remaining constant within the actions illustrated, the alternate actions show changes in the costs. (See columns one and two.) For example, if somewhat over seven PTF are substituted for one FTF at College A, 7.8 more 
productive hours result. If the FTF become more productive or if the PTF become less productive, the productive hours increase from shifting from FTF to PTF declines. Thus, if FTF become 10 percent more productive, an increase of 3.6 hours (rather than 7.8 ) results if one FTF is replaced by $6 \frac{1}{2}$ PTF.

The number of productive hours which can be produced with an additional $\$ 100$ increases or decreases in direct proportion with PTF productivity changes (as shown in columns three and four of Tables LXXXII, LXXXIII, and LXXXIV). Using College $C$ as an example, the budget increase of $\$ 100$ allows the college to hire slightly over one PTF and to increase total productive hours by 13.2. If the PTF become more productive, the total productive hours increase; for example, it increases to 15 if the PTF become 10 percent more productive. Breakpoints also exist for this model. (See Table XLIII.) They result from two causes: first, a decrease in PTF productive hours, and second, an increase in FTF productivity. Both cause the college to hire exclusively FTF in the extreme case in which the output can be maximized by use of only FTF. The model indicates that the college reacts to productivity changes at the breakpoints only; the additional information of tradeoffs and additional costs allows the college to make decisions based on marginal changes. 
TABLE XLIII

\section{BREAKPOINTS OF PRODUCTIVITY RATIO ADJUSTMENTS : \\ PROBLEM VIEWED AS MAXIMIZATION OF OUTPUT*}

College

A

B

C
FTF Productive

Hours Increase

$49.9 \%$

44.7

123.8
PTF Productive Hours Decrease

$16.6 \%$

30.9

55.4

Source: calculated using linear programing with data gathered with faculty and personnel office questionnaires and from college records. Refer to Tables XXX, XXXI, and XXXII for data upon which results were derived. Round-off error is present.

*A "breakpoint" is defined as that point where the cost of the FTF productive hours becomes less than the cost of the PTF productive hours.

This chapter has described a number of adjustments which may occur if cost ratios or productivity ratios between the two faculty groups change. Both models examined ratio adjustments in the context of the model if viewed as maximization of total output and minimization of total cost. 
CHAPTER VIII

CONCLUSIONS AND IMPLICATIONS

This dissertation has examined the effect of costs and constraints upon the employment by urban community colleges of full-time faculty (FTF) and part-time faculty (PTF). The hypothesis that community colleges act in a rational way was examined with respect to the employment of the two groups. It was argued earlier (see Chapter IV) that the faculty are divided into two distinct labor markets, each of which has a separate supply and demand schedule. The supply for the groups can be approximated by two perfectly elastic curves. On the demand side, faculty groups are represented by a number of costs: wages, fringe benefits, and turnover costs. While the labor markets are segmented, the services performed for the colleges by the FTF and PTF are similar enough that the two groups can be considered nearly perfect substitutes.

To determine the value of the work performed by each faculty group, measurements for productivity were developed as suggested by the literature of human resource investment. The productivity measurements included background characteristics of faculty, such as education and experience. While the measurements excluded consideration of faculty characteristics which help students learn (although these characteristics may be the same as those actually used), the measurements developed follow the reward structure of college policy.

Data were gathered by two questionnaires and college records. One questionnaire was mailed directly to the two faculty groups and the 
other was sent to the personnel offices of the three colleges. The data collected included cost of the faculty groups to the college, turnover of each group, and education and experience levels of the two groups.

Using data on costs, productivity, and the constraints faced by the college, the research performed two functions: first, the decisionmaking process within the college was examined. Economic theory predicts that firms behave in a rational way, when faced by costs, productivity, and constraints, such that output will be maximized or costs minimized. The research found that the three colleges employed the optimum number of FTF and PTF and thus act in a rational way.

Second, a number of simulations examined the impact of various constraint changes, costs and productivity relationships, and total budget and total output adjustments. The purpose of the simulations was twofold: to examine the impact of various conditions upon options faced by the colleges, and to test the theory that the PTF rather than the FTF are the more variable factor of production.

The dissertation concentrated on specific, measurable economic variables and examined the decision-making process within the community college, assuming that the goal of the college is to maximize output or minimize cost. The actual decision-making process within each community college may be more complex than suggested by this dissertation. College behavior can be approximated by the microeconomic theory of minimization or maximization. However, as public institutions which are supported by tax dollars, the colleges may have goals which are noneconomic. The colleges must satisfy political demands made by a number of 
organizations and individuals, Including legislators and pressure groups. The ultimate goals of the college may include satisfying community education needs in areas which are not revenue-producing.*

Community colleges may face pressure groups which persuade the college to make decisions based on additional non-economic goals.

Those who review wage determination and wage policy at community colleges may be influenced by pressure groups. Smith (1977a, 1977b) found evidence of an upward bias of wages among public workers which she attributes to political pressure. Lawmakers and public officials must attempt to satisfy two voting groups: taxpayers and government employees. Government workers are wel1-informed on wage issues and can form a powerful political group. Taxpayers may be against wage increases which ultimately lead to a tax increase, ** but are probably not as well informed or as interested in government wage issues as the government employees.

In the past the PTF formed not only a small group of government employees but a group that was probably less interested in wage policy. There are two reasons for the growing interest in attainment of higher wages among PTF:*** first, teaching part-time is the sole occupation of many PTF who rely on this income source alone (Tuckman and Vogler 1978). In the past, many PTF were probably moonlighters. Those who

*For example, the community college may offer non-income producing programs for ethnic or minority students because it is felt that such programs will benefit the entire community.

**Wage increases can bring about a service decrease rather than a tax increase.

***This growing interest is evidenced by recent unionization of PTF. See Abel 1977, Lombardi 1975, and "Part-time PSU Faculty Pact OK'd" 1979. 
hold a full-time job and who moonlight are presumably less interested in the next increment of income than a person with a smaller income.* Second, the size of the group that teaches part-time has grown substantially in the last decade and now outnumbers the FTF (see Table. IV). Given these two characteristics, the PTF may become interested in attaining a wage increase. This common interest in a wage increase coulc unite the individual members.

The colleges currently pay the FTF a wage equal to their marginal revenue product (MRP) and the PTF a wage less than their MRP (see Chapter VI). The college attempts to pass the cost of training to the PTF because of their high turnover. If training is completely general, the PTF will benefit by being better trained after the employment experience than before, and thus will be better able to secure a higher paying position in the future. The benefits to training are probably not completely general but have elements of both general and specific training. If this is so, the PTF do not benefit from the full cost of training but only a portion of it.

The PTF may form into pressure groups (for example, unions) to attempt to gain a higher wage, that is, attempt to persuade the college to pay a wage closer to their MRP. Depending on how successful the PTF are, the wage may increase such that PTF are earning a wage closer to their MRP.

In terms of the goals of output maximization or cost minimization, a potential wage increase may or may not cause employment patterns to

*This assumes that income has a "typical" utility function and that interpersonnel comparisons of utility functions can be made. 
respond. (See Chapter VI.) Additional non-economic goals appear to favor the continued use of PTF by the colleges even if a wage increase were to be granted.*

Institutions of higher education, Including community colleges, appear to face a period of slow or zero growth because of demographic factors (Freeman 1975). This is coupled with the need by community colleges to respond to the changing community needs by providing special interest classes periodically. Where colleges previously adjusted to changing or shifting enrollments by expansion of FTF into needed academic areas, this adjustment mechanism cannot be utilized in periods of slow growth. PTF provide an adjustment to enrollment shifts and other internal and external changes which affect the college (see Chapters VI and VII) and can be expected to become a permanent part of the community college employment. The college will find it necessary to balance the goal of flexibility and cost savings with the goal of stability. The assumption was made earlier (see Chapter VI) that the college found it necessary to employ a specific number of FTF to provide stability. Further research is necessary to determine the implications of the non-economic goals of community colleges and how they influence the employment of FTF and PTF.

\footnotetext{
*Community colleges, of course, will not employ PTF at any wage.
} 


\section{A SELECTED BIBLIOGRAPHY}

Abel, Emily, "Invisible and Indispensable: Part-time Teachers in California Community Colleges," Community/Junior College Research Quarterly, Fall 1977, pp. 77-91.

Alexander, Arthur, "Income, Experience, and the Structure of Internal Labor Markets," Quarterly Journal of Economics, February 1974, pp. 63-85.

American Association of Junior Colleges. The Community, Junior, and Technical College Directory. Washington, D.C., various years.

Arrow, Kenneth, "Models of Job Discrimination," in Racial Discrimination in Economic Life, A.H. Pascal (ed.), Lexington, Mass., D.C. Heath, 1972, Pp. 83-102.

Arrow, Kenneth, "The Theory of Discrimination," in Discrimination in Labor Markets, Orley Ashenfelter and Albert Rees (eds.), Princeton, New Jersey, Princeton University Press, 1973, pp. 333.

Ashenfelter, Orley C. and Ehrenberg, Ronald G., "The Demand for Labor in the Public Sector," in Labor in the Public and Non-profit Sectors, Daniel Hamermesh (ed.), Princeton, New Jersey, Princeton University Press, 1975.

Ball, R.J. and Cyr, E.B.A., "Short-Term Employment Functions in British Manufacturing Industry," Review of Economic Studies, July 1955, pp. 179-208.

Baumol, William. Economic Theory and Operations Analysis. Second Edition. Englewood Cliffs, ivew Jersey, Prentice-Fal1, Inc., 1965.

Bayer, Alan. College and University Faculty: A Statistical Description. Washington, D.C., American Council on Education, 1970.

Beazley, Richard M. Salary, Tenure, and Fringe Benefits of Full-Time Instructional Faculty in Institutions of Higher Education 19751976. U.S. Department of Health, Education, and Welfare, 1977.

Becker, Gary S. The Economics of Discrimination. Chicago, University of Chicago Press, 1957.

Becker, Gary. Human Capital. New York, Columbia University Press, 1964.

Becker, Gary, "Investment in Human Capital: A Theoretical Analysis," Journal of Political Economy, Supplement, October 1962, pp. 949. 
Becker, Gary S., and Barry R. Chiswick, "Education and the Distribution of Earnings," American Economic Review, Papers and Proceedings, May 1966, pp. 358-369.

Birnbaum, R., "The Effects of Collective Bargaining on Faculty Compensation In Higher Education," Collective Bargaining in Higher Education, Proceedings, Second Annual Conference, April 1974, pp. 83-95.

Brown, Charles, "Equalizing Differences in the Labor Market," The Quarterly Journal of Economics, February 1980, pp. 113-134.

Brown, David. The Market for College Teachers: An Economic Analysis of Career Patterns among Southeastern Social Scientists. Chapel Hill, University of North Carolina Press, 1965.

Brown, David, The Mobile Professors. Washington, D.C., American Council on Education, 1967.

Brown, W., and C. Stone, "Academic Unions in Higher Education: Impacts on Faculty Salary, Compensation, and Promotions," Economic Inquiry, July 1977, pp. 385-396.

Cain, Glen, "The Challenge of Segmented Labor Market Theories to Orthodox Theory: A Survey," The Journal of Economic Literature, December 1976, pp. 1215-1257.

Cain, Glen, "Unemployment and the Labor Force Participation of Secondary Workers," Industrial and Labor Relations Review, January 1967, pp. 276-297.

Cairnes, John. Some Leading Principles of Political Economy Newly Expanded. New York, Harper and Brothers,

Carlsson, Robert, and James Robinson, "Toward a Public Employment Wage Theory," Industrial and Labor Relations Review, January 1969, pp. 243-248.

Cartter, Allen M. Ph.D.'s and the Academic Labor Market. A Report Prepared for the Carnegie Commission on Higher Education. New York, McGraw-Hill Book Company, 1976.

Cartter, Allen, "The Supply of and Demand for College Teachers," The Journal of Human Resources, Summer 1966, pp. 22-38.

Cartter, Allen, and John McDowell, "Changing Employment Patterns and Faculty Demographics," in Assuring Academic Progress Without Growth, Allen C. Edwards (ed.), San Francisco, New Directions for Institutional Research, Issue 6, Jossey-Bass, Inc., Publishers, Summer 1975. 
Clark, John M. Studies in the Economics of Overhead Costs. Chicago, The University of Chicago Press, 1923.

Corcoran, Mary, and Greg Duncan, "Work History, Labor Force Attachment, and Earnings Differences between the Races and Sexes," The Journal of Human Resources, Winter 1979, pp. 1-20.

Daski, Robert S., "Area Wage Survey Test Focuses on Part-timers," Monthly Labor Review, April 1974, pp. 60-62.

Deutermann, William V. and Scott C. Brown, "Voluntary Part-time Workers: A Growing Part of the Labor Force," Monthly Labor Review, June 1978, pp. 3-10.

Doeringer, Peter B., "Determinants of the Structure of Industrial Type Internal Labor Markets, Industrial and Labor Relations Review, January 1967, pp. 206-220.

Doeringer, Peter, and Michael Piore. Internal Labor Markets and Manpower Analysis. Lexington, Mass., D.C. Heath and Company, 1971.

Doeringer, Peter, and Michael Piore, "Labor Market Adjustment and Internal Training," in Industrial Relations Research Association Proceedings of the 18th Annual Winter Meeting, G.G. Somers (ed.), 1965, pp. 250-296.

Dunham, Ralph, Patricia Wright, and Marjorie Chandler. Teaching Faculty in Universities and Four-Year Colleges, Spring, 1963. Washington, D.C., U.S. Office of Education, 1966.

Dunlop, John T., "The Task of Contemporary Wage Theory," in New Concepts in Wage Determination, George W. Taylor and Frank C. Pierson (eds.), New York, McGraw-Hil1, 1957.

Dyer, James S., "Academic Resource Allocation Models at UCLA," in Decision Models in Academic Administration, A.C. Heinlein (ed.) The Decision Science Institute of the Center for Business and Economics, Kent State University, 1974.

Dyer, James S., and John M. Mulvey, "An Integrated Optimization/Information System for Academic Departmental Planning," Management Science, August 1976, pp. 1332-1341.

Dymond, W. and G. Sanders, "Hours of Work in Canada," in Hours of Work, C. Dankert (ed.), Evanston, Harper and Row, 1966.

Ehrenberg, Ronald G., "The Demand for State and Local Government Employees," American Economic Review, June 1973, pp. 366-379.

Ehrenberg, Ronald G. Fringe Benefits and Overtime Behavior. Lexington, Mass., D.C. Heath and Company, 1971a. 
Ehrenberg, Ronald G., "Heterogeneous Labor, the Internal Labor Market, and the Dynamics of the Employment-Hours Decision," Journal of Economic Theory, March 1971b, pp - 85-104.

Ehrenberg, Ronald G., "The Impact of the Overtime Premium on Employment and Hours in the U.S. Industry," Western Economic Journal, June 1971c, pp. 199-207.

Eisner, R., and M.I. Nadiri, "On Investment Behavior and Neoclassical Theory," Review of Economics and Statistics, August 1968, pp. 369-382.

Estle, Edwin F., "The Extent of Private Industrial Training in New England," New England Business Review, February 1964, pp. 1-5.

Eymonerie, Maryse, "Report on the Annual Survey of Faculty Compensation, 1977-78," AAUP Bulletin, September 1978, pp. 193-200.

Fair, Roy C. The Short-Run Demand for Workers and Hours. Amsterdam, North Holland Publishing Company, 1969.

Feldstein, M., "Specification of the Labor Input in the Aggregate Production Function," Review of Economic Studies, October 1967, pp. 375-386.

Fisher, Boyd, "Methods of Reducing the Labor Turnover," in Personnel and Employment Problems in Industrial Management, M. Bloomfield and J. Willis (eds.), The Annals, 1917, pp. 144-145.

Freeman, Richard B., "Demand for Labor in a Nonprofit Market: University Faculty," in Labor in the Public and Nonprofit Sectors, Daniel Hamermesh (ed.), Princeton, New Jersey, Princeton University Press, 1975.

Freeman, Richard B.,"Employment Opportunities in the Doctorate Manpower Market," Industrial and Labor Relations Review, January 1980a, pp. 185-197.

Freeman, Richard B., "The Facts about the Declining Economic Value of College," The Journal of Human Resources, Winter 1980b, pp. 124142.

Freeman, Richard B., "The Job Market for College Faculty," Discussion Paper Number 596, Harvard Institute of Economic Research, Harvard University, December 1977.

Freeman, Richard B. The Market for College-Trained Manpower. Cambridge, Harvard University Press, 1971.

Freeman, Richard B., and James L. Medoff, "New Estimates of Private Sector Unionism in the United States," Industrial and Labor Relations Review, January 1979, pp. 143-174. 
Freeman, Richard B. The Overeducated American. New York, Academic Press, 1976.

Freeman, Richard B., "Overinvestment in College Training," Journal of Human Resources, Summer 1975b, Pp. 287-311.

Friedlander, Jack, "Instructional Practices of Part-time and Full-time Faculty," Community College Review, Winter 1979, pp. 65-72.

Friend, Edward H. First National Survey of Employee Benefits of Ful1time Personnel of U.S. Municipalities. Washington, D.C., Labor-Management Relations Service, October 1972.

Gannon, Martin, "A Profile of the Temporary Help Industry and its Workers," Monthly Labor Review, May 1974, pp. 44-49.

Garbarino, Joseph, "Fringe Benefits and Overtime as Barriers to Expanding Employment," Industrial and Labor Relations Review, April 1964, pp. 426-442.

Garbarino, Joseph, "Reply," Industrial and Labor Relations Review, July 1966, pp. 569-572.

Garbarino, Joseph, and B. Aussieker. Faculty Bargaining. New York, McGraw-Hill, 1975.

Gass, Saul. Linear Programming. New York, McGraw-Hill, 1975.

Geoffrion, A.M., J.S. Dyer, and A. Feinberg, "An Interactive Approach for Multi-Criterion Optimization with an Application to the Operation of an Academic Department," Management Science, December 1972, pp. 357-368.

Gintis, Herbert, "Education, Technology, and Characteristics of Worker Productivity," American Economic Review, May 1971, pp. 266-79.

Goldfarb, Robert S., and James R. Hosek, "Explaining Male-Female Wage Differentials for the 'Same Job'," Journal of Human Resources, Winter 1976, pp. 98-108.

Gottschalk, Peter T., "A Comparison of Marginal Productivity and Earnings by Occupation," Industrial and Labor Relations Review, April 1978, pp. 368-378.

Gould, J.P., "Adjustment Costs in the Theory of Investment of the Firm," Review of Economic Studies, January, 1968, pp. 47-55.

Gramm, Wendy Lee, "Labor Force Decision of Married Female Teachers: A Discriminant Analysis Approach," The Review of Economics and

Statistics, August 1973, pp. 341-348. 
Gustman, Alan L., and M.Q. Clement, "Teachers' Salary Differentials and Equality of Education Opportunity," Industrial and Labor Relations Review, October 1977, pp. 61-70.

Guthrie, J., "A Survey of School Effectiveness Studies," Do Teachers Make a Difference? A Report on Recent Research on Pupil Achievement, Washington, D.C., U.S. Office of Education, 1970.

Guthrie-Morse, Barbara, "The Utilization of Part-time Faculty," Community College Frontiers, Spring 1979, pp. 8-17.

Hadley, George, Linear Programming. Reading, Mass., Addison-Wesley Publishing Co., 1962.

Ha11, Robert E., "Turnover in the Labor Force," in Brookings Papers on Economic Activity, Arthur Okum and George L. Perry (eds.), Washington, D.C., The Brookings Institute, 1972, pp. 709-756.

Hallaire, Jean. Part-time Employment: Its Extent and Its Problems. Paris, Organization for Economic Co-operation and Development, 1968.

Hallaire, Jean, "Working Hours Per Week and Pay," New Patterns for Working Time, International Conference, Paris, September 1972. Supplement to Final Report, Paris, Organization for Economic Cooperation and Development, 1973.

Hiamermesh, Daniel, "The Effect of Government Ownership on Union Wages," in Labor in the Public and Non-profit Sectors, D. Hamermesh (ed.), Princeton, New Jersey, Princeton University Press, 1975, pp. 227255.

Hamilton, Mary T., "Sex and Income Inequality among the Employed," The Annuals of the American Academy, September 1973, pp. 42-60.

Hanushek, E., "The Production of Education, Teacher Quality, and Efficiency," Do Teachers Make a Difference? A Report on Recent Research on Pupil Achievement, Washington, D.C., U.S. Office of Education, 1970.

Harrison, Bennett, "Additional Thoughts on the Dual Labor Market," Monthly Labor Review, April 1972, pp. 37-39.

Hedges, Janice, and Stephen Gallogly, "Full and Part-time: A Review of Definitions," Monthly Labor Review, March 1977, pp. 21-41.

Hildebrand, G.H., "External Influences and the Determination of the Internal Wage Structure," in Internal Wage Structures, J.L. Meij (ed.), Amsterdam, North Holland Publishing Company, 1963. 
Holmes, Alexander, "Effects of Union Activity on Teacher's' Earnings," Industrial Relations, October 1976, pp. 328-337.

Holt, Charles, Franco Modigliani, John Muth, and Herbert Simon. Planning Production, Inventories, and Work Force. Englewood Cliffs, Prentice-Ha11, 1960.

Holt, Geoffrey, "Human Capital Investment under Constrained Optimization," Quarterly Review of Economics and Business, September 1975, pp. 46-51.

Holtmann, A.G., "On-the-Job Training, Options, and Retraining," Southern Economic Journal, January 1972, PP. 414-417.

Holtmann, A.G., "The Timing of Investments in Human Capital: A Case of Education," Public Finance Quarterly, July 1973, pp. 300-306.

Horowitz, Stanley, and Allan Sherman, "A Direct Measure of the Relationship between Human Capital and Productivity," Journal of Human Resources, Winter 1980, pp. 67-76.

Hyclak, Thomas, "The Effect of Unions on Earnings Inequality in Local Labor Markets," Industrial and Labor Relations Review, October 1979, pp. 77-84.

"Industrial Investment in Manpower," New England Business Review, February 1964, pp. 1-5.

Jones, Ethel B., and James E. Long, "Part-Week Work and Human Capital Investment by Married Women," Journal of Human Resources, Fall 1979, pp. 563-578.

Kahn, Lawrence, "The Effect of Unions on the Earnings of Nonunion Workers," Industrial and Labor Realtions Review, January 1978, pp. 205-216.

Kahn, Lawrence, "Unionism and Relative Wages: Direct and Indirect Effects," Industrial and Labor Relations Review, July 1979, pp. 520-532.

Kasper, Hirsche1, "The Effects of Collective Bargaining on Public School Teachers' Salaries: Reply," Industrial and Labor Relations Review, April 1972, pp. 417-423.

Kerr, Clark, "The Balkanization of Labor Markets," in Labor Mobility and Economic Opportunity, E.W. Bakke and others (eds.), New York, Wiley, 1954, pp. 92-110.

Klitgaard, Robert E., "The Dual Labor Market and Manpower Policy," Monthly Labor Review, November 1971, pp. 45-48. 
Koltai, Leslie, "King Solomon and the Bowl of Spaghetti," Community and Junior College Journal, September 1977, pp. 18-20.

Krueger, Anne 0., "The Economics of Discrimination," in Racial Discrimination in Economic Life, Anthony Pascale (ed.), Lexington, Mass., Lexington Books, 1972.

Kuh, Edwin, "Cyclical and Secular Labor Productivity in United States Manufacturing," The Review of Economics and Statistics, February 1965, Pp. 1-12.

Langley, Paul, "An Empirical Study of Labor Market Segmentation: Comment," Industrial and Labor Relations Review, October 1978, pp. 86-93.

Leigh, Duane E., "Occupational Advancement in the Late 1960's: An Indirect Test of the Dual Labor Market Hypothesis," Journal of Human Resources, Spring 1976, pp. 155-171.

Leon, Carol, and Robert W. Bednarzik, "A Proflle of Women on Part-time Schedules," Monthly Labor Review, October 1978, pp. 3-12.

Leslie, L. and T. Hu, "The Financial Implications of Collective Bargaining," Journal of Education Finance, Summer 1977, pp. 32-53.

Lester, Richard A., "Benefits as a Preferred Form of Compensation," Southern Economic Review, April 1967, pp. 488-495.

Levin, Henry, "A Cost-Effective Analysis of Teacher Selection," Journal of Human Resources, Winter 1970, pp. 24-32.

Lipsky, David B., "Interplant Transfer and Terminated Workers: A Case Study," Industrial and Labor Relations Review, January 1970, pp. 191-206.

Lipsky, David B., and John E. Drotning, "The Influence of Collective Bargaining on Teacher Salaries in New York State," Industrial and Labor Relations Review, October 1972, pp. 18-35.

Livernask, E. Robert, "The Internal Wage Structure," in New Concepts in Wage Determination, George W. Taylor and Frank C. Pierson (eds.), New York, McGraw-Hi11, 1957.

Lombardi, John. Part-time Faculty in Community Colleges. Topical Paper No. 54, ERIC Clearinghouse, University of California at Los Angeles, December 1975.

Lombardi, John, "Salaries for Part-time Faculty: New Trends," Community College Review, January 1976. 
Long, James E., "Public-Private Sectoral Differences in Employment Discrimination," Southern Economiz Journal, July 1975, pp. 89-96.

Lowe, M., "No Equal Pay for Part-time Workers," New Statesman, October 27,1978, p. 542 .

MacDonald, Robert, "The Fringe Barrier Hypothesis and Overtime Behaviors," Industrial and Labor Relations Review, July 1966, pp. 562-569.

Magarre11, Jack, "Part-time Professors on the Increase," The Chronicle of Higher Education, January 16, 1978, pp. 1-4.

Marris, Robin. The Economic Theory of "Managerial" Capitalism. Cambridge, Cambridge University Press, 1964.

Marshall, Joan L,. "The Effects of Collective Bargaining on Faculty Salaries in Higher Education," The Journal of Higher Education, May/June 1979, pp. 310-322.

Marsha11, R. Ray, Allen King, and Vernon Briggs. Labor Economics, Wages, Employment, and Trade Unionism. Homewood, Illinois, Richard D. Irwin, 1980.

McGuire, W. Gary, "Emerging Trends in State Support," in Coping with Reduced Resources, Richard L. Alfred (ed.), San Francisco, JosseyBass, Inc., 1978, pp. 15-26.

Meij, J.L., "Wage Structure and Organization Structure," in Internal Wage Structure, J.L. Meij (ed.), Amsterdam, North Holland Publishing Company, 1963.

Mil1, John Stuart. Principles of Political Economy, New York, D. Appleton and Company, 1884.

Mincer, Jacob, "The Distribution of Labor Incomes: A Survey, with Special Reference to Human Capital Approach," Journal of Economic Literature, March 1970, pp. 1-26.

Mincer, Jacob, "On-the-Job Training: Costs, Returns, and Some Implications," Journal of Political Economy, October 1962, pp. 50-79.

Moore, Gary A., "The Effect of Collective Bargaining on Internal Salary Structures in the Public Schools," Industrial and Labor Relations Review, April 1976, pp. 352-362.

Morgenstern, Richard, and William Hamovitch, "Labor Supply of Married Women in Part-Time and Full-Time Occupations," Industrial and Labor Relations Review, October 1976, pp. 59-67. 
Morse, Dean. The Peripheral Worker. New York, Columbia University Press, 1969.

Mott, Paul, "Hours of Work and Moonlighting," in Hours of Work, Clyde Dankert and others (eds.), New York, Harper and Row, Publishers, 1965.

Myers, Charles Andrew. The Role of the Private Sector in Manpower Development. Baltimore, Johns Hopkins Press, 1971.

Myers, John G., "Hiring Costs: Some Survey Findings," The Conference Board Record, January 1967, pp. 33-42.

Myers, John G. Job Vacancies in the Firm and the Labor Market. New York, The Conference Board, 1969.

Nyers, John G. and Daniel Cramer. Measuring Job Vacancies. New York, The Conference Board, 1967.

Nadiri, M. Ishaq, "The Effects of Relative Prices and Capacity for the Demand for Labor in the U.S. Manufacturing Sector," Review of Economic Studies, July 1968, pp. 273-288.

Nadiri, M. Ishaq, and Sherwin Rosen. A Disequilibrium Model of Demand for Factors of Production. New York, National Bureau of Economic Research, 1973.

Nadiri, M. Ishaq, and Sherwin Rosen, "Interrelated Factor Demand Functions," American Economic Review, September 1969, pp. 457-471.

National Bureau of Economic Research. The Measurement and Interpretation of Job Vacancies. New York, A Conference Report, 1966.

Nollen, Stanley, Brenda Eddy, Virginia Martin, and Douglas Monroe, "Permanent Part-time Employment: An Interpretive Review," Employment and Training Administration, U.S. Department of Labor, February 1976.

Oaxaca, Ronald L., "Estimation of Union/Non-union Wage Differentials within Occupational/Regional Subgroups," Journal of Human Resources, Fal1 1975, pp. 529-537.

Oaxaca, Ronald, "Male-Female Wage Differentials in Urban Labor Markets," International Labor Review, October 1973, pp. 693-709.

01, Walter, "Labor as a Quasi-Fixed Factor," Journal of Political Economy, December 1962, pp. 529-537.

Oregon Department of Education. Biennial Report. Salem, Oregon, Community College Division, June 1979. 
Oregon State Treasury Department. Computer Report BNK 006C. Salem, Oregon, State Investment Pool, 1977-78.

Osterman, Paul, "An Empirical Study of Labor Market Segmentation," Industrial and Labor Relations Review, July 1975, pp. 508-523.

Osterman, Paul, "Reply," Industrial and Labor Relations Review, October 1978, pp. 92-94.

Owen, John D., "An Empirical Study of the Part-Time Labor Market," U.S. Department of Labor, Manpower Administration, 1977a.

Owen, John D., "Flexitime: Some Problems and Solutions," Industrial and Labor Relations Review, January 1977b, pp. 152-160.

Owen, John D., "Toward a Public Employment Wage Theory: Some Econometric Evidence on Teacher Quality," Industrial and Labor Relations Review, January 1972, pp. 213-222.

Owen, John D., "Why Part-time Workers Tend to be in Low-Wage Jobs," Monthly Labor Review, June 1978, pp. 11-14.

"Part-time PSU Faculty Pact OK'd," Oregon Journal, October 25, 1979, p. 19.

Pencave1, John H. An Analysis of the Quit Rate in American Manufacturing Industry. Princeton, New Jersey, Industrial Relations Section, Princeton University Press, 1970.

Perlman, Richard, "Observations on Overtime and Moonlighting," Southern Economic Journal, October 1966, pp. 237-244.

Perloff, Stephen H., "Comparing Municipal Salaries with Industry and Private Pay," Monthly Labor Review, October 1971, pp. 46-50.

Phair, T.S. Staffing Patterns in California Community Colleges: A 1972 overview. Eric Clearinghouse, Sacramento, California Community and Junior College Association, 1972.

Piore, Michael J., "Fragments of a 'Sociological' Theory of Wages," American Economic Review, Papers and Proceedings, May 1973, PP. 377-384.

Piore, Michael J., "The Impact of the Labor Market on the Design and Selection of Productive Techniques within the Manufacturing Plant," Quarterly Journal of Economics, November 1968b, pp. 602-620.

Piore, Michael, "Jobs and Training," in The State and the Poor, S.H. Beer and R.E. Barringer (eds.), Cambridge, Mass., Winthrop Press, 1970, pp. 53-83. 
Piore, Michael J., "On-the-Job Training and Adjustment to Technological Change," Journal of Human Resources, Fall 1968a, pp. 435-449.

Piore, Michael J., "Primary and Secondary Labor Markets: A Critique of the Dual Approach: Comment," Brookings Papers on Economic Activities, 1974, pp. 684-688.

Price, Floyd H., and William H. Lane, "An Analysis of Community and Junior College Use of Part-time Faculty," ERIC Clearinghouse, April 1976.

Radner, Roy and others. Demand and Supply in U.S. Higher Education. A Report Prepared for the Carnegie Commission on Higher Education, New York, McGraw Hill Book Company, 1975.

Raymond, Richard, and Michael Sesnowitz, "The Returns to Education: Some New Evidence," Journal of Human Resources, Spring 1975, pp. 139-154.

Razin, Assaf, and James D. Campbell, "Internal Allocation of University Resources," Western Economic Journa1, Spring 1972, pp. 308-320.

Reder, Melvin, "The Theory of Employment and Wages in the Public Sector," in Labor in the Public and Nonprofit Sectors, Daniel Hamermesh (ed.), Princeton, New Jersey, Princeton University Press, 1975.

Rees, Albert, "Spatial Wage Differentials in a Large City Labor Market," in Proceedings of the 21st Annual Winter Meeting of the Industrial Research Association, Gerlan Somers (ed.), December 1968, pp. 237247.

Rosen, Sherwin, "On the Interindustry Wage and Hours Structure," Journal of Political Economics, March/April 1969, pp. 249-273.

Rosen, Sherwin, "Short-Run Employment Variation on Class-I Railroads in the U.S.," Econometrica, July 1968, pp. 511-529.

Rosen, Sherwin, "Unionism and the Occupational Wage Structure in the U.S.," International Economic Review, June 1970, pp. 269-286.

Ross, Arthur M., "Do We Have a New Industrial Feudalism," American Economic Review, December 1958, pp. 903-920.

Sawhil1, Isabe1 V., "The Economics of Discrimination Against Women: Some New Findings," The Journal of Human Resources, Summer 1973, pp. 383-396.

Schmidt, P., and R.P. Strauss, "Effects of Unions on Earnings and Earnings on Unions: A Mixed Logic Approach," International Economic Review, February 1976, pp. 204-212. 
Schultz, Theodore. The Economic Value of Education. New York, Columbia University Press, 1963.

Schultz, Theodore, "Investment in Human Capital," American Economic Review, March 1961, pp. 1-17.

Scott, L.C., "The Economic Efficiency of On-the-Job Training: The Experience of the Bureau of Indian Affairs," Industrial and Labor Relations Review, January 1970, pp. 220-236.

Scully, M.G., "Part-time Teachers: Many are Angry," Chronicle of Higher Education, January 1975, pp. 1-3.

Shapiro, David, "Relative Wage Effects of Unions in the Public and Private Sectors," Industrial and Labor Relations Review, January 1978, pp. 193-204.

Smith, Sharon. Equal Pay in the Public Sector: Fact or Fantasy. Princeton, New Jersey, Princeton University Press, 1977a.

Smith, Sharon, "Goverment Wage Diffentials," Journal of Urban Economics, July 1977b, pp. 248-271.

Smith, Sharon, "Government Wage Differentials by Sex," Journal of Human Resources, Spring, 1976a, pp. 185-199.

Smith, Sharon, "Pay Differentials Between Federal Government and Private Sector Workers," Industrial and Labor Relations Review, January 1976b, pp. 179-197.

Solnick, i.oren, "Unionism and Fringe Benefit Expenditures," Industrial Relations, February 1978, pp. 102-107.

Thurow, Lester. Investment in Human Capital. Belmont, California, Wadsworth Publishing Company, 1970.

Thurow, Lester. Poverty and Discrimination. Washington, D.C., The Brookings Institution, 1969.

Tobias, S., and M.L. Rumbarger, "Full-Status Part-time Faculty," in Women in Higher Education, W.T. Furniss and Patricia A. Graham (eds.), Washington, D.C., American Council on Education, 1974.

Tuckman, Barbara H., and Howard P. Tuckman, "Part-timers, Sex Discrimination, and Career Choice at Two-Year Institutions: Further Findings from the AAUP Survey," Academe, March 1980, pp. 71-76.

Tuckman, Howard P., "Who is Part-time in Academe?" AAUP Bulletin, Winter 1978, pp. 305-315.

Tuckman, Howard P., and Jamie Caldwe11, "The Reward Structure for Parttimers in Academe," Journal of Higher Education, November/December 1979, pp. 745-760. 
Tuckman, Howard P., J.S. Caldwe11, and W.D. Vogler, "Part-timers and the Labor Market of the Eighties," American Sociologist, November 1978, pp. 184-195.

Tuckman, H.P., J.H. Gapinski, and R.P. Hagermann, "Faculty Skills and the Salary Structure in Academe: A Market Perspective," American Economic Review, September 1977, pp. 692-702.

Tuckman, H.P. and W.D. Vogler, "The 'Part' in Part-time Wages," AAUP Bulletin, Spring 1978, pp. 70-77.

U.S. Bureau of the Census, Census of Population: 1970, Subject Reports, Final Report DC(2)-7A, Occupational Characteristics, Washington, D.C., U.S. Government Printing Office, 1973.

Wachter, Michael L., "Primary and Secondary Labor Markets: A Critique of the Dual Approach," Brookings Papers on Economic Activity, Washington, D.C., The Brookings Institute, 1974, Pp. 637-649.

Weisbrod, Burton, "Education and Investment in Human Capital," Journal of Political Economy, Supplement, October 1962, pp. 106-123.

Weisbrod, Burton, "Investing in Human Capital," The Journal of Human Resources, Summer 1966, pp. 5-21.

Woytinsky, Wladimir. Three Aspects of Labor Dynamics. A Report Prepared for the Comittee on Social Security, Westport, Connecticut, Greenwood Press, 1974. 
APPENDIX A

QUESTIONNAIRES

FACULTY MEMBER QUESTIONNAIRE

1. Age

2. Department __ Subjects Taught

3. Length of Time as an instructor at College (A, B, or $C)$ : (Excluding summer term)

As Full-time Instructor Terms

As Part-time Instructor Terms

4. Number of sections taught by term:

Fal1 1977 Winter 1978 Spring 1978

5. Salary for 1977-78 School Year (exclude summer term): If full-time $\$$ per term If part-time $\$$ per term

6. Highest degree attained Hours Beyond

7. Approximately how many hours do you spend in an average week of the term in the following activities:

(a) Preparing lectures or class discussion material

(b) Preparing or grading tests or exams

(c) Meeting, lecturing, and in-class activities

(d) Counseling or advising students

(e) Curriculum and course development

(f) Attending/organizing meetings (non-classroom)

(g) Other: please specify 
8. Do you feel your wage level is commensurate with the amount of time and effort you expend at your teaching job for this college? Very Satisfied Satisfied Unsatisfied Very Unsatisfied

9. Are you satisfied with your teaching position at this college? Very Satisfled Satisfled Unsatisfied Very Unsatisfied

10. List your experience at other educational institutions. List the most recent first.

KIND OF INSTITUTION JOB TITLE OR DATES EMPLOYED FULL OR SALARY PER (college, etc.) DESCRIPTION (from--to) PART-TIME QUARTER

11. List your work or volunteer experience which has helped to increase your teaching skills. (Other than those listed above.) List the most recent first.

KIND OF INSTITUTION JOB TITLE OR DATES EMPLOYED FULL OR SALARY PER (college, etc.) DESCRIPTION (from--to) PART-TIME QUARTER

(Continue on back if necessary.) 
PERSONNEL OFFICE QUESTIONNAIRE

To the personnel officer:

Below are some types of costs that may be incurred by the college in recruiting, hiring, and terminating faculty. Please estimate costs on the "typical" case regardless of term for faculty in college transfer departments only. Include full-time, part-time who have been employed by the college recently $(x)$, and part-time who have not been employed by the college before (y).

External Costs:

Cost of one "typical" case
FTF PTF

Employment Agency Fees

Want Ads in Newspapers or Elsewhere

Telephone and Other Communication

Fees

Other: Please Specify

Internal Hiring Costs:

Recruiting Trips by College

Visits by Applicants (Paid for by

College)

Total Salaries of Administrators, officers, and Faculty during

Interview Time

Adding New Employees to Records

Other: Please Specify 
Internal Termination of Quit Costs:

Salaries of Administrators, officers, and Faculty During Interview Time

Taking Employee off Records

Other: Please Specify

Training and Orientation Cost of New Faculty

Salaries of Instructors

Materials and Supplies

Other: Please Specify 
APPENDIX B

MEAN AND MEDIAN HOURS PER WEEK AT EACH ACTIVITY BY FTF AND PTF

TABLE XLIV

MEAN HOURS PER WEEK AT EACH ACTIVITY BY FTF AND PTF

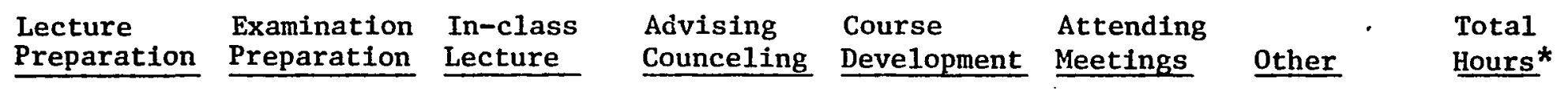

\title{
College A
}

\section{FTF}

PTF

Co1lege B

\begin{abstract}
FTF
\end{abstract}
PTF

College C

\begin{abstract}
FTF
\end{abstract}
PTF

\begin{abstract}
7.7
\end{abstract}
3.1

$$
7.2
$$

14.9

1.5

5.2

5.8

.8

\begin{abstract}
8.4
\end{abstract}
3.5

7.1

16.1

2.2

$$
4.4
$$

6.1

.8

2.7
.5

2.6

.4
1.8
.1

2.2

.1

42.3

11.2 
TABLE XLV

MEDIAN HOURS PER WEEK AT EACH ACTIVITY BY FTF AND PTF

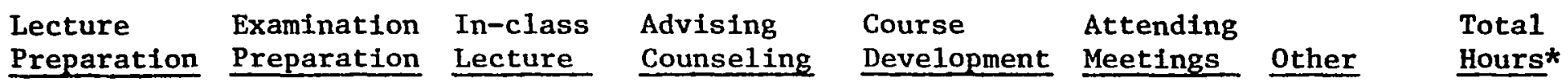

College A

$\begin{array}{ll}\text { FTF } & 8 \\ \text { PTF } & 2\end{array}$

$5 \quad 15$

3

.3

1

1

0

41

1

.3

0

0

0

7.5

College B

FTF

7.5

5

15

5

2

2

0

41

PTF

3

1

$4 \quad .2$

0

0

0

10

College C

FTF

6

4

15

5

2

1

0

41

PTF

5

1

5

1

0

0

0

Source: derj.ved from data gathered with faculty questionnaire.

*The total may not add due to rounding. 


\section{APPENDIX C \\ CLASSES TAUGHT BY FACULTY}

TABLE XLVI

NUMBER AND PERCENT OF CLASSES TAUGHT BY FACULTY

Full-time Faculty Part-time Faculty Total Classes

College Number Percent Number Percent Number Percent

A

$576 \quad 60.7 \%$

389

$40.3 \%$

$965 \quad 100 \%$

B

339

72.7

127

27.3

$466 \quad 100$

C

210

70.0

90

30.0

300

100

Source: derived from data gathered with faculty questionnaire. 


\section{APPENDIX D}

TURNOVER COSTS

\section{TABLE XLVII}

COST OF INDIVIDUAL TURNOVER FOR FTF, $\mathrm{PTF}_{\mathrm{x}},{ }^{*}$ AND $\mathrm{PTF}_{\mathrm{y}}{ }^{+}$

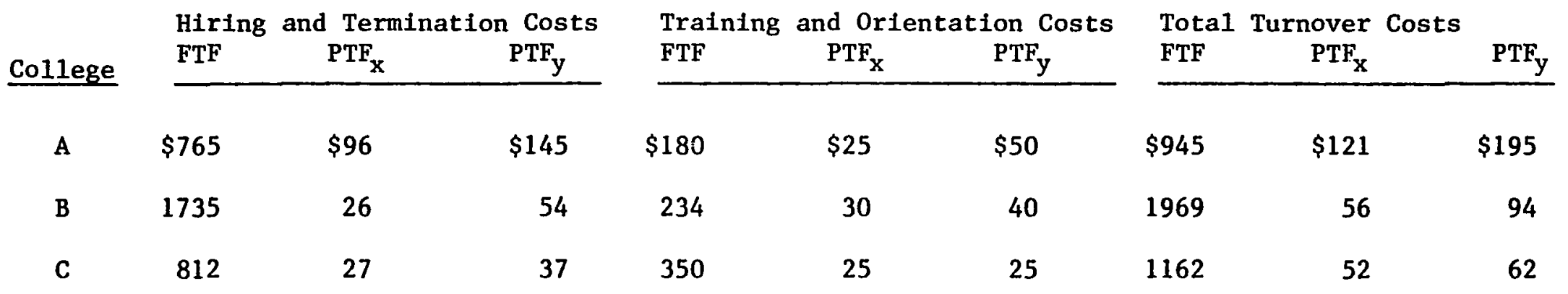

Source: data gathered with personnel office questionnaire.

${ }^{*} \mathrm{PTF}_{\mathrm{X}}$ are faculty who have worked for the college previously.

${ }^{+}{ }_{\text {PTF }}$ are faculty who have not worked for the college previously. 


\section{APPENDIX E}

\section{REGRESSION MODEL AND RESULTS}

The step-wise SPSS model REGRESSION was run with the following

format:

$$
Y=a_{0}+a_{1} X_{1}+a_{2} X_{2}+a_{3} X_{3}+\cdot \cdot \cdot+a_{10} X_{10}+u
$$

where $Y$ is the dependent variable salary, and the a's are the parameters, $u$ is the error term, and the $X^{\prime} s$ are the variables defined as:

$$
\mathrm{X}_{1}=\mathrm{LFT} \text {, the length of full-time experience at the community col- }
$$
lege where currently employed.

$X_{2}=L P T$, the length of part-time experience at the community college where currently employed.

$X_{3}=S E X$, the sex of the respondent.

$\mathrm{X}_{4}=\mathrm{DEG}$, the highest degree attained.

$\mathrm{X}_{5}=$ UFT, the length of full-time experience at four-year colleges, universities, and other community colleges.

$\mathrm{x}_{6}=\mathrm{UPT}$, the length of part-time experience at four-year colleges, universities, and other community colleges.

$\mathrm{X}_{7}=\mathrm{OFT}$, the length of full-time experience at grade and high schools, and other teaching experience not classified elsewhere.

$\mathrm{X}_{8}=\mathrm{OPT}$, the length of part-time experience at grade and high schools, and other teaching experience not classified elsewhere.

$\mathrm{X}_{9}=\mathrm{PFT}$, the length of professional full-time experience.

$\mathrm{X}_{10}=\mathrm{PPT}$, the length of professional part-time experience. 
Regression results by college follow (the standard error is in

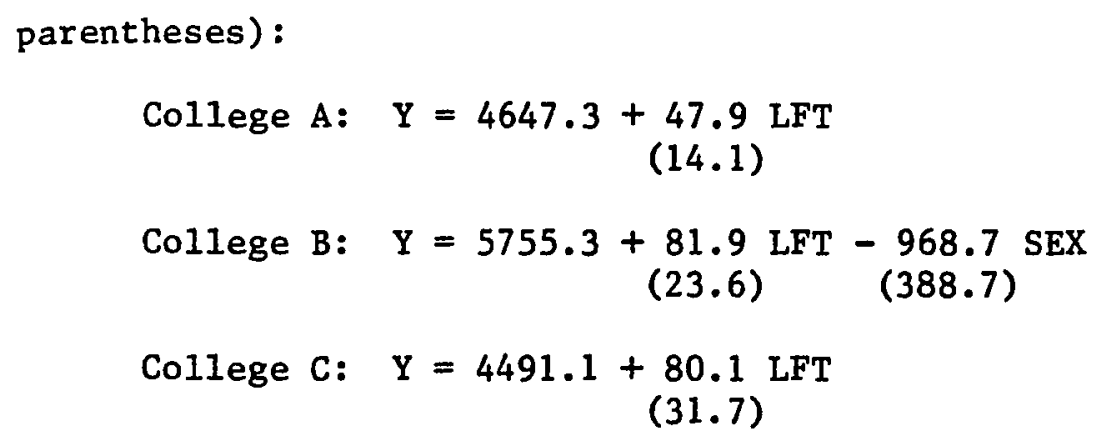


APPENDIX F

SALARY PLACEMENT AND LEVEL ADVANCEMENT: COLLEGE A

(A) The parties to this Agreement believe that excellence in teaching and other professional activity demands that only fully qualified persons be hired and retained as faculty members and that continued education and training are essential for the maintenance and improvement of professional standards. To this end the faculty salary plan has been designed to:

(1) Provide an adequate starting salary for professionally qualified faculty without experience.

(2) Reward the improvement in performance that is the result of professional experience.

(3) Provide reasonable adjustments to compensate for changes in economic conditions.

(B) This salary plan specifically provides for the following actions:

(1) Initial salary placement upon employment of a new faculty member by the College.

(a) Initial placement of a new faculty member on a first year probationary contract shall be determined by eductional qualifications and experience.

(b) The salary placement of a faculty member who meets minimum education and/or experience requirements to teach in his field or perform the professional functions of librarian or counselor shall be Level A, Step 1.

(c) If qualifications include a master's degree in the 
appropriate subject or professional area, minimum placement shall be Leve1 A, Step 3 .

(d) Advanced salary placement for professional, business or industrial experience may be allowed as follows:

(1) Approved full-time paid teaching or professional experience, one additional step for each two years completed.

(2) Approved ful1-time paid business or industrial experience, one additional step for each two years completed.

(e) Maximum level of placement for any combination of education and experience shall not exceed Level A, Step 6 . (2) A faculty member shall advance from step to step on Level A upon demonstration of satisfactory progress twoard completion of basic professional development requirements.

(a) Basic professional development requirements: The Community College--3 hours Evaluation Techniques--3 hours Organization of Instruction--3 hours Development of Instructional Materials--3 hours College Orientation Program

(1) Except for the orientation requirements, credit will be allowed for approved courses completed prior to employment by the college. If required courses are not avallable elsewhere in the metropolitan area they will be offered by the College.

(2) Satisfactory progress shall mean completion 
of at least one unfulfilled requirement in each probationary year.

(b) Satisfactory evaluation and renewal of contract. (3) Advancement from Level A to Level B shall take place simultaneously and automatically with advancement from probationary to continuous appointment status.

(a) Placement on Level B shall be at the step which is one step above the lowest step that would provide a salary higher than the step on Level A from which advanced.

(4) A faculty member shall advance annually from step to step on Level B upon meeting professional improvement requirements.

Source: College A, Faculty Agreement. 
COLLEGE A

FACULTY MEMBER SALARY GUIDE 1977-78

(180 DAY)

\begin{tabular}{lcccccccccc}
\hline Step & 1 & 2 & 3 & 4 & 5 & 6 & 7 & 8 & 9 & 10 \\
\hline Leve1 A & 10,608 & 11,110 & 11,674 & 12,262 & 12,865 & 13,512 & 14,195 & 14,900 & 15,648 & 16,473 \\
& & & & & & & & & & \\
Leve1 B & 12,712 & 13,308 & 13,974 & 14,669 & 15,404 & 16,191 & 16,999 & 17,845 & 18,833 & 19.761
\end{tabular}

Source: College A, Faculty Agreement. 
COLLEGE B

(A) Placement.

(1) The inftial placement for each faculty employee shall be based on the following criteria:

(a) Below the Associate Degree, Level A, Step 0.

(b) Associate Degree, Leve1 A, Step 1.

(c) Bachelor's Degree, Level A, Step 2.

(d) Master's Degree, Level B, Step 0.

(e) A.B.D., Level B, Step 1.

(f) Doctorate Degree, Level B, Step 2.

(2) One step for each year of college teaching experience.

(3) One-half step for each year of public or private school teaching.

(4) One-half step for each year of ful1-time commercial and industrial work experience where directly applicable to subject field.

(5) A maximum of ten steps is all that will be allowed in the initial placement for teaching and/or work experience.

(6) Both parties further agree that all present faculty members who were screened, evaluated, and judged are placed properly and in accord with the recommendation of the Pay Study Committee established earlier.

(B) Advancement.

(1) The division chairman for each division will effectively recommend any faculty advancement or non-advancement to the administration. 
(2) The Dean of the College and his staff will recommend advancement and non-advancement to the President's Staff, whereon the College President will make his recommendation to the College Board who will act and make the final decision on the recommendation.

(3) The Faculty Associatiion Academic Affairs Committee may recommend guidelines, standards, and criteria for advancement to the Dean of the College, but such recommendation(s) is advisory only.

(4) The following criteria are the minimum standards for determining adequate performance:

(a) Satisfactory knowledge of one's subject area;

(b) Substantial compliance with course outlines and objectives;

(c) Preparation of relevant lesson presentations;

(d) Satisfactory attendance at classes;

(e) Reasonable retention of class sizes from start of quarter to end of quarter;

(f) Satisfying relevant instructional needs of the students;

(g) Satisfactory learning rapport between the instrutor and students;

(h) Satisfactory student involvement in the learning process;

(i) Satisfactory classroom order and control;

(j) Adherence to District Policies and College Regu1ations. 
(5) Faculty members who cannot meet the minimum criteria for adquate performance will be subject to non-advancement.

(6) The minimum criteria for adequate performance is specfied in this section for advancement and non-advancement only and do not bar any other recourse under the 1aw, Board Policies, or College Regulations.

Source: College B, Faculty Agreement. 
COLLEGE B

FACULTY MEMBER SALARY GUIDE 1977-78

(180 DAY)

\begin{tabular}{lcccccccc}
\hline Step & 0 & 1 & 2 & 3 & 4 & 5 & 6 & 7 \\
\hline Leve1 A & 10,423 & 10,882 & 11,362 & 11,868 & 12,399 & 12,953 & 13,537 & 14,147 \\
Level B & 11,552 & 12,068 & 12,606 & 13,172 & 13,765 & 14,388 & 15,042 & 15,728 \\
\hline Step & 8 & 9 & 10 & 11 & 12 & 13 & 14 & 15 \\
\hline Leve1 A & 14,147 & 15,462 & 16,169 & 16,909 & 17,686 & 18,501 & 19,356 & 20,255 \\
Leve1 B & 16,447 & 17,601 & 17,992 & 18,824 & 19,694 & 20,609 & 21,567 & 22,573
\end{tabular}

Source: College B, Faculty Agreement. 
COLLEGE C

(A) General Rule--Step Placement

(1) Instructors at the College shall meet the following minimum standards to qualify for Level A:

(a) Lower Division:

(1) A master's degree in the subject matter to be taught or a master's degree in any field with a minimum of 30 quarter hours of graduate credit in the primary teaching assignment. To qualify for a second teaching field, the candidates will be expected to have a minimum of 24 quarter hours of graduate in the second teaching area.

(2) Under certain circumstances the College recognizes that there are areas where individuals have demonstrated their competencies and served in professional fields with distinction yet do not possess the master's degree. Representative of such areas might we11 be the performing arts, foreign languages, government services, and recreational sports. Under such circumstances the instuctional Dean will provide the president with the necessary documentation to support that the individual has demonstrated the proficiencies which would reflect a high level of competency in the field.

(2) In the placement of new faculty on the salary schedule, previous experience will be evaluated as follows, with each of the 
following equal to a College teaching year:

(a) One year teaching or certificated employment at another college or vocational school.

(b) Two years teaching or certificated employment at elementary or secondary schools.

(c) Three years of related work experience.

(d) Five years of military service (maximum of 4 steps.)

(3) The administration will evaluate other experience or training relevant to assignment at the College in making initial placement.

(4) New faculty will normally be placed on the appropriate step of Level A with a usual maximum entry at Step 6. Usually, instructors will not be placed lower than a reasonable interpretation of these rules would indicate. However, if indicated because of special considerations or qualifications and upon recommendation of the President an instructor may be placed at a higher step or level.

(5) A faculty member who has an earned Doctorate will receive pay equivalent to one additional step.

(B) General Rules--Level Advancement.

(1) Academic Staff-Level B Qualifications:

(a) Master's degree and ninety quarter hours or post B.A. work.

(b) Three years of teaching experience at the college.

(c) Recommendation of the Faculty Review Committee and recommendation of the Dean. 
(2) College equivalent credit will be granted for the following training or professional services. The number of equivalent credits will be determined by the appropriate administrator and the staff member.

(a) Approved instruction related conference, short schools and workshops which are primarily lecture/discussion will be granted 1-3 hours of college equivalent credit for forty hours of instruction.

(b) Approved employment which will materially improve the instructor's knowledge of his/her field will be granted one hour of credit for each thirty hours worked, but no more than ten such hours may be granted in one year.

(c) Research and development culminating in a formal project proposal or other professionally developed work of merit outside normal assignment expectations.

Source: College C, Faculty Agreement. 
COLLEGE C

FACULTY MEMBER SALARY GUIDE 1977-78

(180 DAY)

\begin{tabular}{lcccccccccc}
\hline Step & 1 & 2 & 3 & 4 & 5 & 6 & 7 & 8 & 9 & 10 \\
\hline Level A & 12,744 & 13,308 & 13,908 & 14,532 & 15,192 & 15,876 & 16,596 & 17,352 & 18,144 & 18,984 \\
& & - & & & & & & & & \\
Leve1 B & 13,644 & 14,256 & 14,892 & 15,564 & 16,272 & 17,016 & 17,796 & 18,612 & 19,476 & 20,376
\end{tabular}

Source: College C, Faculty Agreement. 
APPENDIX G

HYPOTHETICAL SALARY DATA AND CALCULATIONS

TABLE XIVIII

DATA AND CALCULATIONS OF HYPOTHETICAL SALARY

OF PTF IF WORKED FULL-TIME: COLLEGE A

\begin{tabular}{|c|c|c|c|c|c|}
\hline PTF & $\begin{array}{l}\text { Teaching or } \\
\text { Professional }\end{array}$ & $\begin{array}{l}\text { Business or } \\
\text { Industrial }\end{array}$ & Steps* & Degree $^{+}$ & $\begin{array}{l}\text { Hypothetical } \\
\text { Salary** }\end{array}$ \\
\hline 1 & 1 & 0 & $\frac{1}{2}$ & $\mathbf{M}$ & $\$ 12,262$ \\
\hline 2 & 0 & $6 \frac{1}{2}$ & $3 \frac{1}{4}$ & B & 12,262 \\
\hline 3 & 0 & 4 & 1 & B & 11,110 \\
\hline 4 & 0 & 0 & 0 & B & 10,608 \\
\hline 5 & 3 & 0 & 2 & $\mathbf{M}$ & 12,865 \\
\hline 6 & 7 & 0 & $3 \frac{1}{-2}$ & $\mathbf{M}$ & 13,512 \\
\hline 7 & 0 & 0 & 0 & $\mathrm{M}$ & 11,674 \\
\hline 8 & 0 & 0 & 0 & $\mathbf{M}$ & 11,674 \\
\hline 9 & 33 & 0 & 11 & B & 13,512 \\
\hline 10 & 13 & 0 & 6 & $\mathbf{M}$ & 13,512 \\
\hline 11 & 3 & 5 & 4 & $M$ & 13,512 \\
\hline 12 & 1 & 6 & $3 \frac{1}{2}$ & M & 13,512 \\
\hline 13 & 0 & 0 & 0 & $M$ & 11,674 \\
\hline 14 & 3 & 0 & $1 \frac{1}{2}$ & $\mathbf{M}$ & 12,865 \\
\hline 15 & 0 & 2 & 1 & $\mathbf{M}$ & 12,262 \\
\hline 16 & 30 & 0 & 10 & $M$ & 13,512 \\
\hline 17 & 28 & $6 \frac{1}{2}$ & $17 \frac{1}{4}$ & $\mathbf{M}$ & 13,512 \\
\hline 18 & 0 & 0 & 0 & $\mathbf{M}$ & 11,674 \\
\hline 19 & 15 & 0 & $7 \frac{1}{2}$ & $\mathbf{M}$ & 13,512 \\
\hline
\end{tabular}


Years of Full-time Experience

\begin{tabular}{|c|c|c|c|c|c|}
\hline PTF & $\begin{array}{l}\text { Teaching or } \\
\text { Professional }\end{array}$ & $\begin{array}{l}\text { Business or } \\
\text { Industrial }\end{array}$ & Steps* & Degree ${ }^{+}$ & $\begin{array}{l}\text { Hypothetical } \\
\text { Salary** }\end{array}$ \\
\hline 20 & 0 & 0 & 0 & $\mathbf{M}$ & $\$ 11,674$ \\
\hline 21 & 0 & 40 & 10 & $\mathbf{M}$ & 13,512 \\
\hline 22 & 0 & 0 & 0 & $\mathbf{M}$ & 11,674 \\
\hline 23 & 0 & 0 & 0 & B & 10,608 \\
\hline 24 & 4 & 4 & 4 & $\mathbf{M}$ & 13,512 \\
\hline 25 & 0 & 0 & 0 & $\mathrm{M}$ & 11,674 \\
\hline 26 & 0 & 0 & 0 & $M$ & 11,674 \\
\hline 27 & 13 & 3 & 8 & $\mathbf{M}$ & 13,512 \\
\hline 28 & 0 & 14 & 7 & B & 13,512 \\
\hline 29 & 10 & 0 & 5 & $M$ & 13,512 \\
\hline 30 & 2 & 0 & 1 & B & 11,110 \\
\hline 31 & 0 & $6 \frac{1}{2}$ & $3 \frac{1}{4}$ & $M$ & 13,512 \\
\hline 32 & 0 & 0 & 0 & B & 10,608 \\
\hline 33 & 4 & 0 & 2 & $\mathbf{M}$ & 12,865 \\
\hline 34 & 5 & 0 & $2 \frac{1}{2}$ & $\mathrm{M}$ & 13,512 \\
\hline 35 & 2 & 16 & 9 & B & 13,512 \\
\hline 36 & 0 & 0 & 0 & $\mathbf{M}$ & 11,674 \\
\hline 37 & 1 & 6 & $3 \frac{1}{2}$ & $M$ & 13,512 \\
\hline 38 & $2 \frac{1}{2}$ & 0 & $1 \frac{1}{4}$ & $M$ & 12,262 \\
\hline 39 & 0 & 4 & 1 & $\mathrm{M}$ & 12,262 \\
\hline 40 & 30 & 4 & 7 & M & 13,512 \\
\hline 41 & 0 & 7 & $3 \frac{1}{2}$ & M & 13,512 \\
\hline 42 & 0 & $24 \frac{1}{2}$ & $12 \frac{1}{4}$ & B & 13,512 \\
\hline 43 & 4 & 0 & 2 & B & 11,674 \\
\hline
\end{tabular}


Years of Ful1-time Experience

\begin{tabular}{|c|c|c|c|c|c|}
\hline PTF & $\begin{array}{l}\text { Teaching or } \\
\text { Professional }\end{array}$ & $\begin{array}{l}\text { Business or } \\
\text { Industrial }\end{array}$ & Steps* & Degree $^{+}$ & $\begin{array}{l}\text { Hypothetical } \\
\text { Salaryk* }\end{array}$ \\
\hline 44 & 7 & 0 & $3 \frac{1}{2}$ & B & $\$ 12,865$ \\
\hline 45 & 3 & 2 & $2 \frac{1}{2}$ & $\mathbf{M}$ & 13,512 \\
\hline 46 & 0 & 0 & 0 & M & 11,674 \\
\hline 47 & 3 & 30 & $16 \frac{1}{2}$ & $\mathbf{M}$ & 13,512 \\
\hline
\end{tabular}

COLLEGE B

Years of Full-time Experience

Public or Commercial/

College Private Industrial

PT Teaching Teaching Work

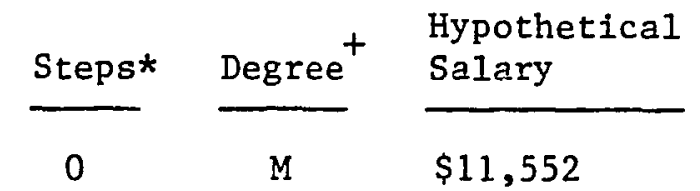

2

3

4

5

6

7

8

9

10

11

12

13

14

15

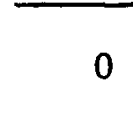

0

0

0

0

0

10

M

11,552

0

0

0

0

$\frac{1}{2}$

$2 \frac{1}{4}$

0

0

M

11,552

10

0

0

0

0

0

$6 \frac{1}{2}$

M

17,992

2

$1 \frac{1}{2}$

$\frac{1}{2}$

2

0

0

M

12,606

M

11,552

M

11,552

2

0

4

0

0

0

0

M

15,728

B

11,868

M

12,606

M

11,552

0

0

0

0

3

M

11,552

M

11,552

0

6

M

11,552

0

M

13,712 
Years of Fu11-time Experience

\section{Public or Commercial}

College Private Industrial

PTF Teaching Teaching Work

$\frac{\text { Steps }^{*}}{5 \frac{1}{2}} \frac{\text { Degree }^{+}}{M} \frac{\begin{array}{l}\text { Hypothetical } \\ \text { Salary** }\end{array}}{\$ 15,042}$

17

18

19

20

21

22

\section{3}

24

25

26

27

28

29

30

31

32

33

34

35

36

37

38

0

0

1

18

0

0

0

2

0

B

10,423

10

5

M

14,388

2

M

12,606

0

B

10,423

0

M

11,552

B

10,423

M

11,552

M

16,447

M

12,068

M

13,765

M

11,552

M

17,201

M

13,172

B

10,423

M

13,172

M

12,068

12

B

13,537

2

0

0

M

12,606

0

3

0

2


Years of Ful1-time Experience

\begin{tabular}{|c|c|c|c|c|c|c|}
\hline PTF & $\begin{array}{l}\text { College } \\
\text { Teaching }\end{array}$ & $\begin{array}{l}\text { Public or } \\
\text { Private } \\
\text { Teaching }\end{array}$ & $\begin{array}{l}\text { Commercial/ } \\
\text { Industrial } \\
\text { Work }\end{array}$ & Steps* & Degree $^{+}$ & $\begin{array}{l}\text { Hypothetical } \\
\text { Salary** }\end{array}$ \\
\hline 39 & 0 & 0 & 0 & 0 & B & $\$ 10,423$ \\
\hline 40 & 0 & 4 & 0 & 2 & $M$ & 12,606 \\
\hline 41 & 0 & 0 & 0 & 0 & $\mathrm{M}$ & 11,552 \\
\hline 42 & 0 & 0 & $\frac{1}{2}$ & $\frac{1}{4}$ & M & 11,552 \\
\hline 43 & 2 & $2 \frac{1}{2}$ & 0 & $3 \frac{1}{4}$ & $M$ & 13,172 \\
\hline 44 & 0 & 0 & 0 & 0 & B & 10,423 \\
\hline
\end{tabular}

COLLEGE C

Years of Full-time Experience

Elementary/

PTF Teaching Teaching Work $\begin{aligned} & \text { College Secondary Professional } \\ & \text { Steps* Degree }\end{aligned}$ H $^{*} \begin{aligned} & \text { Hypothetical } \\ & \text { Salary }\end{aligned}$

$\begin{array}{ccccccc}1 & 0 & 0 & 4 \frac{1}{2} & 1 \frac{1}{2} & \mathrm{~B} & \$ 13,308 \\ 2 & 0 & 2 & 0 & 1 & \mathrm{M} & 13,308 \\ 3 & 1 & 0 & 0 & 0 & \mathrm{M} & 12,744 \\ 4 & 0 & 12 & 11 \frac{1}{2} & 10 & \mathrm{M} & 16,596 \\ 5 & 0 & 9 & 0 & 4 \frac{1}{2} & \mathrm{M} & 15,192 \\ 6 & 0 & 0 & 3 & 1 & \mathrm{M} & 13,308 \\ 7 & 0 & 11 & 0 & 5 \frac{1}{2} & \mathrm{M} & 15,876 \\ 8 & 0 & 1 & 0 & \frac{1}{2} & \mathrm{M} & 13,308 \\ 9 & 0 & 3 & 0 & 1 \frac{1}{2} & \mathrm{~B} & 13,308 \\ 10 & 0 & 0 & 0 & 0 & \mathrm{M} & 12,744 \\ 11 & 7 & 4 & 0 & 8 & \mathrm{M} & 18,144 \\ 12 & 0 & 0 & 3 \frac{1}{4} & 1 & \mathrm{M} & 13,308\end{array}$




\begin{tabular}{|c|c|c|c|c|c|c|}
\hline \multirow[b]{2}{*}{ PTF } & \multicolumn{3}{|c|}{ Years of Full-time Experience } & \multirow[b]{2}{*}{ Steps* } & \multirow[b]{2}{*}{ Degree $^{+}$} & \multirow[b]{2}{*}{$\begin{array}{l}\text { Hypothetical } \\
\text { Salary ** }\end{array}$} \\
\hline & $\begin{array}{l}\text { College } \\
\text { Teaching }\end{array}$ & $\begin{array}{l}\text { Elementary/ } \\
\text { Secondary } \\
\text { Teaching }\end{array}$ & $\begin{array}{l}\text { Professional } \\
\text { Work }\end{array}$ & & & \\
\hline 13 & 0 & 0 & 0 & 0 & $\mathbf{M}$ & $\$ 12,744$ \\
\hline 14 & 4 & 0 & $2 \frac{1}{4}$ & $4 \frac{1}{2}$ & $\mathbf{M}$ & 15,876 \\
\hline
\end{tabular}

Source: data derived from faculty questionnaire.

*"Steps" refers to the number of steps on the appropriate college salary schedule. If a PTF attained one-half or more of a step, then the individual is placed on the next higher salary. The colleges may have a maximum attainable beginning salary amount. See appendix $\mathrm{F}$ for salary schedules.

+'M" refers to master's degree and "B" refers to bachelor's
degree.

**The hypothetical salary is derived from placement of the faculty member according to the number of steps attained and the degree held. See appendix F. 


\section{APPENDIX H}

CONSTRAINT ADJUSTMENT OF FACULTY GROUPS

TABLE XLIX

CONSTRAINT AJUSTMENT OF FACULTY GROUPS: COLLEGE A PROBLEM VIEWED AS MINIMIZATION OF TOTAL COST

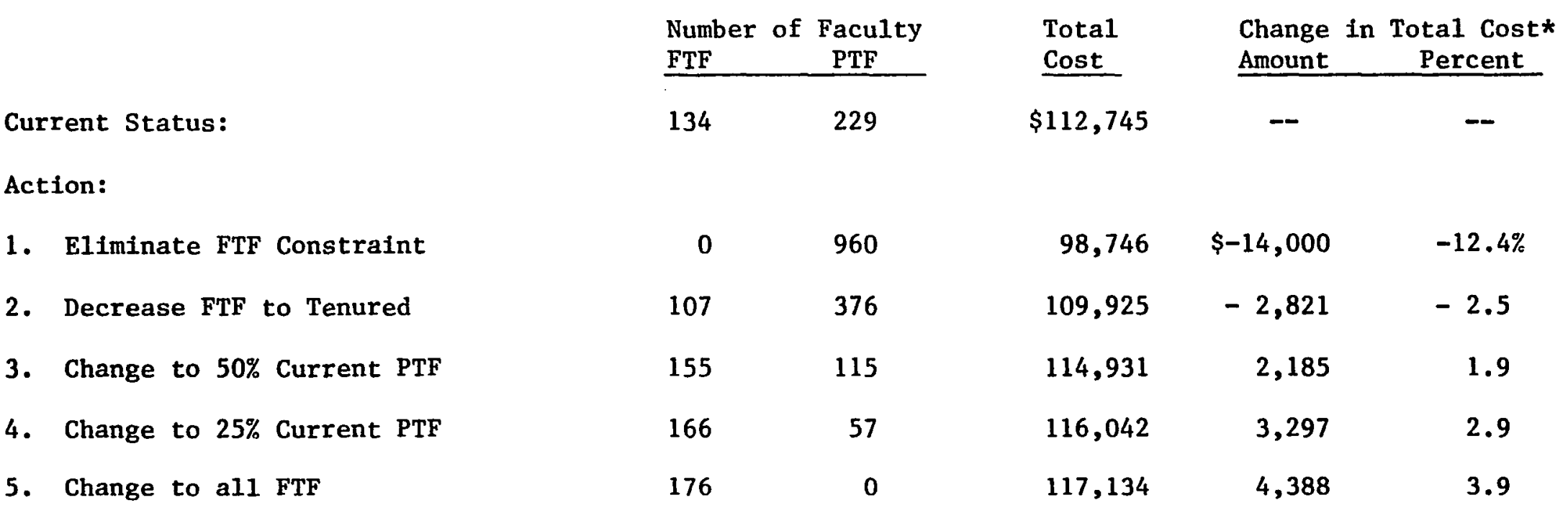

Source: calculated using linear programming with data gathered with faculty and personnel office questionnaires and from college records. Refer to Tables XXX, XXXI, and XXXII for data upon which results were derived. Round-off error is present.

*A11 changes are calculated from the current status. 
TABLE L

CONSTRAINT ADJUSTMENT OF FACULTY GROUPS: COLLEGE B PROBLEM VIEWED AS MINIMIZATION OF TOTAL COST

\begin{tabular}{|c|c|c|c|c|}
\hline $\begin{array}{l}\text { Number } \\
\text { FTF }\end{array}$ & $\begin{array}{l}\text { Faculty } \\
\text { PTF } \\
\end{array}$ & $\begin{array}{l}\text { Total } \\
\text { Cost } \\
\end{array}$ & $\begin{array}{l}\text { Change } \\
\text { Amount }\end{array}$ & $\begin{array}{c}\text { otal Cos } \\
\text { Percent }\end{array}$ \\
\hline 77 & 86 & $\$ 58,442$ & -- & -- \\
\hline 0 & 532 & 42,492 & $\$-15,950$ & $-27.3 \%$ \\
\hline 53 & 225 & 53,470 & $-4,971$ & 8.5 \\
\hline 84 & 43 & 59,979 & 1,538 & 2.6 \\
\hline 88 & 22 & 60,720 & 2,279 & 3.9 \\
\hline 92 & 0 & 61,516 & 3,074 & 5.3 \\
\hline
\end{tabular}

Source: calculated using linear programming with data gathered with faculty and personnel office questionnaire and from college records. Refer to Tables XXX, XXXI, and XXXII for data upon which results were derlved. Round-off error is present.

*All changes are calculated from the current status. 
TABLE LI

CONSTRAINT ADJUSTMENT OF FACULTY GROUPS: COLLEGE $C$ PROBLEM VIEWED AS MINIMIZATION OF TOTAL COST

Current Status:

Action:

1. Eliminate FTF Constraint

2. Decrease FTF to Tenured

3. Change to $50 \%$ Current PTF

4. Change to $25 \%$ Current PTF

5. Change to all FTF

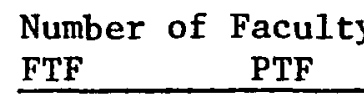

50

0

41

58

62

66
Total

Cost

$\$ 39,807$
Change in Total Cost* Amount Percent

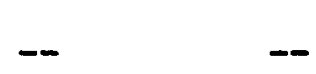

$\begin{array}{rr}\$-19,238 & -48.3 \% \\ 3,423 & -8.6 \\ 3,036 & 7.6 \\ 4,631 & 11.6 \\ 6,156 & 15.5\end{array}$

Source: calculated using linear programming with data gathered with faculty and personnel office questionnaires and from college records. Refer to Tables XXX, XXXI, and XXXII for data upon which results were derived. Round-off error is present.

*A1l changes are calculated from the current status. 
TABLE LII

CONSTRAINT ADJUSTMENT OF FACULTY GROUPS: COLLEGE A PROBLEM VIEWED AS MAXIMIZATION OF OUTPUT

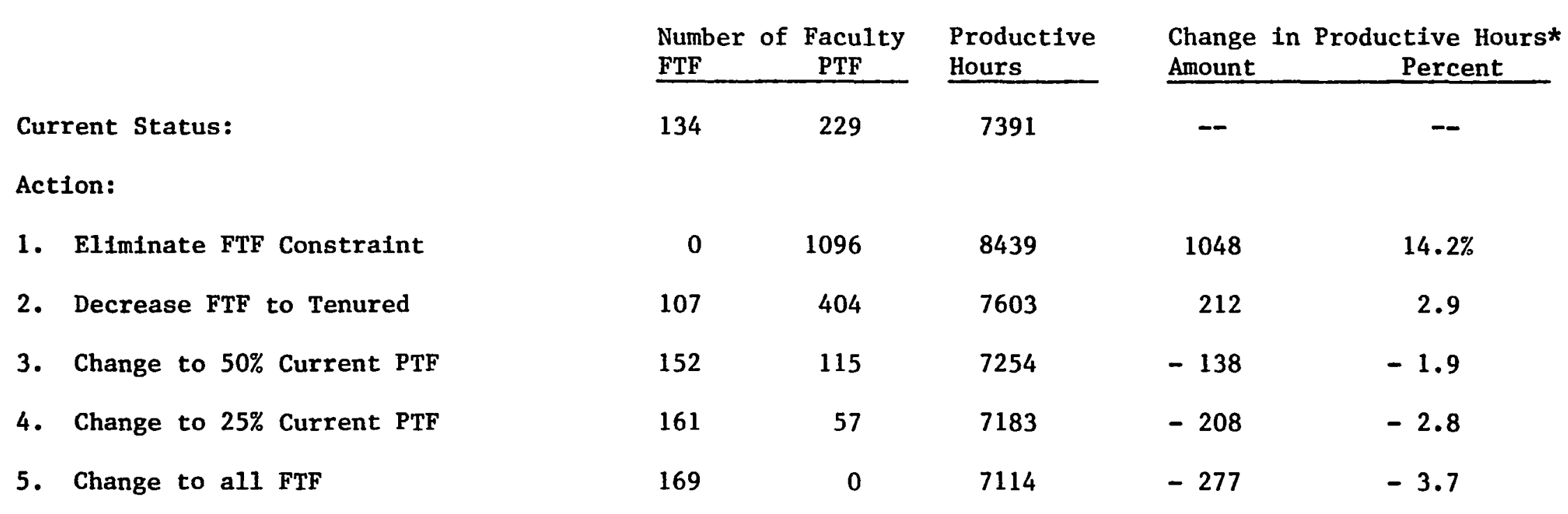

Source: calculated using linear programming with data gathered with faculty and personnel office questionnaires and from college records. Refer to Tables XXX, XXXI, and XXXII for data upon which results were derived. Round-off error is present.

*A1l changes are calculated from the current status. 


\section{TABLE LIII}

CONSTRAINT ADJUSTMENT OF FACULTY GROUPS: COLLEGE B PROBLEM VIEWED AS MAXIMIZATION OF OUTPUT

\begin{tabular}{cccccc}
$\begin{array}{l}\text { Number } \\
\text { FTF }\end{array}$ & $\begin{array}{c}\text { Faculty } \\
\text { PTF }\end{array}$ & $\begin{array}{l}\text { Productive } \\
\text { Hours }\end{array}$ & & $\begin{array}{c}\text { Change in } \\
\text { Amount }\end{array}$ & $\begin{array}{c}\text { Productive Hours* } \\
\text { Percent }\end{array}$ \\
\cline { 1 - 2 } 77 & 86 & & 4041 & -- & - \\
0 & 732 & 5558 & 1517 & $37.5 \%$ \\
53 & 287 & 4514 & 473 & 11.7 \\
82 & 43 & 3940 & & -101 & -2.5 \\
85 & 22 & 3891 & -150 & -3.7 \\
87 & 0 & 3839 & -202 & -5.0
\end{tabular}

Source: calculated using linear programing with data gathered with faculty and personnel office questionnaires and from college records. Refer to Tables XXX, XXXI, and XXXII for data upon which results were derived. Round-off error is present.

*All changes are calculated from the current status. 
TABLE LIV

CONSTRAINT ADJUSTMENT OF FACULTY GROUPS: COLLEGE C PROBLEM VIEWED AS MAXIMIZATION OF OUTPUT

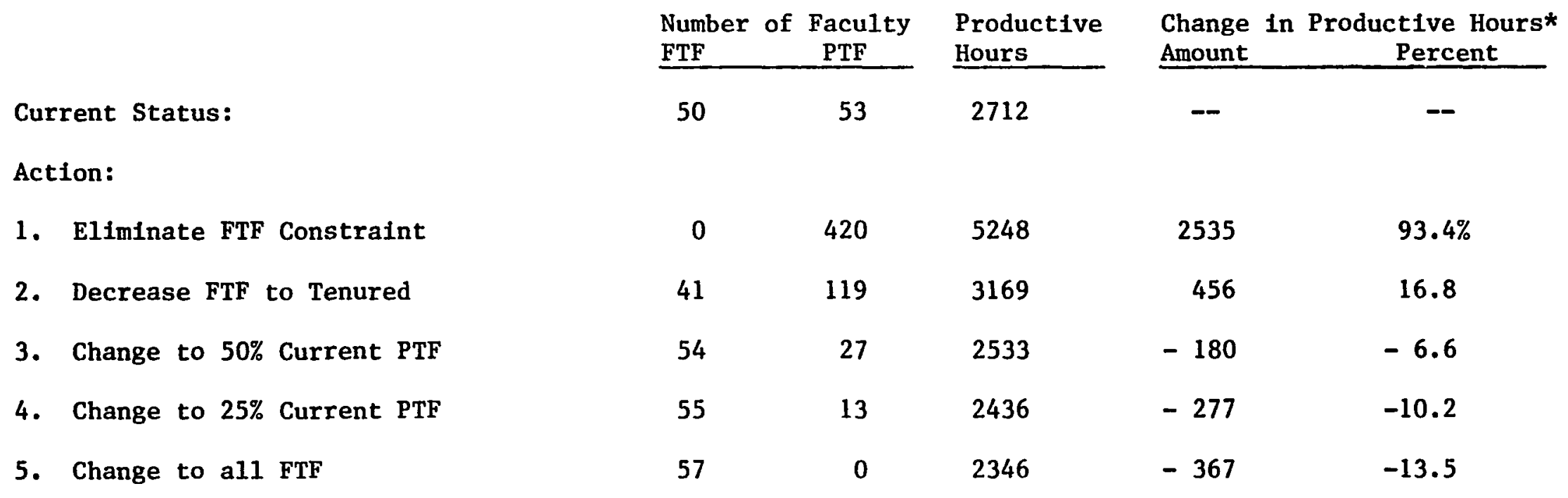

Source: calculated using linear programming with data gathered with faculty and personnel office questionnaires and from college records. Refer to Tables XXX, XXXI, and XXXII for data upon which results are derived. Round-off error is present.

*A11 changes are calculated from the current status. 


\section{APPENDIX I}

ADJUSTMENT OF BUDGET CONSTRAINTS

TABLE LV

ADJUSTMENT OF BUDGET CONSTRAINTS: COLLEGE A PROBLEM VIEWED AS MAXIMIZATION OF OUTPUT

\begin{tabular}{|c|c|c|c|c|c|}
\hline $\begin{array}{l}\text { Total } \\
\text { Budget }\end{array}$ & $\begin{array}{l}\text { Number of } \\
\text { FTF }\end{array}$ & $\begin{array}{c}\text { Faculty } \\
\text { PTF }\end{array}$ & $\begin{array}{l}\text { Total } \\
\text { Productive } \\
\text { Hours } \\
\end{array}$ & $\begin{array}{l}\text { Change } \\
\text { Product } \\
\text { Amount }\end{array}$ & $\begin{array}{l}\text { n Total } \\
\text { ve Hours } \\
\text { Percent } \\
\end{array}$ \\
\hline$\$ 122,736$ & 134 & 229 & 7391 & - & - \\
\hline 135,283 & 134 & 448 & 9079 & 1688 & $22.8 \%$ \\
\hline 124,010 & 134 & 339 & 8235 & 844 & 11.4 \\
\hline 101,462 & 134 & 119 & 6547 & -844 & -11.4 \\
\hline 90,188 & 134 & 10 & 5703 & -1688 & -22.8 \\
\hline
\end{tabular}

Source: calculated using linear programming with data gathered with faculty and personnel office questionnaires and from college records. Refer to Tables XXX, XXXI, and XXXII for data upon which results were derived. Round-off error is present.

*A1l changes are calculated from the current status. 
TABLE LVI

ADJUSTMENT OF BUDGET CONSTRAINTS: COLLEGE B PROBLEM VIEWED AS MAXIMIZATION OF OUTPUT

\begin{tabular}{|c|c|c|c|c|c|c|}
\hline & $\begin{array}{l}\text { Total } \\
\text { Budget }\end{array}$ & $\begin{array}{l}\text { Number } \\
\text { FTF }\end{array}$ & $\begin{array}{c}\text { of Faculty } \\
\text { PTF } \\
\end{array}$ & $\begin{array}{l}\text { Total } \\
\text { Productive } \\
\text { Hours } \\
\end{array}$ & $\begin{array}{l}\text { Change } \\
\text { Product } \\
\text { Amount }\end{array}$ & $\begin{array}{l}\text { Total } \\
\text { e Hours* } \\
\text { Percent }\end{array}$ \\
\hline Current Status: & $\$ 58,439$ & 77 & 86 & 4041 & -- & -- \\
\hline \multicolumn{7}{|l|}{ Action: } \\
\hline 1. Increase Budget $20 \%$ & 70,127 & 77 & 232 & 5152 & 1111 & $27.5 \%$ \\
\hline 2. Increase Budget $10 \%$ & 64,283 & 77 & 159 & 4597 & 556 & 13.8 \\
\hline 3. Decrease Budget $10 \%$ & 52,595 & 77 & 13 & 3485 & -556 & -13.8 \\
\hline 4. Decrease Budget $20 \%$ & 46,751 & \multicolumn{3}{|c|}{ No Feasible Solution } & & \\
\hline
\end{tabular}

Source: calculated using linear programming with data gathered with faculty and personnel office questionnatres and from college records. Refer to Tables XXX, XXXI, and XXXII for data upon which results were derived. Round-off error is present.

*A1l changes are calculated from the current status. 
TABLE LVII

ADJUSTMENT OF BUDGET CONSTRAINTS: COLLEGE C PROBLEM VIEWED AS MAXIMIZATION OF OUTPUT

\begin{tabular}{llll} 
Total & Number of Faculty & $\begin{array}{l}\text { Total } \\
\text { Productive }\end{array}$ & $\begin{array}{l}\text { Change in Total } \\
\text { Productive Hours* } \\
\text { Budget }\end{array}$ \\
\hline
\end{tabular}

Current Status:

Action:

1. Increase Budget $20 \%$

2. Increase Budget $10 \%$

3. Decrease Budget $10 \%$

4. Decrease Budget $20 \%$
Budget

$\$ 39,818$

47,782

50

43,800

50

35,836

50

31,854
53

2712

3762

3237

2188

11

11

No Feasible Solution
Amount Percent

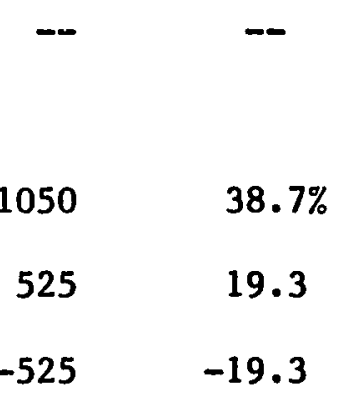

$-525 \quad-19.3$

Source: calculated using linear programming with data gathered with faculty and personnel office questionnaires and from college records. Refer to Tables XXX, XXXI, and XXXII for data upon which results were dertved. Round-off error is present.

*A1l changes are calculated from the current status. 
APPENDIX J

ADJUSTMENT OF TOTAL PRODUCTIVE HOURS: COST MINIMIZATION MODEL

TABLE LVIII

ADJUSTMENT OF TOTAL PRODUCTIVE HOURS: COLLEGE A PROBLEM VIEWED AS MINIMIZATION OF TOTAL COST

\section{Total}

Productive

Hours

Number of Faculty

Total

FTF

PTF

Cost

7392

134

229

$\$ 112,745$

\section{Action:}

1. Increase Total

Productive Hours 20\%

8869

134

421

132,476

Change in Total Cost*

Amount

Percent

2. Increase Total

Productive Hours 10\%

8130

134

325

122,604

$\$ 19,730$

$17.5 \%$

3. Decrease Tota1

Productive Hours 10\%

6652

134

134

102,860

$-9,885$

$-8.8$

4. Decrease Total

Productive Hours 20\%

5913

134

37

$92,988 \quad-19,757$

$-17.5$

Source: calculated using linear programming with data gathered with faculty and personnel office questionnaires and from college records. Refer to Tables XXX, XXXI, and XXXII for data upon which results were derived. Round-off error is present.

*All changes are calculated from the current status. 
TABLE LIX

ADJUSTMENT OF TOTAL PRODUCTIVE HOURS: COLLEGE B PROBLEM VIEWED AS MINIMIZATION OF TOTAL COST

Total

Productive Number of Faculty Total Change in Total Cost*

Hours

FTF PTF Cost

Current Status:

4041

77

86

$\$ 58,442$

Amount

Percent

Action:

1. Increase Total

Productive Hours 20\%

4849

77

192

66,938

$\$ 8,496$

$14.5 \%$

2. Increase Total

Productive Hours 10\%

77

139

62,690

4,248

7.3

3. Decrease Total

Productive Hours 10\%

3637

77

32

54,194

$-4,248$

$-7.3$

4. Decrease Total

Productive Hours $20 \%^{+}$

77

0

$51,575 \quad-6,866$

$-11.7$

Source: calculated using linear programming with data gathered with faculty and personnel office questionnaires and from college records. Refer to Tables XXX, XXXI, and XXXII for data upon which results were derived. Round-off error is present.

*A11 changes are calculated from the current status.

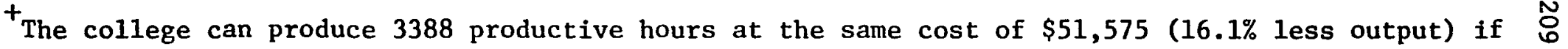
it continues to hire 77 FTF. 
TABLE LX

ADJUSTMENT OF TOTAL PRODUCTIVE HOURS: COLLEGE C PROBLEM VIEWED AS MINIMIZATION OF TOTAL COST

\begin{tabular}{|c|c|c|c|c|c|}
\hline $\begin{array}{l}\text { Productive } \\
\text { Hours }\end{array}$ & $\begin{array}{l}\text { Number } \\
\text { FTF } \\
\end{array}$ & $\begin{array}{c}\text { of Faculty } \\
\text { PTF }\end{array}$ & $\begin{array}{l}\text { Total } \\
\text { Cost } \\
\end{array}$ & $\begin{array}{l}\text { Change } \\
\text { Amount }\end{array}$ & $\begin{array}{r}\text { otal Cos } \\
\text { Percen } \\
\end{array}$ \\
\hline 2712 & 50 & 53 & $\$ 39,807$ & -- & -- \\
\hline 3253 & 50 & 96 & 43,919 & $\$ 4,112$ & $9.8 \%$ \\
\hline 2982 & 50 & 75 & 41,863 & 2,056 & 5.0 \\
\hline 2440 & 50 & 31 & 37,751 & $-2,057$ & -5.3 \\
\hline 2169 & 50 & 10 & 35,694 & $-4,112$ & -10.8 \\
\hline
\end{tabular}

Source: calculated using linear programming with data gathered with faculty and personnel office questionnatres and from college records. Refer to Tables XXX, XXXI, and XXXII for data upon which results were derlved. Round-off error is present.

*All changes are calculated from the current status. 
APPENDIX $K$

COST RATIO ADJUSTMENTS: PROBLEM VIEWED AS MAXIMIZATION OF OUTPUT

TABLE LXI

COST RATIO ADJUSTMENTS: PROBLEM VIEWED AS MAXIMIZATION OF OUTPUT, COLLEGE A

Current Status:

Action:

1. Increase FTF Cost $20 \%$

2. Increase FTF Cost $10 \%$

3. Increase PTF cost $20 \%$

4. Increase PTF Cost $10 \%$

5. Decrease PTF Cost $10 \%$

6. Decrease PTF Cost $20 \%$

7. Decrease FTF Cost $10 \%$

8. Decrease FTF Cost $20 \%$

\begin{tabular}{|c|c|c|c|}
\hline $\begin{array}{l}\text { Cost of } \\
\text { FTF }\end{array}$ & $\begin{array}{l}\text { Faculty } \\
\text { PTF }\end{array}$ & $\begin{array}{l}\text { Number of } \\
\text { FTF }\end{array}$ & $\begin{array}{c}\text { Faculty } \\
\text { PTF }\end{array}$ \\
\hline$\$ 665.53$ & $\$ 102.86$ & 134 & 229 \\
\hline
\end{tabular}

$\begin{array}{rrr}798.64 & 102.86 & 134 \\ 732.52 & 102.86 & 134 \\ 665.53 & 123.43 & 169 \\ 665.53 & 113.15 & 134 \\ 665.53 & 92.57 & 134 \\ 665.53 & 82.29 & 134 \\ 598.98 & 102.86 & 134 \\ 532.42 & 102.86 & 212\end{array}$

Total

Productive

Hours

7391

56

142

0

208

254

286

316

0

Change in Total

Productive Hours* Amount Percent

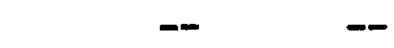

$\begin{array}{rrr}6056 & -1335 & -18.1 \% \\ 6719 & -672 & -9.1 \\ 7114 & -277 & -3.7 \\ 7231 & -160 & -2.2 \\ 7587 & 196 & 2.6 \\ 7832 & 441 & 6.0 \\ 8059 & 668 & 9.0 \\ 8893 & 1502 & 20.3\end{array}$

Source: calculated using linear programing with data gathered with faculty and personnel office questionnalres and college records. Refer to Tables XXX, XXXI, and XXXII for data upon which results were derived. Round-off error is present.

*All changes are calculated from the current status. 


\section{TABLE LXII}

COST RATIO ADJUSTMENTS: PROBLEM VIEWED AS MAXIMIZATION OF OUTPUT, COLLEGE B

Current Status:

Action:

1. Increase FTF Cost $20 \%$

2. Increase FTF Cost $10 \%$

3. Increase PTF Cost $20 \%$

4. Increase PTF Cost $10 \%$

5. Decrease PTF Cost $10 \%$

6. Decrease PTF Cost $20 \%$

7. Decrease FTF Cost $10 \%$

8. Decrease FTF Cost $20 \%$
803.77

79.81

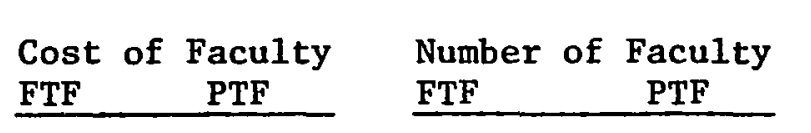

$\$ 669.81 \quad \$ 79.81$

736.79

79.81

669.81

95.77

669.81

87.79

669.81

71.83

669.81

63.85

602.83

79.81

535.85

79.81
Total

Productive

Hours

4041

No Feasible Solution

21

3550

3932

3981

4113

4204

4531

5022
Change in Total

Productive Hours*

Amount Percent

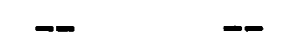

Source: calculated using linear programing with data gathered with faculty and personnel office questionnaires and from college records. Refer to Tables XXX, XXXI, and XXXII for data upon which results were derived. Round-off error is present.

*A11 changes are calculated from the current status. 
TABLE LXIII

COST RATIO ADJUSTMENTS: PROBLEM VIEWED AS MAXIMIZATION OF OUTPUT, COLLEGE C

\section{Current Status:}

\section{Action:}

1. Increase FTF cost $20 \%$

2. Increase FTF Cost $10 \%$

3. Increase PTF Cost $20 \%$

4. Increase PTF Cost $10 \%$

5. Decrease PTF Cost $10 \%$

6. Decrease PTF Cost $20 \%$

7. Decrease FTF Cost $10 \%$

8. Decrease FTF Cost $20 \%$

$\begin{array}{cc}\begin{array}{c}\text { Cost of } \\ \text { FTF }\end{array} & \begin{array}{c}\text { Facu1ty } \\ \text { PTF }\end{array} \\ \$ 695.83 & \$ 94.84\end{array}$

\begin{tabular}{l} 
Number of Faculty \\
FTF \\
\hline
\end{tabular}

Tota1

Productive

Hours

2712

\begin{tabular}{rrrrrrrr}
835.00 & 94.84 & \multicolumn{7}{c}{ No Feasible Solution } \\
765.41 & 94.84 & 50 & 16 & 2254 & -459 & $-14.5 \%$ \\
695.83 & 113.81 & 50 & 44 & 2602 & -110 & -4.1 \\
695.83 & 104.32 & 50 & 48 & 2652 & -61 & -2.2 \\
695.83 & 85.36 & 50 & 59 & 2786 & 73 & 2.7 \\
695.83 & 75.87 & 50 & 66 & 2878 & 166 & 6.1 \\
626.25 & 94.84 & 50 & 84 & 3105 & 394 & 14.5 \\
556.66 & 94.84 & 50 & 126 & 3630 & 917 & 33.8
\end{tabular}

Source: calculated using linear programming with data gathered with faculty and personnel office questionnaires and from college records. Refer to Tables XXX, XXXI, and XXXII for data upon which results were derived. Round-off error is present.

*All changes are calculated from the current status. 
TABLE LXIV

OPTIONS TO INCREASE OUTPUT: ADJUSTMENTS OF COST RATIOS PROBLEM VIEWED AS MAXIMIZATION OF OUTPUT, COLLEGE A

If Decrease FTF by One Member

Number of PTF Resulting Increase to Replace FTF in Productive Hours*

Current Status:

\section{Action:}

1. Increase FTF Cost $20 \%$

2. Increase FTF Cost $10 \%$

3. Increase PTF Cost $20 \%$

4. Increase PTF Cost $10 \%$

5. Decrease PTF Cost $10 \%$

6. Decrease PTF Cost $20 \%$

7. Decrease FTF Cost $10 \%$

8. Decrease FTF Cost $20 \%$
6.5

7.8

7.8

7.1

17.8

12.8

$5.9 \quad 3.3$

7.2

13.4

8.1

20.3

5.8

2.8

Hire no PTF
Hire no PTF
If Increase Budget by $\$ 100$

$\begin{array}{ll}\text { Number of } & \text { Increase in Total } \\ \text { Additional PTF } & \text { Productive Hours }\end{array}$
Additional PTF Productive Hours
7.5

7.5

7.5

Hire no PTF

$.9 \quad 6.8$

$1.1 \quad 8.3$

$1.2 \quad 9.4$

1.0

7.5

Source: see Table LXI.

*The increase in productive hours results with no increase in total cost. 
TABLE LXV

OPTIONS TO INCREASE OUTPUT: ADJUSTMENTS OF COST RATIOS PROBLEM VIEWED AS MAXIMIZATION OF OUTPUT, COLLEGE B

If Decrease FTF by One Member

Number of PTF Resulting Increase

to Replace FTF in Productive Hours*

Current Status:

\section{Action:}

1. Increase FTF Cost $20 \%$

2. Increase FTF Cost $10 \%$

3. Increase PTF Cost $20 \%$

4. Increase PTF Cost $10 \%$

5. Decrease PTF Cost $10 \%$

6. Decrease PTF Cost 20\%

7. Decrease FTF Cost $10 \%$

8. Decrease FTF Cost $20 \%$
8.4

19.7

No Feasible Solution

$\begin{array}{rr}9.2 & 26.1 \\ 7.0 & 9.1 \\ 7.6 & 13.9 \\ 9.3 & 26.9 \\ 10.5 & 35.7 \\ 7.6 & 13.3 \\ 6.7 & 7.0\end{array}$

If Increase Budget by $\$ 100$

\begin{tabular}{ll}
\hline Number of & Increase in Total \\
Additional PTF & Productive Hours
\end{tabular}

1.3

951

No Feasible Solution

$1.3 \quad 951$

1.0793

$1.1 \quad 865$

$1.4 \quad 1058$

$1.6 \quad 1190$

1.3951

$1.3 \quad 951$

Source: see Table LXII.

*The increase in productive hours results with no increase in total cost. 
TABLE LXVI

OPTIONS TO INCREASE OUTPUT: ADJUSTMENTS OF COST RATIOS PROBLEM VIEWED AS MAXIMIZATION OF OUTPUT, COLLEGE $C$

If Decrease FTF by One Member

\begin{tabular}{ll}
$\begin{array}{l}\text { Number of PTF } \\
\text { to Replace FTF }\end{array}$ & $\begin{array}{l}\text { Resulting Increase } \\
\text { in Productive Hours* }\end{array}$ \\
\hline
\end{tabular}

Current Status:

\section{Action:}

1. Increase FTF cost $20 \%$

2. Increase FTF Cost $10 \%$

3. Increase PTF Cost $20 \%$

4. Increase PTF Cost $10 \%$

5. Decrease PTF Cost $10 \%$

6. Decrease PTF Cost $20 \%$

7. Decrease FTF Cost $10 \%$

8. Decrease FTF Cost $20 \%$
7.3

50.7

No Feasible Solution

$\begin{array}{ll}8.1 & 59.9 \\ 6.1 & 35.4 \\ 6.7 & 42.4 \\ 8.2 & 60.9 \\ 9.2 & 73.6 \\ 6.6 & 41.5 \\ 5.9 & 32.4\end{array}$

If Increase Budget by $\$ 100$

\begin{tabular}{cc}
$\begin{array}{l}\text { Number of } \\
\text { Additional PTF }\end{array}$ & $\begin{array}{l}\text { Increase in Total } \\
\text { Productive Hours }\end{array}$ \\
\hline 1.1 & 1318
\end{tabular}

No Feasible Solution

$\begin{array}{ll}1.1 & 1318 \\ .9 & 1098 \\ 1.0 & 1198 \\ 1.2 & 1464 \\ 1.3 & 1648 \\ 1.1 & 1318 \\ 1.1 & 1318\end{array}$

Source: see Table LXIII.

*The increase in productive hours results with no increase in total cost. 
APPENDIX L

COST RATIO ADJUSTMENTS: PROBLEM VIEWED AS MINIMIZATION OF TOTAL COST

TABLE IXXVII

COST RATIO ADJUSTMENTS: PROBLEM VIEWED AS MINIMIZATION OF TOTAL COST, COLLEGE A

\section{Current Status:}

Action:

1. Increase FTF Cost $20 \%$

2. Increase FTF Cost $10 \%$

3. Increase PTF Cost $20 \%$

4. Increase PTF Cost $10 \%$

5. Decrease PTF Cost $10 \%$

6. Decrease PTF Cost $20 \%$

7. Decrease FTF Cost $10 \%$

8. Decrease FTF Cost $20 \%$

Cost of Faculty
FTF $\quad$ PTF

$\$ 665.53 \$ 102.86$
Number of Faculty

FTF

134

$\begin{array}{rrr}798.64 & 102.86 & 134 \\ 732.08 & 102.86 & 134 \\ 665.53 & 123.43 & 176 \\ 665.53 & 113.15 & 134 \\ 665.53 & 92.57 & 134 \\ 665.53 & 82.29 & 134 \\ 598.98 & 102.86 & 134 \\ 532.64 & 102.86 & 176\end{array}$

229

229

0

229
Total

PTF Cost

$\$ 112,745$

Change in Total Cost*

Amount

Percent

Source: calculated using linear programming with data gathered with faculty and personnel office questionnaires and from college records. Refer to Tables XXX, XXXI, and XXXII for data upon which results were derived. Round-off error is present.

*A11 changes are calculated from the current status. 
TABLE LXVIII

COST RATIO ADJUSTMENTS: PROBLEM VIEWED AS MINIMIZATION OF TOTAL COST, COLLEGE B

\section{Current Status:}

Action:

1. Increase FTF Cost $20 \%$

2. Increase FTF Cost $10 \%$

3. Increase PTF Cost $20 \%$

4. Increase PTF Cost 10\%

5. Decrease PTF Cost 10\%

6. Decrease PTF Cost $20 \%$

7. Decrease FTF Cost $10 \%$

8. Decrease FTF Cost $20 \%$

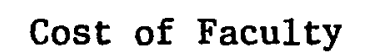

$$
\text { FTF }
$$$$
\$ 669.81
$$

PIT

Number of Faculty
FTF

77

$\begin{array}{lll}803.77 & 79.81 & 77 \\ 736.79 & 79.81 & 77 \\ 669.81 & 95.77 & 77 \\ 669.81 & 87.79 & 77 \\ 669.81 & 71.83 & 77 \\ 669.81 & 63.85 & 77 \\ 602.83 & 79.81 & 77 \\ 535.85 & 79.81 & 77\end{array}$

Total

Cost

86

$\$ 58,442$
Change in Total Cost*

Amount

Percent

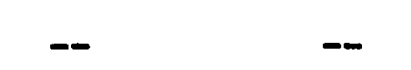

$\begin{array}{rrrr}86 & 68,757 & \$ 10,315 & 17.6 \\ 86 & 63,599 & 5,158 & 8.8 \\ 86 & 59,815 & 1,373 & 2.3 \\ 86 & 59,128 & 687 & 1.2 \\ 86 & 57,747 & -695 & -1.2 \\ 86 & 57,061 & -1,381 & -2.4 \\ 86 & 53,275 & -5,167 & -8.8 \\ 86 & 48,118 & -10,324 & -17.7\end{array}$

Source: calculated using linear programming with data gathered with faculty and personnel office questionnaires and from college records. Refer to Tables XXX, XXXI, and XXXII for data upon which results were derived. Round-off error is present.

*All changes are calculated from the current status. 
TABLE LXIX

COST RATIO ADJUSTMENTS: PROBLEM VIEWED AS MINIMIZATION OF TOTAL COST, COLLEGE C

\section{Current Status:}

Action:

1. Increase FTF Cost $20 \%$

2. Increase FTF Cost $10 \%$

3. Increase PTF Cost $20 \%$

4. Increase PTF cost $10 \%$

5. Decrease PTF Cost $10 \%$

6. Decrease PTF Cost $20 \%$

7. Decrease FTF Cost $10 \%$

8. Decrease FTF Cost $20 \%$

Cost of Faculty
FTF

$\$ 695.83 \$ 94.84$
Number of Faculty

FTF

50

$\begin{array}{rrr}835.00 & 94.84 & 50 \\ 765.41 & 94.84 & 50 \\ 695.83 & 113.81 & 50 \\ 695.83 & 104.32 & 50 \\ 695.83 & 85.36 & 50 \\ 695.83 & 75.87 & 50 \\ 626.25 & 94.84 & 50 \\ 556.66 & 94.84 & 50\end{array}$

Tota1

Cost

$\$ 39,807$
Change.in Total Cost*

Amount

Percent

$53 \quad \$ 39,807$

$\begin{array}{cccc}53 & 46,765 & \$ 6,958 & 17.5 \% \\ 53 & 43,286 & 3,479 & 8.7 \\ 53 & 40,810 & 1,003 & 2.5 \\ 53 & 40,308 & 501 & 1.3 \\ 53 & 39,312 & -495 & -1.2 \\ 53 & 38,810 & -997 & -2.5 \\ 53 & 36,335 & -3,472 & -8.7 \\ 53 & 32,856 & -6,951 & -17.5\end{array}$

Source: calculated using linear programing with data gathered with faculty and personnel office questionnaires and from college records. Refer to Tables XXX, XXXI, and XXXII for data upon which results were derived. Round-off error is present.

*A11 changes are calculated from the current status. 
TABLE LXX

OPTIONS TO SAVE COSTS OR INCREASE OUTPUT: COST RATIO ADJUSTMENTS PROBLEM VIEWED AS MINIMIZATION OF TOTAL COST, COLLEGE A

If Decrease FTF by One Member

\section{Number of PTF Resulting}

to Replace FTF Cost Savings*

Current Status:

Action:

1. Increase FTF Cost $20 \%$

2. Increase FTF Cost $10 \%$

3. Increase PTF Cost $20 \%$

4. Increase PTF Cost $10 \%$

5. Decrease PTF Cost $10 \%$

6. Decrease PTF Cost $20 \%$

7. Decrease FTF Cost $10 \%$

8. Decrease FTF Cost $20 \%$

$5.5 \quad \$ 104.48$

5.5

237.59

171.03

Hire no PTF

5.5

48.35

5.5

160.60

5.5

216.68

5.5

37.93

Hire no PTF
If Increase Output by 100 Productive Hours

$\begin{array}{ll}\text { Number of } & \text { Increase in } \\ \text { Additional PTF } & \text { Total Cost }\end{array}$

Total Cost
$\$ 1336$

1336

1336

Hire no PTF

1469

1202

1069

1336

Source: see Table LXVII.

*The cost savings result with no decrease in productive hours. 
TABLE LXXI

OPTIONS TO SAVE COSTS OR INCREASE OUTPUT: COST RATIO ADJUSTMENTS PROBLEM VIEWED AS MINIMIZATION OF TOTAL COST, COLLEGE B

If Decrease FTF by One Member

\begin{tabular}{ll}
\hline $\begin{array}{l}\text { Number or PTF } \\
\text { to Replace FTF }\end{array}$ & Resulting \\
Cost Savings*
\end{tabular}

\section{Current Status:}

Action:

1. Increase FTF Cost $20 \%$

2. Increase FTF Cost $10 \%$

3. Increase PTF Cost $20 \%$

4. Increase PTF Cost $10 \%$

5. Decrease PTF Cost $10 \%$

6. Decrease PTF Cost $20 \%$

7. Decrease FTF Cost $10 \%$

8. Decrease FTF Cost $20 \%$

$$
5.8
$$

5.8

5.8

5.8

5.8

5.8

5.8

5.8

$\$ 207.14$

341.10

274.12

114.62

160.88

253.95

296.15

140.77

73.18
If Increase Output by 100 Productive Hours

Number of Increase in

Additional PTF Total cost

13

$\$ 1052$

13

1052

13

1052

13

1262

13

1157

13

945

13

840

13

1052

13

1052

Source: see Table LXVIII.

*The cost savings result with no decrease in productive hours. 
TABLE LXXII

OPTIONS TO SAVE COSTS OR INCREASE OUTPUT: COST RATIO ADJUSTMENTS

PROBLEM VIEWED AS MINIMIZATION OF TOTAL COST, COLLEGE C

If Decrease FTF by One Member

Number of PTF Resulting

to Replace FTF Cost Savings*

Current Status:

Action:

1. Increase FTF Cost $20 \%$

2. Increase FTF Cost $10 \%$

3. Increase PTF Cost $20 \%$

4. Increase PTF Cost $10 \%$

5. Decrease PTF Cost $10 \%$

6. Decrease PTF Cost $20 \%$

7. Decrease FTF Cost $10 \%$

8. Decrease FTF Cost $20 \%$

\section{3}

3.3

523.92

3.3

454.33

3.3

322.53

3.3

353.66

3.3

415.85

3.3

446.98

3.3

315.17

3.3

245.58
If Increase Output by 100 Productive Hours

Number of Increase in

Additional PTF Total Cost

Source: see Table LXIX.

*The cost savings result with no decrease in productive hours. 
APPENDIX M

PRODUCTIVITY RATIO ADJUSTMENTS: PROBLEM VIEWED AS MINIMIZATION OF TOTAL COST

TABLE LXXIII

PRODUCTIVITY RATIO ADJUSTMENTS: PROBLEM VIEWED AS MINIMIZATION OF TOTAL COST, COLLEGE A

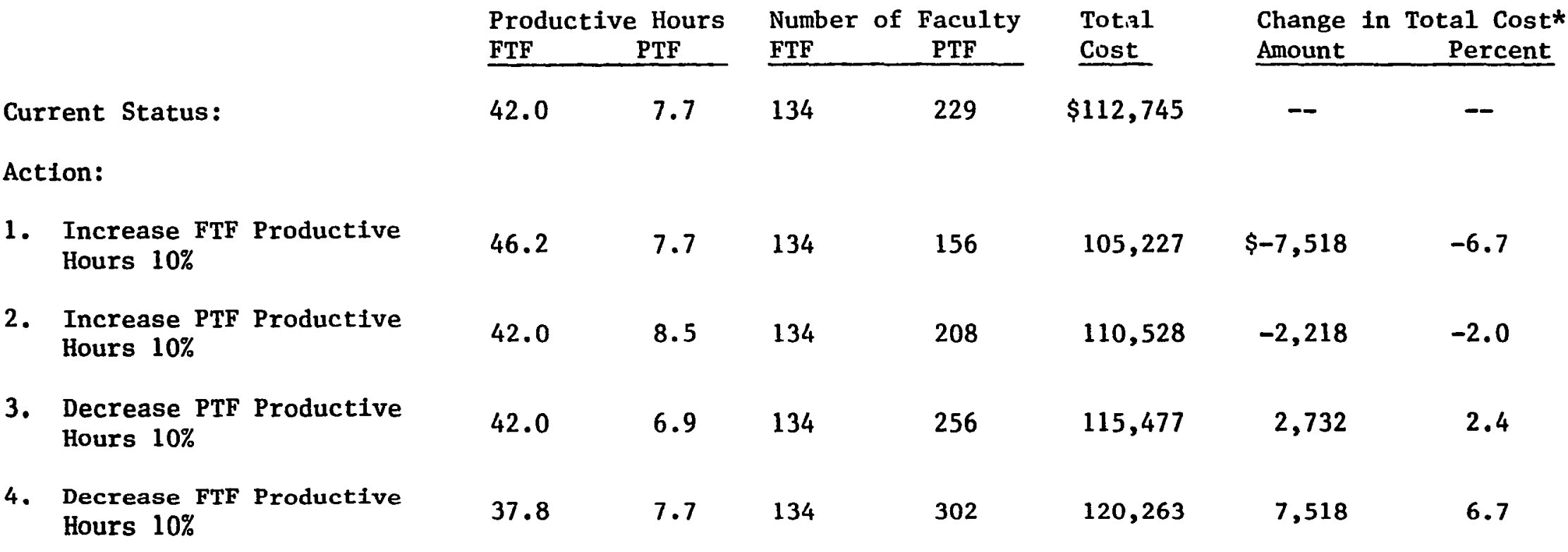

Source: calculated using linear programing with data gathered with faculty and personnel office questionnaires and from college records. Refer to Tables XXX, XXXI, and XXXII for data upon which results were derived. Round-off error is present.

*A11 changes are calculated from the current status. 
TABLE LXXIV

PRODUCTIVITY RATIO ADJUSTMENTS: PROBLEM VIEWED AS MINIMIZATION OF TOTAL COST, COLLEGE B

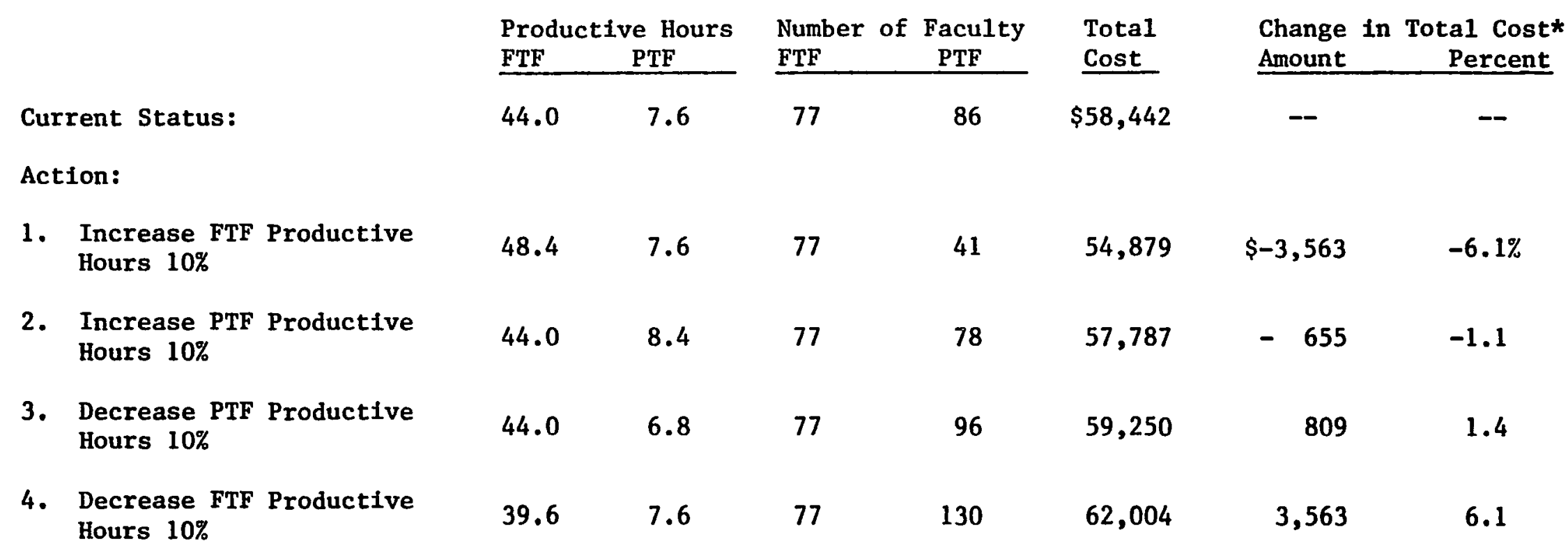

Source: calculated using linear programing with data gathered with faculty and personnel office questionnaires and from college records. Refer to Tables XXX, XXXI, and XXXII for data upon which results were derived. Round-off error is present.

*A11 changes are calculated from the current status. 
TABLE LXXV

PRODUCTIVITY RATIO ADJUSTMENTS: PROBLEM VIEWED AS MINIMIZATION OF TOTAL COST, COLLEGE C

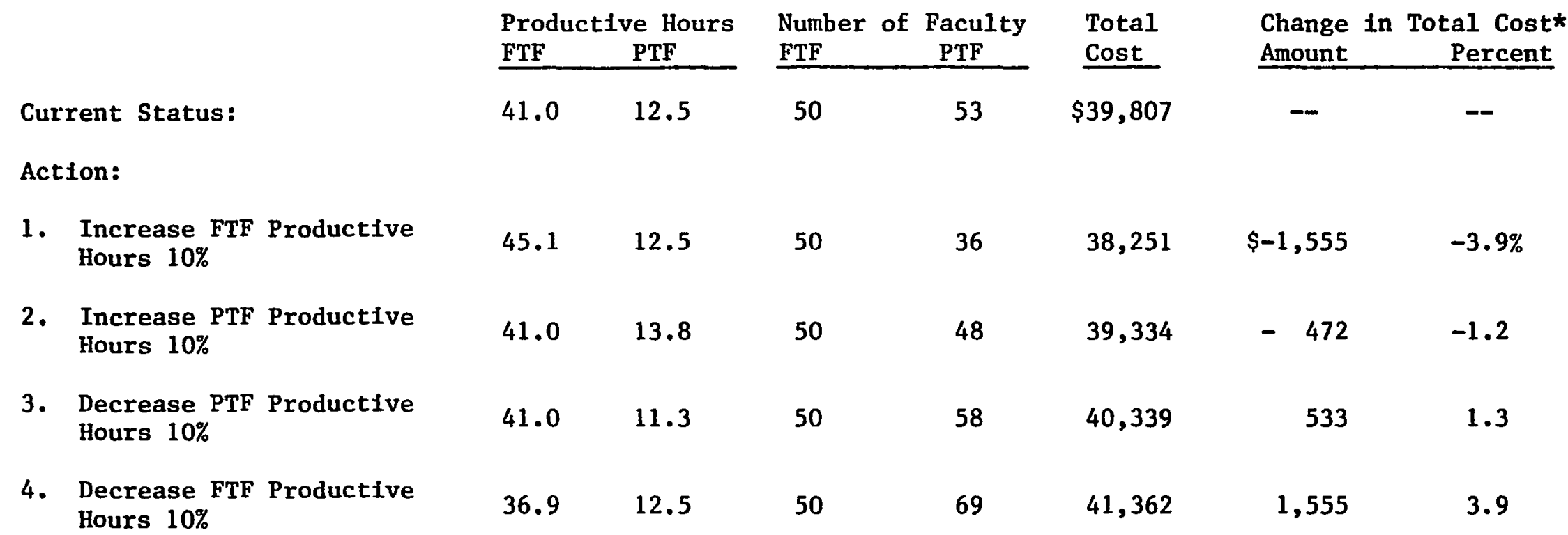

Source: calculated using linear programming with data gathered with faculty and personnel office questionnaires and from college records. Refer to Tables XXX, XXXI, and XXXII for data upon which results were derived. Round-off error is present.

*A11 changes are calculated from the current status. 


\section{TABLE LXXVI}

OPTIONS TO SAVE COST OR INCREASE OUTPUT: PRODUCTIVITY RATIO ADJUSTMENTS PROBLEM VIEWED AS MINIMIZATION OF TOTAL COST, COLLEGE A

If Decrease FTF by One Member

\begin{tabular}{ll}
$\begin{array}{ll}\text { Number of PTF } & \text { Resulting } \\
\text { to Replace FTF } & \text { Cost Savings* }\end{array}$ \\
\hline
\end{tabular}

Current Status:
5.5

$\$ 104.48$
If Increase Output by 100 Productive Hours

\begin{tabular}{ll}
\hline Number of & Increase in \\
Additional PTF & Total Cost \\
\hline
\end{tabular}

13

$\$ 1336$

Action:

1. Increase FTF Productive Hours $10 \%$
6.0
48.37

13

1336

2. Increase PTF Productive Hours $10 \%$

4.9

157.28

12

1210

3. Decrease PTF Productive Hours $10 \%$

6.1

39.42

14

1491

4. Decrease FTF Productive Hours $10 \%$

$4.9 \quad 160.58$

13

1336

Source: see Table LXXIII.

*The cost savings result with no decrease in total productive hours. 
TABLE LXXVII

OPTIONS TO SAVE COST OR INCREASE OUTPUT: PRODUCTIVITY RATIO ADJUSTMENTS PROBLEM VIEWED AS MINIMIZATION OF TOTAL COST, COLLEGE B

If Decrease FTF by One Member

\begin{tabular}{ll}
\hline $\begin{array}{l}\text { Number of PTF } \\
\text { to Replace FTF }\end{array}$ & $\begin{array}{l}\text { Resulting } \\
\text { Cost Savings* }\end{array}$ \\
\hline
\end{tabular}

Current Status:
5.8

$\$ 207.14$
13

12

15

13
If Increase Output by 100 Productive Hours

Number of Increase in

Additional PTF

Total Cost

Action:

1. Increase FTF Productive Hours $10 \%$

6.4

161.55

251.26

Hours $10 \%$

6.5

152.63

13

$\$ 1052$

Hours $10 \%$

5.2

253.41

Hours $10 \%$

Source: see Table LXXIV.

*The cost savings result with no decrease in total productive hours. 
TABLE LXXVIII

OPTIONS TO SAVE COST OR INCREASE OUTPUT: PRODUCTIVITY RATIO ADJUSTMENTS PROBLEM VIEWED AS MINIMIZATION OF TOTAL COST, COLLEGE C

If Decrease FTF by One Member

Number of PTF Resulting

to Replace FTF Cost Savings*

Current Status:

Action:

1. Increase FTF Productive Hours $10 \%$

2. Increase PTF Productive Hours $10 \%$

3.3

$\$ 384.75$

3.6

353.65

3.0

414.06

3.6

351.72

3.0

415.86

3. Decrease PTF Productive Hours 10\%

4. Decrease FTF Productive
If Increase Output by 100 Productive Hours

Number of Addi Increase in
Additional PTF Tota1 Cost Hours $10 \%$

Source: see Table LXXV.

*The cost savings result with no decrease in total productive hours. 


\section{APPENDIX N}

PRODUCTIVITY RATIO ADJUSTMENTS: PROBLEM VIEWED AS MAXIMIZATION OF OUTPUT

\section{TABLE LXXIX}

PRODUCTIVITY RATIO ADJUSTMENTS: PROBLEM VIEWED AS MAXIMIZATION OF OUTPUT, COLLEGE A

\section{Productive}

Current Status:

\section{Action:}

1. Increase FTF Productive Hours $10 \%$

2. Increase PTF Productive Hours 10\%

3. Decrease PTF Productive Hours 10\%

4. Decrease FTF Productive Hours 10\%

Hours
FTF PTF

\begin{tabular}{l}
$\begin{array}{l}\text { Number of Faculty } \\
\text { FTF }\end{array}$ \\
\hline
\end{tabular}

$42.0 \quad 7.7$

$\begin{array}{lll}46.2 & 7.7 & 134\end{array}$

$42.0 \quad 8.5 \quad 134$

$\begin{array}{lll}42.0 & 6.9 & 134\end{array}$

$\begin{array}{lll}37.8 & 7.7 & 134\end{array}$

229

\begin{tabular}{l} 
Total \\
Productive \\
Hours \\
\hline
\end{tabular}

7391

7954

7575

7208

6829
Change in Total Productive Hours* Amount Percent

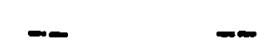

7.6

.5

$-183 \quad-2.5$

$-562 \quad-7.6$

Source: calculated using linear programming with data gathered with faculty and personnel office questionnaires and from college records. Refer to Tables XXX, XXXI, and XXXII for data upon which results were derived. Round-off error is present.

*Al1 changes are calculated from the current status. 
TABLE LXXX

PRODUCTIVITY RATIO ADJUSTMENTS: PROBLEM VIEWED AS MAXIMIZATION OF OUTPUT, COLLEGE B

\section{Current Status:}

\section{Action:}

1. Increase FTF Productive Hours $10 \%$

2. Increase PTF Productive Hours $10 \%$

3. Decrease PTF Productive Hours $10 \%$

4. Decrease FTF Productive Hours $10 \%$

\begin{tabular}{l} 
Productive \\
Hours \\
FTF PTF \\
\hline
\end{tabular}

44.0

7.6

Number of Faculty

FTF

77

$\begin{array}{lll}48.4 & 7.6 & 77\end{array}$

44.0

8.4

77

44.0

6.8

77

39.6

7.6

77
Total

Productive

Hours

4041

86

86

86

86

86

4110

3971
Change in Total Productive Hours* Amount Percent

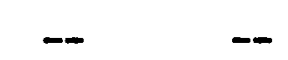

339

8.4

$\begin{array}{ll}69 & 1.7\end{array}$

$\begin{array}{ll}-70 & -1.7\end{array}$

Source: calculated using linear programming with data gathered with faculty and personnel office questionnaires and from college records. Refer to Tables XXX, XXXI, and XXXII for data upon which results were derived. Round-off error is present.

*A11 changes are calculated from the current status. 
TABLE LXXXI

PRODUCTIVITY RATIO ADJUSTMENTS: PROBLEM VIEWED AS MAXIMIZATION OF OUTPUT, COLLEGE C

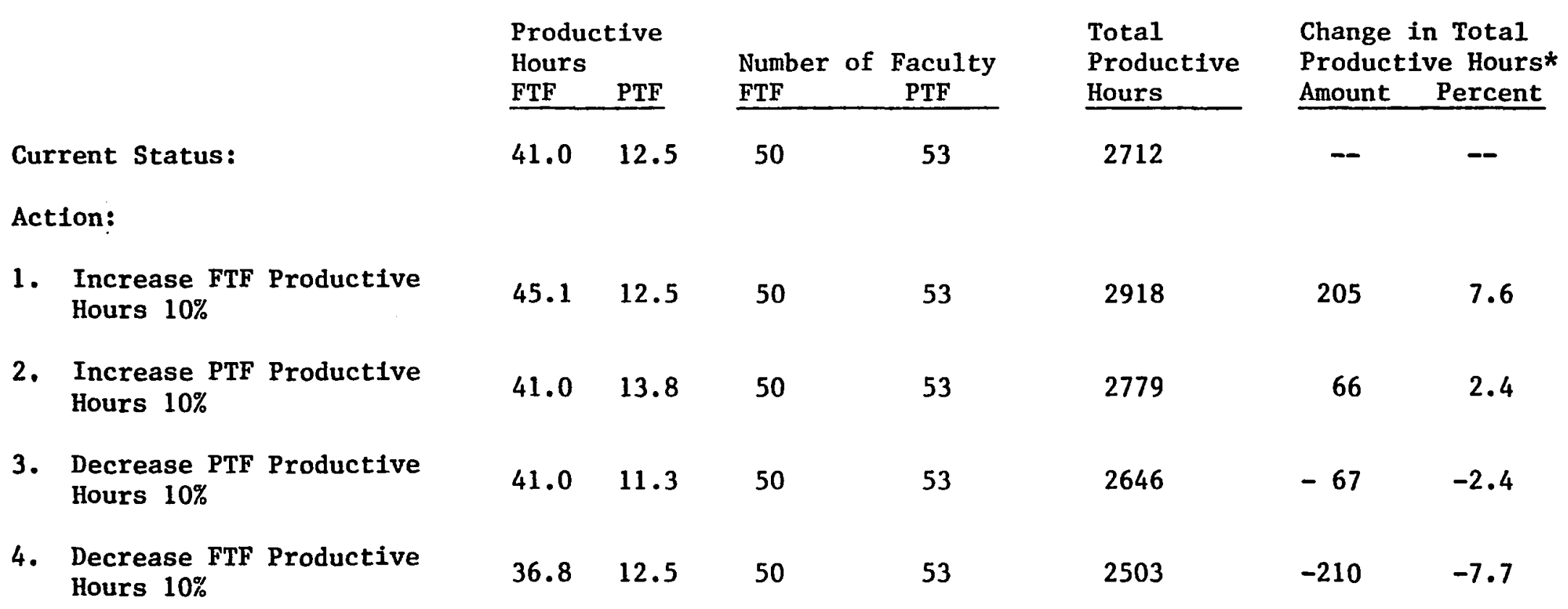

Source: calculated using linear programing with data gathered with faculty and personnel office questionnaires and from college records. Refer to Tables XXX, XXXI, and XXXII for data upon which results were derived. Round-off error is present.

*All changes are calculated from the current status. 
TABLE LXXXII

OPTIONS TO INCREASE OUTPUT: PRODUCTIVITY RATIO ADJUSTMENTS

PROBLEM VIEWED AS MAXIMIZATION OF OUTPUT, COLLEGE A

If Decrease FTF by One Member

\begin{tabular}{ll}
\hline $\begin{array}{l}\text { Number of PTF } \\
\text { to Replace FTF }\end{array}$ & $\begin{array}{l}\text { Resulting Increase } \\
\text { in Productive Hours* }\end{array}$ \\
\hline
\end{tabular}

Current Status:

Action:

1. Increase FTF Productive Hours $10 \%$

2. Increase PTF Productive Hours $10 \%$

3. Decrease PTF Productive Hours $10 \%$

4. Decrease FTF Productive Hours $10 \%$

$$
6.5
$$

6.5

3.6

13.0

2.6

12.0

7.8
6.5

6.5

6.5
If Increase Budget by $\$ 100$

$\begin{array}{cc}\begin{array}{l}\text { Number of } \\ \text { Additional PTF }\end{array} & \begin{array}{l}\text { Increase in Total } \\ \text { Productive Hours }\end{array} \\ 1.0 & 7.5\end{array}$

1.0

1.0

1.0

1.0

7.5

Source: see Table LXXIX.

*The increase in productive hours results with no increase in total cost. 
TABLE LXXXIII

OPTIONS TO INCREASE OUTPUT: PRODUCTIVITY RATIO ADJUSTMENTS PROBLEM VIEWED AS MAXIMIZATION OF OUTPUT, COLLEGE B

If Decrease FTF by One Member

\begin{tabular}{ll}
$\begin{array}{l}\text { Number of PTF } \\
\text { to Replace FTF }\end{array}$ & $\begin{array}{l}\text { Resulting Increase } \\
\text { in Productive lours* }\end{array}$ \\
\hline
\end{tabular}

Current Status:
8.4

8.4

8.4

8.4

8.4
19.7

15.3

26.4

13.0

24.1
If Increase Budget by $\$ 100$

\begin{tabular}{cc}
$\begin{array}{l}\text { Number of } \\
\text { Additional PTF }\end{array}$ & $\begin{array}{l}\text { Increase in Total } \\
\text { Productive Hours }\end{array}$ \\
\hline 1.3 & 9.5
\end{tabular}

1. Increase FTF Productive Hours $10 \%$ Hours $10 \%$

3. Decrease PTF Productive Hours $10 \%$

4. Decrease FTF Productive Hours $10 \%$

$\begin{array}{ll}8.4 & 15.3 \\ 8.4 & 26.4 \\ 8.4 & 13.0 \\ 8.4 & 24.1\end{array}$

1.3

9.5

1.3

10.5

Source: see Table LXXX.

*The increase in productive hours results with no increase in total cost. 
TABLE LXXXIV

OPTIONS TO INCREASE OUTPUT: PRODUCTIVITY RATIO ADJUSTMENTS

PROBLEM VIEWED AS MAXIMIZATION OF OUTPUT, COLLEGE C

If Decrease FTF by One Member

$\begin{array}{ll}\text { Number of PTF } & \text { Resulting Increase } \\ \text { to Replace FTF } & \text { in Productive Hours* }\end{array}$

Current Status:

Action:

1. Increase FTF Productive Hours $10 \%$

2. Increase PTF Productive Hours $10 \%$

3. Decrease PTF Productive Hours $10 \%$

4. Decrease FTF Productive Hours $10 \%$

$$
7.3
$$

50.7

46.6

60.3

41.9

54.8

7.3

7.3
If Increase Budget by $\$ 100$

$\begin{array}{ll}\text { Number of } & \text { Increase in Total } \\ \text { Additional PTF } & \text { Productive Hours }\end{array}$

Additional PTF Productive Hours
13.2
13.2

1.1
14.6

1.1

1.1

11.9

1.1

13.2

Source: see Table LXXXI.

*The increase in productive hours results with no increase in total cost. 